\title{
WATER-ENERGY NEXUS IN THE PEOPLE'S REPUBLIC OF CHINA AND EMERGING ISSUES
}

PRADEEP PERERA and LIJIN ZHONG 



\section{WATER-ENERGY NEXUS IN THE PEOPLE'S REPUBLIC OF CHINA AND EMERGING ISSUES}

PRADEEP PERERA and LIJIN ZHONG October 2017 
(C) 2017 Asian Development Bank

6 ADB Avenue, Mandaluyong City, 1550 Metro Manila, Philippines

Tel +632632 4444; Fax +6326362444

www.adb.org

Some rights reserved. Published in 2017.

ISBN 978-92-9257-989-0 (print), 978-92-9257-990-6 (electronic)

Publication Stock No. TCS178980-2

http://dx.doi.org/10.22617/TCS178980-2

The views expressed in this publication are those of the authors and do not necessarily reflect the views and policies of the Asian Development Bank (ADB) or its Board of Governors or the governments they represent.

ADB does not guarantee the accuracy of the data included in this publication and accepts no responsibility for any consequence of their use. The mention of specific companies or products of manufacturers does not imply that they are endorsed or recommended by ADB in preference to others of a similar nature that are not mentioned.

By making any designation of or reference to a particular territory or geographic area, or by using the term "country" in this document, $A D B$ does not intend to make any judgments as to the legal or other status of any territory or area.

This work is available under the Creative Commons Attribution 3.0 IGO license (CC BY 3.0 IGO)

https://creativecommons.org/licenses/by/3.0/igo/. By using the content of this publication, you agree to be bound by the terms of this license. For attribution, translations, adaptations, and permissions, please read the provisions and terms of use at https://www.adb.org/terms-use\#openaccess

This CC license does not apply to non-ADB copyright materials in this publication. If the material is attributed to another source, please contact the copyright owner or publisher of that source for permission to reproduce it. ADB cannot be held liable for any claims that arise as a result of your use of the material.

Please contact pubsmarketing@adb.org if you have questions or comments with respect to content, or if you wish to obtain copyright permission for your intended use that does not fall within these terms, or for permission to use the ADB logo.

Notes:

In this publication, "\$” refers to US dollars.

ADB recognizes "China” as the People's Republic of China.

Corrigenda to ADB publications may be found at http://www.adb.org/publications/corrigenda 


\section{CONTENTS}

Figures, Tables, and Boxes ii

Foreword iii

Acknowledgments

Abbreviations $v$

Executive Summary vii

Chapter 1 Introduction $\quad 1$

Water Scarcity and Water Stress 2

$\begin{array}{ll}\text { Overview of the Energy Sector in the PRC } & 7\end{array}$

What Is Driving the Water-Energy Nexus? 9

Chapter 2 Water Use in Coal Industry 13

Water Use in Coal Mining $\quad 14$

Water Use in Coal Washing 16

Water Use in Coal Gasification and Coal Liquefaction 16

Water Use in the Production of Synthetic Natural Gas from Coal 17

Recent Trends in Water Use in the Coal Sector 18

Chapter 3 Water Use in the Oil and Gas Sector 19

Water Use in Crude Oil Production $\quad 19$

Water Use in Oil Refineries $\quad 20$

Water Use in Conventional Natural Gas Production and Processing 22

Prospects for Shale Gas Exploration in the PRC and Implications for Water 22

Ensuring Sustainable Water Use in the Oil and Gas Sector in the PRC 24

Chapter 4 Water Use in Electricity Generation 27

Cooling Technologies Used in Thermal Power Plants in the PRC 28

Water Withdrawal and Consumption for Thermal Power Generation 32

Water Use Projections for the Thermal Power Sector 37

Evolving Policy Regime for Water Use Regulation in the Thermal Power Sector 39

Ensuring Sustainable Water Use in Thermal Power Generation 42

Chapter 5 Water Use Implications of Hydropower 43

Status of Hydropower Development in the PRC 44

Role of Pumped-Storage Hydropower in the PRC's Electricity System 47

Hydropower Development in the PRC: Major Issues 48

Ensuring the Sustainable Development of Hydropower 49

Chapter 6 Energy for Water 51

Energy for Groundwater Extraction 51

Surface Water Conveyance and Distribution $\quad 52$

Desalination and Energy Consumption $\quad 54$

Desalination Technologies $\quad 54$

Energy for Water Treatment $\quad 57$

Energy for Wastewater Treatment $\quad 59$

Addressing Energy Consumption in Water Supply: Policy Implications and Challenges $\quad 61$

Chapter 7 Conclusion $\quad 63$

Challenges 63

Opportunities 63

$\begin{array}{ll}\text { References } & 68\end{array}$ 


\section{FiguRES}

1: Freshwater Withdrawals in the PRC, by Sector, 1950-2010 5

2: Baseline Water Stress and Provincial Water Withdrawals in the PRC, by Sector, 2012

3: Primary Energy Supply in the PRC, 2000-2014 8

4: Major Coal Bases and Baseline Water Stress in the PRC 13

5: Water Use in Coal Mining in the PRC 14

6: Water Use in Oil Production in the PRC 20

7: Flow Diagram of Refining Process and Water Use in a Refinery with a Hydrocracker 21

8: Schematic Diagram of Water Use in Unconventional Natural Gas (Tight Gas and Shale Gas) Production $\quad 23$

9: Shale Gas Plays and Baseline Water Stress in the PRC 25

10: Power Generation Mix of the PRC, 2014

11: Schematic Diagrams of Different Cooling Technologies Used in Thermal Power Plants 31

12: Trends in Power Generation and Associated Water Withdrawal in the PRC, 2000-2014 32

13: Water Withdrawal and Wastewater Factors for Power Plants in the PRC, 2000-2012 33

14: Cooling Technologies in the PRC Power Sector 33

15: Distribution of Cooling Technologies in the PRC, by Region, 2011

16: Share of Power Production, Water Withdrawal, and Consumption in PRC Totals, by Cooling Type, 2011

17: Water Withdrawal Intensity in the PRC, by Province, 2011

18: Water Consumption Intensity in the PRC, by Province, 2011

19: Share of Power Production, Water Withdrawal, and Consumption, by Region, 2011

20: Freshwater Withdrawal by the Power Sector in the PRC under the Various Reference Scenarios, 2020 and $2030 \quad 38$

21: Water Consumption in the PRC, by Cooling Type, under the Various Reference Scenarios, 2020-2030 39

22: Water Resource Fees for Industrial Use

23: Proposed Hydropower Bases in the PRC 44

24: Schematic Diagram of Pumped Storage Hydropower Plant 47

25: Schematic Flow Diagram of Different Stages of Water Treatment 58

26: Schematic Diagram of a Municipal Wastewater Treatment Plant 59

\section{TABLES}

1: Water Resource Distribution Between the Northern and Southern Regions of the PRC, 2014

2: Water Planning Guidelines $\quad 7$

3: Hydropower Plants in the PRC, by Capacity 445

4: Energy Requirement of Different Desalination Technologies 55

\section{BOXES}

1: Definition of Terms $\quad 4$

2: Classification of Produced Water in Coal Mining 15

3: Cooling Technologies Used in Thermal Power Plants in the PRC 29

4: Reference Scenarios for Water Withdrawal by the Power Sector in the PRC 37

5: Ningxia Water Right Transfer Scheme (Case Study) $\quad 40$

6: The Three Gorges Hydropower Plant 46

7: The South-North Water Transfer Project in the PRC 52

8: Energy Consumption in Water Supply for Qingdao $\quad 56$ 


\section{FOREWORD}

Promoting sustainable and inclusive growth is at the forefront of the assistance program of the Asian Development Bank (ADB) to the People's Republic of China (PRC). With the expansion of the PRC's economy by several folds since 1980, the increasing demand for water and energy is posing significant strains on the fragile ecosystems. At the same time, the sustainability of the PRC's economic growth model and its achievements in poverty reduction and improving the quality of life of its citizens are being threatened due to the challenges associated with meeting the increasing demand for water and energy in a sustainable and coordinated manner.

The PRC has made significant improvement in reducing the water and energy intensity in its economy, and made a commitment to peak the carbon dioxide emissions by 2030 and to cap the water consumption at 700 billion cubic meters. As the PRC's energy sector has a high degree of dependency on carbon-intensive coal, peaking carbon dioxide emissions require significant structural transformation of its energy sector towards low-carbon sources and further improvement in energy efficiency. The government of the PRC is taking measures to further improve water use efficiency in agriculture, promote recycling of water and expand the coverage of wastewater treatment, and transfer water from water-rich southern region to arid northern region. However, the choices made in either the water or energy sector will have significant impact on the other sector with either positive or negative implications. Hence, it is imperative to have a thorough understanding of the trade-offs between water and energy, which is referred to as the water-energy nexus.

$A D B$ is at the forefront of supporting the government in shifting its economic growth trajectory to a more sustainable and climate-friendly path. ADB has provided inputs to the government in formulating the 13th Five-Year Plan in several thematic areas including climate change mitigation and adaptation as well as enhancing water and energy security. In this regard, a clear understanding of water-energy nexus in the context of the PRC is critical to formulate ADB's strategies in water and energy sectors as well as to provide knowledge solutions to the government to address the water energy issues.

The "Water-Energy Nexus in the People's Republic of China and Emerging Issues" provides a comprehensive analysis of the water use in the energy sector in the context of significant geographical imbalances of water availability and the implications of some of the emerging energy technologies such as shale gas development and coal gasification on water availability to other water users. Although the energy consumption for water supply is not significant in the context of the overall energy consumption in the PRC, the publication also analyzes the incremental energy demand due to recent initiatives to meet water demand using energyintensive technologies, such as desalination and long-distance water transfers.

This publication will enhance ADB's contribution to deepen the understanding of developmental challenges faced by the PRC in water and energy sectors and the interlinkages between the two sectors. It will help both the policy makers and development partners of the PRC to design more sustainable solutions and investment projects underpinned by the thorough understanding of interplay between water and energy.

\section{Ayumi Konishi}

Director General

East Asia Department 


\section{ACKNOWLEDGMENTS}

"Water-Energy Nexus in the People's Republic of China and Emerging Issues" was prepared by Pradeep Perera of East Asia Department of the Asian Development Bank under the guidance of Ashok Bhargava, director, Energy Division, East Asia Department, ADB. The publication was prepared based on valuable information, data, and case studies provided by a team of experts from the World Resource Institute led by Lijin Zhong. The other members of the World Resource Institute team included Hua Wen, Xiaotian Fu, Jiao Wang, and Yuan Wang. In addition, Song Du of the China Coal Research Institute and Lili Yu of the General Institute of Water Resource and Hydropower Planning also contributed to the publication.

Patrick Renz did the technical editing while Mary Ann Asico did the copyediting. The layout was done by Brian Tenorio. The administrative support was provided by Katherine Miriam Ozoa and Ma. Carmen Alcantara (ADB). 


$\begin{array}{ll}\text { ABBREVIATIONS } \\ \text { bcm } & \text { billion cubic meter } \\ \text { CHP } & \text { combined heat and power } \\ \text { COD } & \text { chemical oxygen demand } \\ \text { CTL } & \text { coal-to-liquid (technology) } \\ \text { DCTL } & \text { direct coal-to-liquid (technology) } \\ \text { DWR } & \text { Department of Water Resources } \\ \text { FYP } & \text { five-year plan } \\ \text { GDP } & \text { gross domestic product } \\ \text { GHG } & \text { greenhouse gas } \\ \text { GW } & \text { gigawatt } \\ \text { ICTL } & \text { indirect coal-to-liquid (technology) } \\ \text { IMAR } & \text { Inner Mongolia Autonomous Region } \\ \text { kWh } & \text { kilowatt-hour } \\ \text { LNG } & \text { liquefied natural gas } \\ \text { m } 3 & \text { cubic meter } \\ \text { mg/L } & \text { milligrams per liter } \\ \text { MW } & \text { megawatt } \\ \text { MWR } & \text { Ministry of Water Resources } \\ \text { NDRC } & \text { National Development and Reform Commission } \\ \text { PRC } & \text { People's Republic of China } \\ \text { PSH } & \text { pumped-storage hydropower } \\ \text { SEA } & \text { strategic environmental assessment } \\ \text { SNG } & \text { synthetic natural gas } \\ \text { tce } & \text { ton of coal equivalent } \\ \text { TWh } & \text { terawatt-hour } \\ \text { US } & \text { United States } \\ \text { WRI } & \text { World Resources Institute } \\ \text { XUAR } & \text { Xinjiang Uyghur Autonomous Region } \\ & \end{array}$





\section{EXECUTIVE SUMMARY}

\section{Water-Energy Nexus}

The growth in demand for energy and water in the People's Republic of China (PRC) is likely to decelerate in response to the efforts of the government to improve energy and water use efficiency. These efforts are prompted by mounting concern about air pollution caused by the increasing use of coal-based energy, water and soil pollution associated with coal mining, heavy use of water to cool coal-fired power plants, and the need to safeguard the PRC's energy security by promoting the use of cleaner renewable energy and a more diversified energy supply mix with a lower share of coal.

But the PRC must also deal with the uneven distribution of the country's water resources, acute water stress in certain parts of northern PRC including Beijing and other heavily populated urban regions, inefficient use of water in agriculture, and severe water pollution in most rivers in northern PRC. Moreover, the energy sector, especially coal-fired electricity generation, is contributing significantly to freshwater withdrawals (about 10\%), and coal mining is a major factor in groundwater pollution in certain parts of the country (Y. Che and Z. Shang, 2015).

Maintaining its economic growth is imperative for the PRC, but it must proceed at a more moderate and sustainable pace compared with what has been achieved. Given the growth momentum of the PRC's economy, even with significant improvement in energy and water use efficiency, the demand for energy and water is likely to increase further in the next 25-30 years. Choices made in either the energy or the water sector will have significant, multifaceted, and broad impact on the other sector, often with both positive and negative repercussions. This trade-off between energy and water resources is referred to as the water-energy nexus (World Water Assessment Program, 2014).

To address the increasing stress on the country's resources and facilitate sustainable development, the government must understand the water-energy nexus, including the impact of energy development on water and vice versa, and improve its energy development strategies and water management practices. Regulatory and operational innovation toward integrated water-energy resources management is also a critical need. There is increasing realization that water and energy are tightly interlinked and interdependent, given the importance of water for producing energy, the impact of energy production and consumption on water quality and availability, and the demand for energy for water supply (Environment Protection Agency, 2014). 
Uneven distribution of water resources. In contrast with the water-rich south, parts of northern PRC are faced with water scarcity and increasing water stress. Northern PRC has $60 \%$ of the country's farmland and $40 \%$ of its population, but only $20 \%$ of its water resources. Per capita water availability in the Hai River Basin, where Beijing and Tianjin municipalities are located, is only 350 cubic meters $\left(\mathrm{m}^{3}\right)$ (L. Xi, L. Jie, and Z. Chunmiao, 2016).

Water Resource Distribution Between the Northern and Southern Regions of the PRC, 2014

\begin{tabular}{|lccccccccc|}
\hline \multicolumn{8}{c}{ Water Availability $(\mathrm{bcm})$} & \multicolumn{3}{c|}{ Water Withdrawals $(\mathrm{bcm})$} & \multicolumn{3}{c|}{ Water Use Intensity (\%) } \\
\hline Region & Surface & Ground & Totala & Surface & Ground & Totalb & Surface & Ground & Total \\
North & 381.1 & 230.2 & 465.8 & 175.0 & 98.9 & 278.0 & 45.9 & 43.0 & 60.0 \\
South & $2,245.3$ & 544.2 & $2,260.8$ & 317.0 & 12.8 & 331.5 & 14.1 & 2.3 & 14.7 \\
Total & $\mathbf{2 , 6 2 6 . 4}$ & $\mathbf{7 7 4 . 4}$ & $\mathbf{2 , 7 2 6 . 6}$ & $\mathbf{4 9 2 . 0}$ & $\mathbf{1 1 1 . 7}$ & $\mathbf{6 0 9 . 5}$ & $\mathbf{1 8 . 7}$ & $\mathbf{1 4 . 4}$ & $\mathbf{2 2 . 4}$ \\
\hline
\end{tabular}

bcm = billion cubic meter, PRC = People's Republic of China.

a Surface water and groundwater are interrelated and the total amount of water available is less than the sum of surface water and groundwater.

b The total water withdrawn includes surface water, groundwater, and a small portion of water from other water sources (e.g., reclaimed wastewater and harvested rainwater).

Sources: Water availability and water withdrawal data are from the Ministry of Water Resources (2015); and water use intensity data are the author's estimates.

Extensive use of groundwater in northern PRC. Agriculture accounted for 386.9 billion cubic meters $(\mathrm{bcm})(61 \%)$ of water withdrawals in the PRC in 2014, and about one-third of the water used in agriculture in northern PRC is from groundwater sources. The extensive use of groundwater has caused groundwater resource depletion and contamination. The agriculture sector is mainly responsible for the groundwater pollution, as the water used in agriculture is contaminated with pesticides and other chemicals and is rarely treated before discharge. Groundwater extraction consumes about 40 terawatt-hours (TWh) of energy, or close to $1 \%$ of the total electricity consumption of the PRC.

Inefficient use of water. Water scarcity is worsened by the inefficient use of water in the PRC. Irrigation efficiency ${ }^{1}$ averages only about $53 \%$ (in 2014). An increase to $60 \%$ by 2030 is a government target. Industrial water use intensity is $58 \mathrm{~m}^{3}$ per CNY10,000 (about $\$ 1,600$ ) in 2015. This is expected to be reduced to $40 \mathrm{~m}^{3}$ per CNY10,000 by 2030. Leakage from urban water supply schemes is above $20 \%$ and water reuse in industry is only about $60 \%$. Water efficiency indicators across different sectors are below the level in advanced economies. There is significant room for improvement.

High incidence of water pollution. Water quality in more than half of the river sections and reservoirs in the PRC does not meet water quality standards for human consumption after treatment. Recent improvements should not be

1 The ratio of the amount of water consumed by the crop to the amount of water supplied through irrigation. 
overlooked. The number of monitored river sections with better water quality (classes 1-3) increased by 33\% from 2001 to 2014, while the number of rivers with extremely bad water quality (below class 5 ) decreased by $21 \%$. Generalizations based solely on this trend are, however, difficult to make, as regional variations are significant, with water quality undergoing noteworthy improvements in parts of southern PRC but deteriorating in widespread areas of northern PRC.

High to extreme water stress in parts of northern PRC. Water stress, defined as the ratio of water availability to demand for water, has reached crisis proportions in parts of northern PRC. The uneven distribution of water resources in the PRC and the inefficient use of water have contributed to this situation, as well as to the unsustainable use of groundwater and to water quality deterioration and pollution. Climate change, urbanization, and rapid, industrydriven economic growth have intensified the water stress.

Water use planning guidelines. The PRC needs more water for continued economic growth, yet it is less efficient in its water use than more advanced countries. In 2013, the government set targets for controlling water withdrawals and improving water use efficiency in agriculture and industry (the "Three Red Lines"). It singled out water use efficiency in the industry sector, including energy, as a key variable to be monitored. Total water withdrawal has been capped at $700 \mathrm{bcm}$ by 2030, and specific targets have been set for industrial water intensity and irrigation water efficiency (Y. Jiang, 2009).

\section{Water Use in the Energy Sector}

High energy intensity of the economy. The PRC has followed an energyintensive economic growth strategy, and energy intensity-the ratio of energy consumption to gross domestic product-is more than that in advanced economies. Government efforts since 2006 to improve energy efficiency have led to a reduction in the growth of demand for energy and in the energy intensity of the economy. Structural transformation from a heavy industry-oriented economy to a service economy has also helped to slow the growth in energy demand. (International Energy Agency, 2014). However, energy demand in the PRC is projected to grow in the medium term, at least until 2030. Energy consumption is closely associated with water withdrawal and water consumption for primary energy production (e.g., mining of fossil fuels) and energy transformation (electricity generation) (Asia Pacific Regional Committee, 2014).

Coal-dominated energy sector. The country leads the rest of the world in coal production and consumption. Its coal production of 3.75 billion tons and consumption of 3.96 billion tons in 2015 accounted for close to half of global coal production and consumption. Coal provides about $64 \%$ of the PRC's primary energy consumption (and contributes $72.1 \%$ of its primary energy supply) and $67 \%$ of electricity supply in 2015 . The share of coal in the PRC's energy consumption has undergone a gradual and steady decline since 2009 , reaching $64 \%$ in 2015 , compared with $70.4 \%$ in 2009 . The government intends to decommission 500 million tons of coal mining capacity and reduce the share 
of coal in primary energy consumption to $62 \%$ by 2020 . Coal consumption decreased in absolute terms in 2014 and 2015, compared with previous years. But the PRC's energy supply will continue to be dominated by coal for decades (Ecofys, 2015). ${ }^{2}$ Despite its coal reduction targets, the government is developing 14 large coal production and processing bases, with coal mining, coal-fired power generation, and coal chemical production capabilities, and most of these bases are in the water-stressed north.

Water use in coal mining and processing. Although the freshwater required for coal mining is not significant (estimated at less than $2 \mathrm{bcm}$ ), the dewatering of coal mines results in highly contaminated "produced water" (estimated at $6 \mathrm{bcm}$ ). The produced water can be a source of water pollution unless properly treated before discharge. Serious pollution of natural water bodies due to seepage and runoff of polluted produced water can have a lasting impact that extends beyond the closure of the coal mine. The draining of produced water during mining operations also depletes groundwater, which may take years to replenish.

Key coal mining provinces, such as Inner Mongolia Autonomous Region (IMAR), Shaanxi, and Shanxi, the proposed locations of the coal bases, are in water-stressed regions of the country. About $56 \%$ of the coal produced in the PRC undergoes beneficiation (e.g., coal washing) to remove impurities and to reduce the ash content. Water withdrawal for coal washing is about $5 \mathrm{bcm}$ and water consumption is about $0.4 \mathrm{bcm}$. An estimated $85 \%$ of the water used for coal washing (about $4.25 \mathrm{bcm}$ ) can be recycled. Wastewater from coal washing is highly polluted and must be treated before discharge. This, together with produced water from coal mining, adds up to about $4.5 \mathrm{bcm}$ of water from coal mining and washing that needs to be treated.

Water use in coal-based industries. The search for possible replacements for petroleum use in transportation, coal gasification, and coal-to-liquid (CTL) processes, is being considered, given the PRC's abundant supply of coal and limited reserves of oil and conventional natural gas. But the large water requirement of these processes suggests that water availability could be a constraint on their large-scale deployment in the PRC. The government has nonetheless set ambitious targets for further expanding the coal conversion industry. Most of the proposed coal conversion plants will be in coal mining provinces in northern PRC, which are under a high degree of water stress.

The coal gasification plants now being built or planned are in arid and semiarid regions, such as Xinjiang Uyghur Autonomous Region (XUAR) and IMAR, and are likely to consume about $0.5-0.7 \mathrm{bcm}$ of freshwater per year. In addition to the coal gasification and CTL plants, the coal chemical industry uses coal as basic raw material to produce a variety of organic chemicals.

Water use in the oil and gas sector. The conventional oil and gas industry requires a relatively modest amount of water. Oil production may require the

2 A leading international energy and climate consultancy focused on sustainable energy for everyone. 
injection of water into oil fields and the fluids coming out of the production well contain considerable amounts of water (produced water). Oil production in the PRC in 2014 was 211 million tons, water consumption in oil production was about $0.2-0.3 \mathrm{bcm}$, and the volume of produced water that needed to be treated before discharge was in the range of $0.5 \mathrm{bcm}$.

Water consumed in oil refineries serves as coolant for chemical processes, as feedstock for the production of steam for various chemical processes, and also as a source of hydrogen. Cooling water does not have to be of high quality, but water used in chemical processes has to be demineralized. In 2014, the PRC had a refinery capacity of 500 million tons, and water withdrawals of about $1 \mathrm{bcm}$ and water consumption of about $0.2 \mathrm{bcm}$ for oil refining.

Conventional natural gas requires relatively modest amounts of water for preparing the drilling fluids, and little or no water for processing. For the regasification of imported liquefied natural gas (LNG), seawater is generally used.

Water use in shale gas development. The PRC has abundant shale gas resources, mainly in arid and water-stressed XUAR and water-rich Sichuan Province. The amount of water required to complete a shale gas well varies from well to well and from basin to basin, making estimates of water demand for shale gas development uncertain. The water intensity of shale gas production is about 10 times that of conventional gas production, according to data from the United States (World Resource Institute [WRI], 2014).

About $40 \%$ of the PRC's shale resources are in areas of high to extremely high baseline water stress and in arid locations. The Sichuan shale basin is in a region of water stress due to high water demand in relation to the available supply. Shale gas development is likely to exacerbate this situation. The Tarim Basin in XUAR is subject to extremely high baseline water stress in arid conditions, including extremely high groundwater stress and seasonal variability (WRI, 2014).

Water use in thermal power generation. Electricity generation in the PRC is also dominated by coal-based thermal power plants. The PRC has the largest fleet of coal-fired power plants in the world, with an installed capacity of 825 gigawatts (GW) in 2014, compared with $660 \mathrm{GW}$ in 2010. In addition, the PRC had $27 \mathrm{GW}$ of nuclear power plants in 2015 and is constructing $29 \mathrm{GW}$ more. In view of the government's commitment to reduce coal consumption, the installed capacity of coal power plants is expected to peak at around 960 GW by 2020, and then continuously decrease to about $920 \mathrm{GW}$ by 2030. The government is also encouraging the decommissioning of smaller (less than 100 megawatts), inefficient, and older coal power plants. More recently, installed coal power plants use highly efficient ultra-supercritical and supercritical steam technologies. Over 45\% of the PRC's coal power plants are in the highly waterstressed northern PRC (S. Cornot-Gandolphe, 2014).

Water is required for cooling thermal power plants, coal-fired as well as nuclear. The choice of cooling systems determines the water requirement for cooling. 
Wet (water) cooling systems can be configured as once-through (open-loop) or closed-loop cooling systems. In water-scarce locations, dry (air) cooling and hybrid cooling systems that use a combination of wet cooling and dry cooling are adopted. Open-loop cooling systems need access to natural bodies of water (e.g., lakes, rivers, or seas) and require a large volume of water withdrawal, but a relatively smaller share of water is consumed (evaporated) than in closed-loop systems. A relatively smaller volume of water withdrawal is needed for closed-loop systems, but the amount of evaporative loss (water consumption) is significant. Dry-cooling systems require minimal amounts of water but affect power plant efficiency because of the lower cooling capability of air compared with that of water, and the electricity consumed to maintain the airflow (G.A. Thopi and A. Pouris, 2016).

Closed-loop cooling predominates in both northern and southern PRC. But nearly all power plants using open-loop cooling are in southern PRC, providing about $20 \%$ of the thermal power capacity in the region; the technology is not used in northern PRC on account of its lack of suitable surface water bodies. Dry cooling is increasingly being deployed in northern PRC, and accounts for about $20 \%$ of its thermal capacity. Thermal power plants in coastal regions, accounting for $13 \%$ of thermal capacity, as well as the country's nuclear power plants, depend on seawater.

As of 2014, freshwater withdrawals for the PRC's thermal power generation totaled about $48 \mathrm{bcm}$, or roughly $8 \%$ of the country's total water withdrawal. Provinces with significant water withdrawals are mostly in eastern and southern PRC, particularly along the Yangtze River, These provinces have a larger share of power plants using open-loop cooling, accounting for $83 \%$ of water withdrawal in the power sector. Total water consumption in thermal power generation in 2011 was $7 \mathrm{bcm}$, or about 13\% of power sector withdrawals. There is a noticeable difference in geographic distribution between water consumption intensity and water withdrawal intensity for power generation. Provinces where closedloop cooling is extensively used (e.g., in northern PRC) have higher water consumption intensity.

The future water requirement for cooling thermal power plants depends on the cooling technologies adopted at new plants. The appropriate use of dry cooling and seawater cooling, where feasible, could enable the power sector to maintain its current levels of water withdrawal and consumption. The government has also mandated the use of dry cooling among power plants in water-stressed regions and directed the plants to obtain water rights from other water users (e.g., farmers) by investing in water conservation (e.g., in irrigation).

In addition to direct water withdrawal and consumption, the air pollution caused by coal power plants can create acid rain and result in acidification and heavy metal accumulation in surface water bodies. Coal ash also contains heavy metal pollutants such as mercury and may cause water pollution through seepage and runoff. Water returned to natural water bodies after it is used for cooling in open-loop cooling systems of thermal power plants may have been altered in quality or temperature. 
Water use in hydropower development. Hydropower is the most widely used form of renewable energy in the PRC. In 2014, it accounted for 19.2\% of electricity generation and $22.2 \%$ of installed electricity generation capacity. The country's installed hydropower capacity is the world's largest. It exceeded 300 GW in 2014, and is expected to reach 380 GW by 2020 and 450 GW by 2030. The geographic distribution of hydropower development in the PRC closely mirrors water resource availability across the country: most hydropower plants are in the southern and southwestern parts of the country.

Although hydropower systems require a large volume of water, they do not significantly affect water quality and their water consumption is limited to evaporation from reservoirs. They may, however, alter the timing and location of water release, as hydropower plants with storage may cause temporal and spatial water shortages to other water users. The impact is more severe when trans-basin water transfers are involved and appropriate water management regulations are required to balance the competing demands for water. The environmental impact of hydropower is mainly due to the fragmentation of river systems, disrupting the integrity of aquatic ecology and resulting in biodiversity loss due to the obstruction of fish migration along the river systems. The regulation of river flows to suit the needs of hydropower generation can alter seasonal floods and may adversely affect downstream floodplains, wetlands, and groundwater recharge. In addition, hydropower dams are likely to block sediment flows and affect soil fertility and agricultural productivity downstream.

\section{Energy for Water Supply}

The electricity consumed in the course of water extraction, treatment, and distribution and wastewater treatment is in the range of 200 TWh in 2014, or about $4 \%$ of the total electricity consumption of the PRC. Water extraction and conveyance contributes to about $62 \%$ of energy consumption (120 TWh). Surface water conveyance consumes 80 TWh per year, and groundwater extraction, 40 TWh per year. However, groundwater extraction requires more electricity per unit volume than surface water extraction. Desalination, at its current level of capacity, consumes about 1 TWh of electricity per year. In 2014, desalination produced about $0.2 \mathrm{bcm}$ per year of freshwater, compared with surface water withdrawals of $500 \mathrm{bcm}$ per year and groundwater withdrawals of $110 \mathrm{bcm}$ per year.

In addition to the electricity consumed in water extraction and conveyance, water distribution for agriculture requires about $75 \mathrm{TWh}$ per year; residential water supply requires 15 TWh per year, and water supply for commercial or industrial purposes, $36 \mathrm{TWh}$ per year, excluding the energy consumed in water and wastewater treatment. Water treatment for residential, commercial, and industrial purposes requires an additional 55 TWh per year, and wastewater treatment about 13 TWh per year. Water used in agriculture is generally not treated before or after use.

The geographic distribution of energy consumption in water supply in the PRC closely matches the pattern of water withdrawal in different parts of the country. 
Energy consumption for groundwater extraction is mainly concentrated in northern PRC, where surface water resources are scarce. Energy consumption for desalination is centered in the coastal provinces in the north. The more densely populated and economically advanced eastern PRC has a higher share of energy consumption for wastewater treatment. (L. Xi, L. Jie, and Z. Chunmiao, 2016).

\section{Addressing the Water-Energy Nexus}

The government already acknowledges that the current energy- and waterintensive economic structure is unsustainable over the long term because of the deteriorating air quality attributed to fossil fuel use - the PRC's contribution to climate change water stress in northern PRC, groundwater depletion, and water quality issues. It has, therefore, taken steps to reduce the PRC's dependence on fossil fuels, and is promoting energy and water conservation, water recycling, and improvements in water use efficiency. The close links between the water and energy sectors, and the increased emphasis placed by the authorities on ecological civilization, provide opportunities to minimize the impact of energy production, conversion, and consumption on water supply in a more holistic way (Encyclopedia of Sustainability Science and Technology, 2012).

Integrate water and energy planning at the macro level. Traditional water and energy sector investment planning in the PRC is fragmented and poorly coordinated. A more balanced and coordinated approach to allocating limited water resources among the different sectors, including energy, must be taken. Interministerial coordination is needed to derive the most benefit from integrated water and energy sector planning. Decisions about energy supply options and the location of large energy-producing or energy-processing plants, such as coal bases and coal chemical plants, could thus be made after due attention is paid to the availability of water resources and the impact of their use in the energy sector on other water users.

\section{Strengthen water allocation to energy projects by water sector regulatory} agencies. The PRC considers energy a key ingredient of sustained economic growth and industrial expansion, and its water sector regulators have traditionally granted favorable treatment to energy sector investments in water allocation because the investments, usually made by large state-owned enterprises, generate economic benefits and tax revenues for local governments. Water is allocated to energy sector projects at the time the project feasibility studies are approved by the provincial water regulators. By then, the decision to develop a particular energy sector project has already been made as part of a national plan, and the provincial authorities have little choice but to allocate water resources to the projects. The government should consider further empowering provincial water regulators, especially in water-stressed regions, to strictly enforce water use efficiency standards in existing as well as new energy sector activities, and to facilitate investment in water conservation in return for the transfer of water rights from existing water users. 
Strengthen efforts to diversify the energy supply mix away from coal. The government is aware of the need to reduce dependence on coal to meet energy demand. Faced with overcapacity in coal mining, the government should give serious thought to decommissioning coal mines and banning coal-fired power generation altogether in regions suffering from extreme water stress. It has already made the adoption of dry-cooling technology a precondition for the establishment of new coal power plants in those regions (International Energy Agency, 2014). In addition, over $45 \%$ of existing coal power plants are in waterstressed regions. These plants will have to be converted to dry cooling or decommissioned as the PRC diversifies its energy supply mix away from coal. Reducing coal production and consumption could significantly disrupt the economic structure of provinces that depend on coal for much of their economic output and employment generation. The central government may have to provide fiscal subsidies to coal-dependent provinces to manage the economic cost of industrial transformation.

Improve energy efficiency in water supply. The PRC's water sector requires innovative management to integrate and incorporate energy considerations. The government can establish an energy (carbon) accounting system in the urban water sector; build a sludge-to-energy system to recover energy from wastewater and sludge; and prioritize water conservation, rainwater harvesting, and water recycling, which are less energy and capital intensive than water supply options like desalination, long-distance water transfer, and extraction of groundwater from deep aquifers.

\section{Continue efforts to apply economic instruments and market-based} mechanisms in water resource allocation. The underpricing of water resources or water services undervalues them and prevents water users from being truly concerned about water scarcity and increased water risks, and from improving water use efficiency. In view of the relatively low cost of water supply in the energy sector, water tariffs applicable to the energy sector can be substantially increased to encourage water conservation in energy sector activities. In addition to setting appropriate water tariffs, the government should establish a trading system for water use rights and wastewater discharge rights, with transparent allocation and monitoring mechanisms to encourage the efficient use of water.

Invest more in water and energy data collection infrastructure. There is still a lack of reliable data on water withdrawal, consumption, and discharge in energy production, and on energy consumption in water supply. A clear understanding of the water-energy nexus is crucial to an adequate response, and it depends on the availability of timely data related to the water-energy nexus. During the 13th Five-Year Plan period (2016-2020) and beyond, the PRC should establish a reliable and transparent data acquisition and disclosure system for water and energy data, including real-time geographic information system-based monitoring (J. Daqian, and R. Anuradha, 2015). 


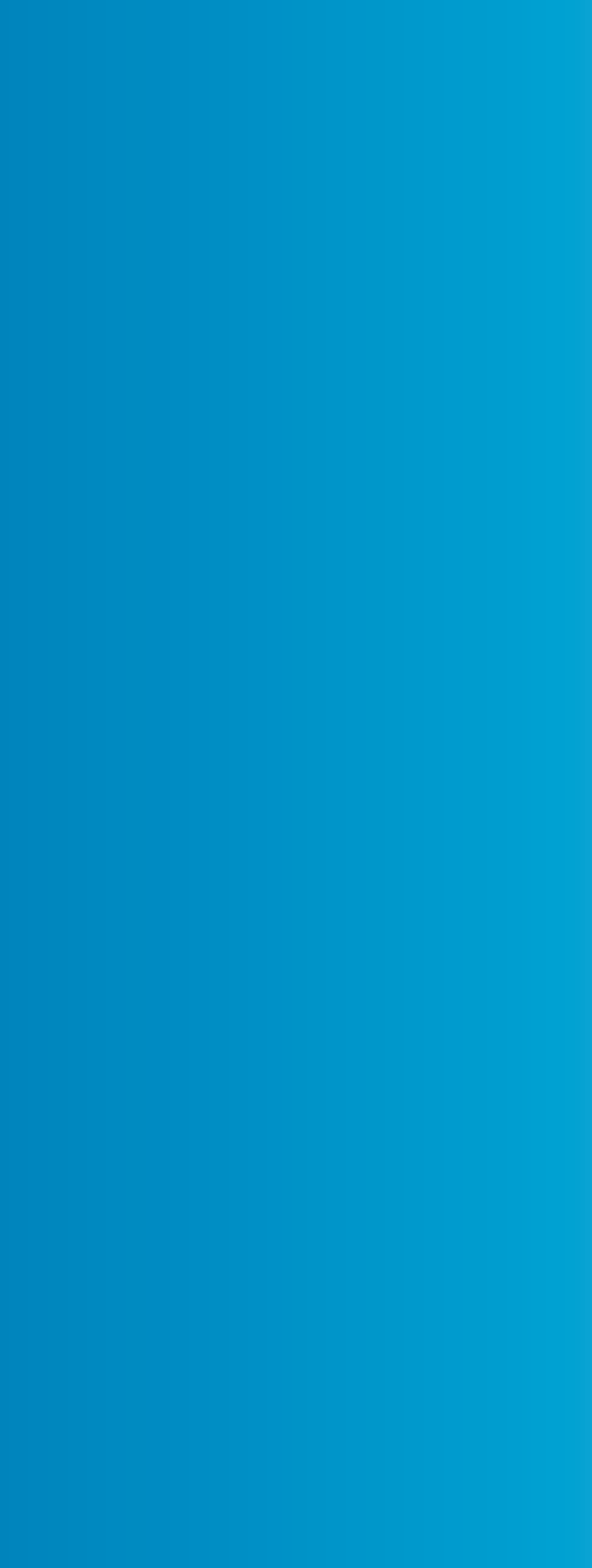


The People's Republic of China (PRC) has achieved remarkable economic growth since initiating market reforms in 1979. Gross domestic product (GDP) has grown by an average of $9.8 \%$ a year in the last 3 decades ${ }^{1}$ - a record for a major economyand per capita GDP in 2015 was roughly $\$ 8,016$. Rapid and sustained economic growth has lifted more than 600 million people out of poverty, and enabled this upper middle-income country to achieve the Millennium Development Goals ahead of schedule.

This historic transformation of the economy has been accompanied by rapid urbanization, the largest movement of people from the countryside to the cities in history, and a structural shift toward industrialization. At the start of economic reforms 30 years ago, $80 \%$ of the population lived in the rural areas and agriculture accounted for about $35 \%$ of GDP. The PRC's urbanization rate is $56.1 \%$, and agriculture contributed $9.0 \%$ of GDP in 2015 . The country has industrialized swiftly, in support of the export-oriented economic strategy it adopted in 1980. Although industry has recently had a decreasing share in overall GDP, its 40.5\% in 2015 was still significantly higher than that of other major economies.

But rapid industrialization is exerting ever-growing stress on the country's natural resources, including water and energy. Environmental issues associated with its industry-led, export-driven, and energy-intensive economic growth strategy and fast-paced urbanization demand solutions. The population, increasingly affluent and urbanizing, is pushing for secure and clean water sources, and the agriculture sector must meet the escalating need for food. Agriculture accounted for $63.5 \%$ of water withdrawals in 2014; the industry sector, including the energy sector, for $22.2 \%$; and the residential sector, including urban water supply, for $12.6 \%$ (2014).

Energy takes different forms-electricity, heat, and petroleum, among themand can be produced in several ways, each with a distinct requirement for water resources and impact on those resources. While the implications for water resources will generally increase as energy demand grows, the energy mix and the energy conversion technologies used will significantly affect water withdrawal and water consumption in the energy sector. Water is an essential resource for producing adequate quantities of energy. Water is used to extract fossil fuels, such as coal, oil,

1 Computed from data published by the National Bureau of Statistics. 
and natural gas; to irrigate biofuel feedstock crops; to wash coal to remove unwanted minerals; and to refine crude oil into petroleum. In electricity generation, water is also required to cool most thermal power plants that depend on fossil fuels and nuclear energy, and it powers the hydroelectric and steam turbines (Q. Ying et al., 2015).

Given the energy-intensive nature of the PRC's industry-led economic growth, the energy sector is a major water user. In 2014, the sector accounted for about 60 , billion cubic meters (bcm), 10\% of total withdrawals (International Energy Agency, 2014). Although most of the water that is withdrawn is returned to natural water bodies, ${ }^{2}$ the timing and location of release in the case of hydropower, and the quality in the case of thermal power and coal mining and processing, may have been significantly altered. As a result, other water users may have been permanently or temporarily prevented from using the water withdrawn by energy sector entities. The water consumption of the energy sector-withdrawn water that has been transformed into a different substance, evaporated, or polluted to the extent that it is not suitable for reuse-is estimated at $10 \mathrm{bcm}$.

Water and energy are both valuable resources and indispensable for human society and economic development. By nature, water and energy are interlinked. Water plays a critical role in the generation of electricity and the production of fuels, such as cooling power plants; energy is required to treat, distribute, and heat water. The availability and quality of freshwater to meet human needs have emerged as toptier global issues for the environment and development (World Economic Forum [WEF], 2013).

Maintaining economic growth is imperative for the PRC, but it must proceed at a pace that is more moderate and sustainable. In view of the growth momentum of the PRC's economy, even with significant improvement in energy and water use efficiency, the demand for energy and water is likely to increase further in the next 25-30 years. Choices made in either the energy or the water sector will have significant, multifaceted, and broad impact on the other sector, often with both positive and negative repercussions. This trade-off between energy and water resources is referred to as the water-energy nexus. (World Water Assessment Program [WWAP], 2014).

To address the increasing stress on the country's resources and facilitate sustainable development, the government must understand the water-energy nexus, including the impact of energy development on water resources and vice versa, and improve its energy development strategies and water management practices. Regulatory and operational innovation toward integrated water-energy resources management is also a critical need.

\section{Water Scarcity and Water Stress}

The PRC's freshwater resource endowment, at 2.8 million $\mathrm{m}^{3}$, is the sixth largest in the world. However, its water resources are declining and unevenly distributed, both spatially and temporally, because of differences in topography and climate. Southern PRC is largely abundant in water resources; northern PRC, on the other hand, has only about $20 \%$ of the PRC's water resources (Table 1 ).

2 The $10 \mathrm{bcm}$ consumed bin 2014 was $17 \%$ of the water withdrawn by the energy sector. 
Table 1: Water Resource Distribution Between the Northern and Southern Regions of the People's Republic of China, 2014

\begin{tabular}{|c|c|c|c|c|c|c|c|c|c|}
\hline & \multicolumn{3}{|c|}{$\begin{array}{l}\text { Water Availability } \\
\text { (bcm) }\end{array}$} & \multicolumn{3}{|c|}{$\begin{array}{l}\text { Water Withdrawals } \\
\text { (bcm) }\end{array}$} & \multicolumn{3}{|c|}{$\begin{array}{c}\text { Water Use Intensity } \\
(\%)\end{array}$} \\
\hline Region & Surface & Ground & Totala & Surface & Ground & Totalb & Surface & Ground & Total \\
\hline North & 381.1 & 230.2 & 465.8 & 175.0 & 98.9 & 278.0 & 45.9 & 43.0 & 60.0 \\
\hline South & $2,245.3$ & 544.2 & $2,260.8$ & 317.0 & 12.8 & 331.5 & 14.1 & 2.3 & 14.7 \\
\hline Total & $2,626.4$ & 774.4 & $2,726.6$ & 492.0 & 111.7 & 609.5 & 18.7 & 14.4 & 22.4 \\
\hline
\end{tabular}

bcm = billion cubic meter

a Surface water and groundwater are interrelated, and the total amount of water available is less than the sum of surface water and groundwater.

b The total water withdrawn includes surface water, groundwater, and a small portion of water from other water sources (e.g., reclaimed wastewater and harvested rainwater).

Sources: Water availability and water withdrawal data are from the Ministry of Water Resources, 2015; and water use intensity data are the author's estimates. (See Box 1 for definitions of these terms.).

Per capita freshwater availability of about $2,100 \mathrm{~m}^{3}$ per year is just above the threshold considered adequate by the United Nations Environment Programme. ${ }^{3}$ However, most parts of northern PRC have an average per capita water availability of less than $700 \mathrm{~m}^{3}$ and are therefore considered "water scarce." Northern PRC has $60 \%$ of the country's farmland and $40 \%$ of its population, but only $20 \%$ of its water resources (L. Xi, L. Jie, and Z. Chunmiao, 2016). Per capita water availability in the Hai River Basin, where Beijing and Tianjin municipalities are located, is only $350 \mathrm{~m}^{3}$. Average rainfall in four river basins is down by $17 \%$. Moreover, groundwater abstraction exceeds sustainable levels and groundwater levels are falling. On average, annual water shortages across the country amount to more than $50 \mathrm{bcm}$ and twothirds of the cities endure water shortages to varying degrees.

Freshwater withdrawals in the PRC in 2014 for residential, industrial, and commercial use amounted to about $164.5 \mathrm{bcm}$, excluding the water requirement for agriculture

3 The United Nations Environment Programme, United Nations Development Programme, Food and Agriculture Organization of the United Nations, and World Bank classify annual per capita freshwater availability as "adequate" (above 2,000 m³), "stressed" (1,000$2,000 \mathrm{~m}^{3}$ ), or "facing water scarcity" (below 1,000 m³). 


\section{Box 1: Definition of Terms}

There is a certain degree of confusion regarding the terms used to describe and quantify water used in industrial processes, including energy production. This confusion is mainly due to the lack of clarity regarding the exact definition of water withdrawal, water consumption, and water use.

Water withdrawal. The amount of water extracted from surface or groundwater. Most of the water withdrawn is usually returned to the water source or a natural water body, but the returned water may have an altered quality or temperature.

Water consumption. The amount of withdrawn water that is not returned to the natural water body from which it was withdrawn because of evaporation, transfer to a different water body, or transpiration. Water consumption, by definition, is less than water withdrawal.

Water use. This nontechnical term usually describes water utilization in different industrial processes and does not distinguish between the water used in one process and its reuse in another process. As a result, the amount of water used can be several times larger than the amount of water withdrawn and the amount of water consumed.

Water stress. The ratio of total water withdrawn to available freshwater in a river basin or catchment. Water stress is categorized as low (<10\%), low to medium (10\%-20\%), medium to high (20\%-40\%), high (40\%-80\%), or extremely high (80\%-100\%). It can also be over $100 \%$ when the water withdrawal exceeds the water available on a sustainable basis from underground aquifers.

Source: William and Simons (2013). www.bp.com.

(386.9 bcm), for the cooling of power plants $(47.8 \mathrm{bcm})$, and for ecological system $(10.3 \mathrm{bcm})$. Water used in the residential, industrial, and commercial sectors usually comes from public water utilities, and is treated before reaching the end users. A significant share of the water supplied to these sectors $(64.2 \mathrm{bcm})$ is consumed, and about $71.1 \mathrm{bcm}$ is discharged into natural bodies of water after use. Wastewater also needs to be treated before it is released. In the PRC, about $80 \%$ of residential and industrial wastewater that is discharged into natural water bodies $(55 \mathrm{bcm})$ is treated. But water used in nonpoint sources, such as agriculture, is not treated before discharge, and this is a major cause of surface water and groundwater pollution.

Although the growth in water withdrawals is driven by the residential and industrial (including energy) sectors, agriculture remains the dominant water user, with over $60 \%$ of total water withdrawals, compared with $28 \%$ for industry and $10 \%$ for the domestic sector (Figure 1). In 2014, freshwater withdrawals in the PRC declined for the first time in years, to $609 \mathrm{bcm}$, but this total was still 10\% higher than water withdrawals in 2000. In addition, about $71 \mathrm{bcm}$ of seawater was used to cool power plants in 2014. Freshwater use in the energy sector (excluding use in hydropower generation) is estimated to range from $50 \mathrm{bcm}$ to $60 \mathrm{bcm}$ per year, or about $10 \%$ 
Figure 1: Freshwater Withdrawals in the PRC, by Sector, 1950-2010 (billion $\mathrm{m}^{3} /$ year)

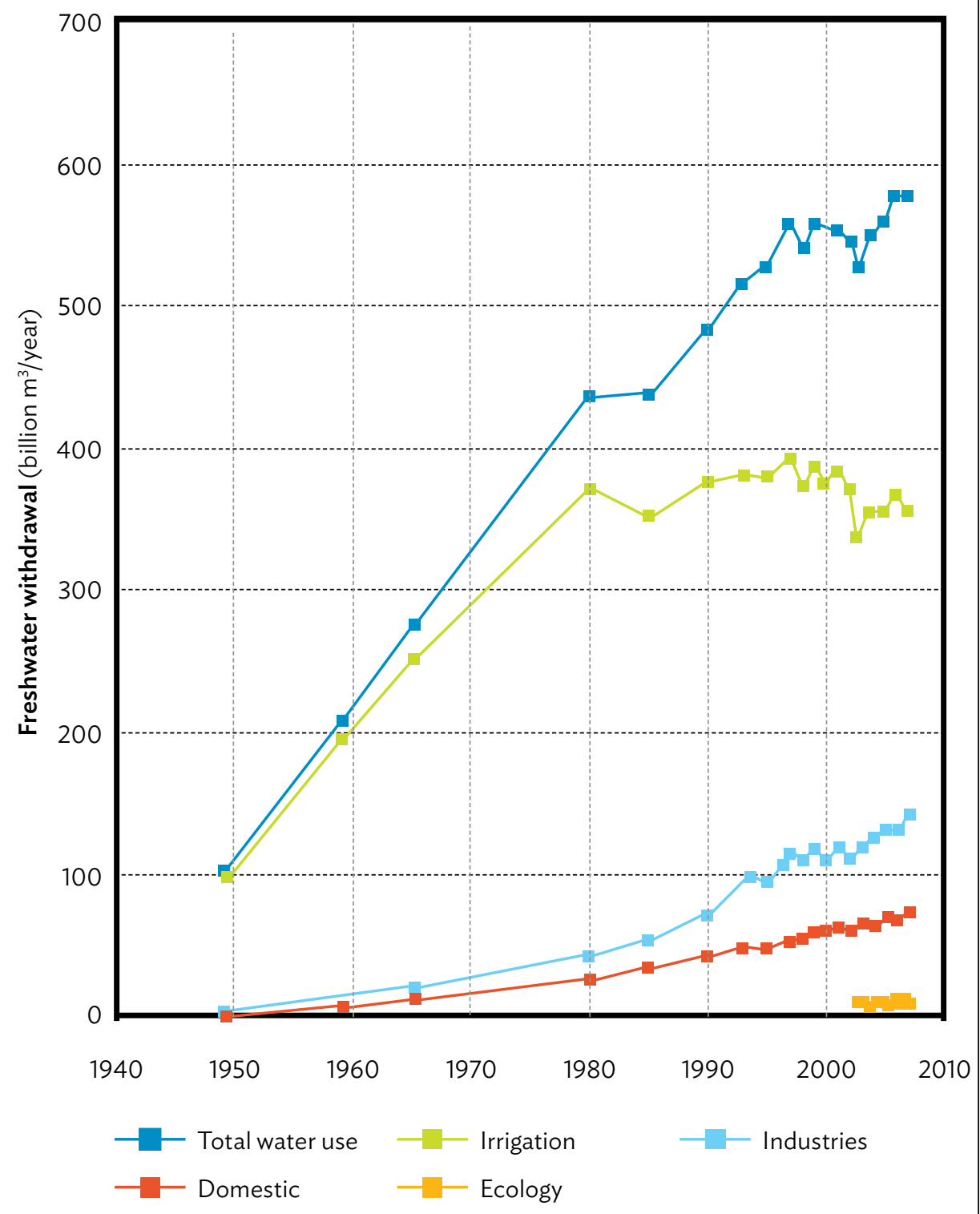

$\mathrm{m}^{3}=$ cubic meter.

Source: Global Water Partnership, 2015.

of freshwater withdrawals in the PRC. About $50 \%$ of freshwater withdrawals are discharged into surface water bodies or groundwater aquifers, while the rest is consumed or evaporated.

Climate change is another factor that accentuates the uneven distribution of water resources. Changing rain patterns, droughts, and extreme weather phenomena have an effect on both the availability and the geographic distribution of water resources (Figure 2). Precipitation is declining in both northern and southern PRC, but the more pronounced impact in northern PRC is undermining the capacity of water bodies in the region to fulfill their ecological functions. Some rivers in northern PRC are unable to maintain even minimum environmental and ecological flows (M. Oppenheimer et al., 2014). 
Figure 2: Baseline Water Stress and Provincial Water Withdrawals in the PRC, by Sector, 2012

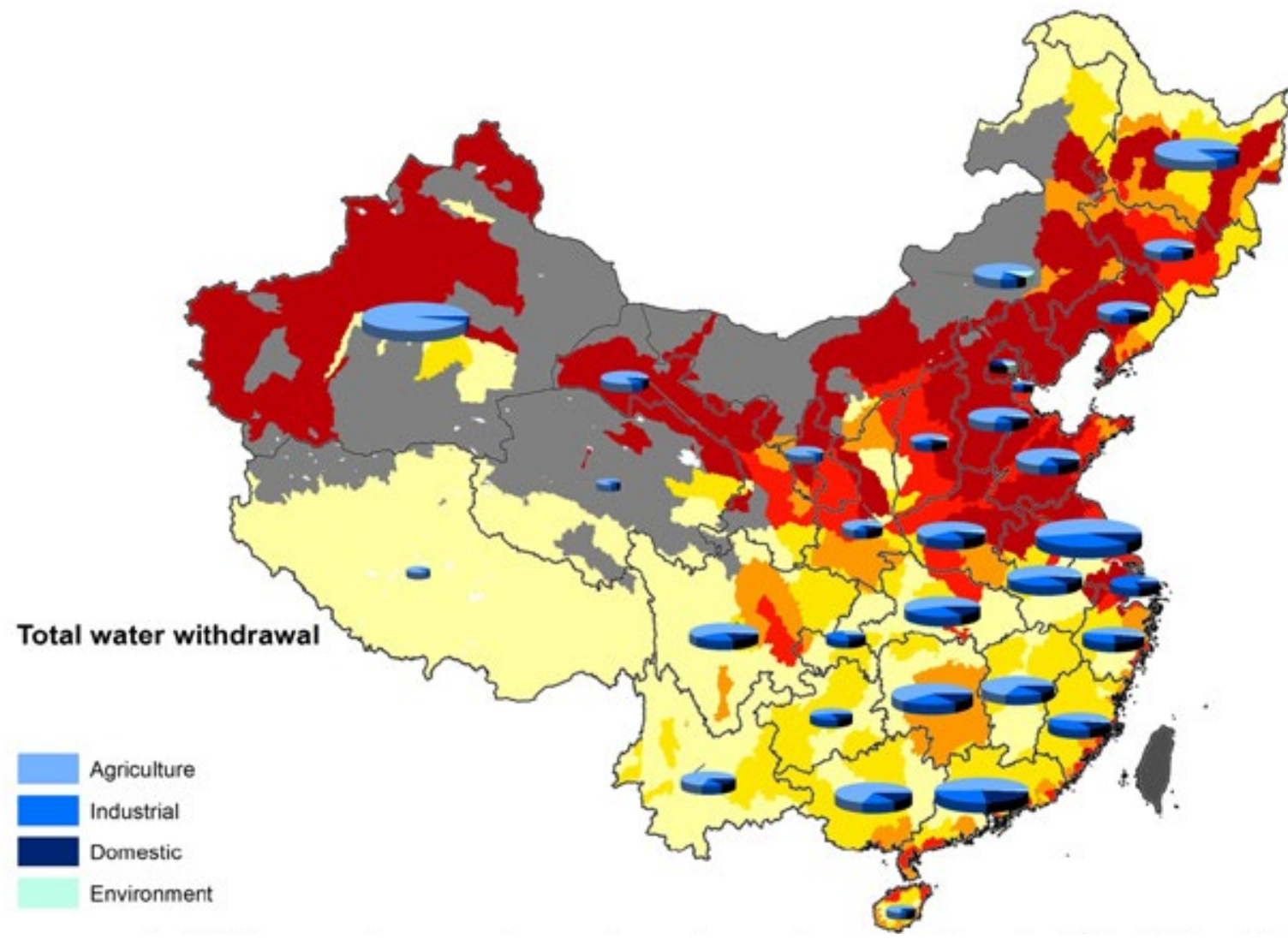

\begin{tabular}{rlr|rrr} 
Arid \& low water use & Low & Low to medium Medium to high High & Extremely high \\
Ratio: withdrawals/supply & $<10 \%$ & $10-20 \%$ & $20-40 \%$ & $40-80 \%$ & $>80 \%$
\end{tabular}

Sources: Water withdrawal data referred to provincial water resources bulletins issued by the provincial water resources management agencies; and the World Resources Institute's Baseline Water Stress China Map (Wang, et al., 2016).

The heavily populated and industrialized northeastern region and the north-central and northwest provinces (IMAR, Shaanxi, and XUAR) suffer from severe water stress. Apart from water-intensive agriculture, industrial activities in provinces like Hebei, Heilongjiang, Liaoning, Shandong, and Tianjin, and increasing residential water use in urban centers such as Beijing and Tianjin, are contributing to the water stress. Climate change is expected to alter the rainfall and may intensify aridity in northern PRC, making both groundwater and surface water even scarcer.

The PRC needs more water for continued economic growth, yet it is less efficient in its water use than more advanced countries. In 2013, the government set targets (Table 2) for controlling water withdrawals and improving water use efficiency in agriculture and industry (the "Three Red Lines"-reduce, increase, and protect). It singled out water use efficiency in the industry sector, including energy, as a key variable to be monitored. The planning guidelines need to be translated into policies, regulations, and standards to improve water efficiency. However, as water resource allocation and management reform lags behind other sectors, the conflict between 
Table 2: Water Planning Guidelines

\begin{tabular}{|lcccc|}
\hline Item & 2014 Performance & 2015 & 2020 & 2030 \\
\hline $\begin{array}{l}\text { Maximum amount } \\
\text { of water withdrawn } \\
\text { (bcm) }\end{array}$ & 609.5 & 635 & 670 & 700 \\
$\begin{array}{l}\text { Industrial water } \\
\text { intensity } \\
\text { (m3/CNY10,000 } \\
\text { of industrial value } \\
\text { addition) }\end{array}$ & 59.5 & Below 63 & 65 & 40 \\
$\begin{array}{l}\text { Irrigation water } \\
\text { efficiency }\end{array}$ & 0.53 & $53 \%$ & $55 \%$ & $60 \%$ \\
$\begin{array}{l}\text { Water zones } \\
\text { complying with water } \\
\text { quality standards }\end{array}$ & $51.8 \%$ & $60 \%$ & $80 \%$ & $95 \%$ \\
\hline
\end{tabular}

$\mathrm{bcm}=$ billion cubic meter, $\mathrm{m}^{3}=$ cubic meter.

Source: Qin et al., 2016.

maintaining the momentum of economic growth and promoting sustainable water use must be resolved through market-based mechanisms (Y. Jiang, 2009).

The government intends to ensure compliance with its water use guidelines by establishing a water allocation plan and water use quotas for water withdrawal from rivers, lakes, and groundwater aquifers. These quotas will form the basis for water licensing decisions and will be set at river basin level, as well as at the level of administrative units (provinces, prefectures, and counties). New applications for water withdrawal will be approved on the basis of water availability, water use efficiency, extent of water pollution control, potential for water saving, and water rights transfer. Applications that exceed the water use quota for the river basin or the administrative unit will not be approved.

The industrial water intensity standard will apply to the thermal power generation, oil refining, iron and steel, textile, paper, chemical, and food processing industries. Compliance with the standards for industrial water use and irrigation water use efficiency will be monitored through self-reporting and routine inspections by provincial units of the MWR. Water quality will be measured within water function zones of major rivers and lakes designated as such by the MWR. These will consist of major rivers and their tributaries with a catchment area of more than 1,000 square kilometers $\left(\mathrm{km}^{2}\right)$, lakes and reservoirs of national importance, and protected water bodies of national significance.

\section{Overview of the Energy Sector in the PRC}

The PRC is the world's largest energy consumer, with an energy sector heavily dominated by coal. The country is the world's largest producer and consumer of coal. In 2014, it consumed 3.87 billion tons of coal-about half of global coal consumption-and relied on coal for $66 \%$ of its primary energy supply and over $70 \%$ 
of its electricity supply. The reduction of coal consumption continued to 3.75 billion tons in 2015. However, there has been a gradual and steady decline in the share of coal in the PRC's energy consumption, from $70.4 \%$ in 2009 to $64 \%$ in 2015. A further reduction to $62 \%$ of primary energy consumption by 2020 is a government target. The gradual cleanup of the energy sector is attributed mainly to an increase in the use of nonfossil energy, such as hydro, wind, and nuclear, and in the use of less carbonintensive natural gas. Between 2013 and 2014, even as total energy consumption increased by $2.2 \%$, coal consumption declined by $2.9 \%$. This decline in absolute terms was the first in 2 decades. In 2015, coal consumption continued to decline by $3.7 \%$ from 2014. Slowing energy demand and decreased use of coal resulted in a $0.7 \%$ reduction in greenhouse gas (GHG) emissions in 2014 from the previous year's level.

The PRC has made significant progress in increasing the penetration of renewable energy into its energy mix (Figure 3). The share of nonfossil fuel sources in the country's energy consumption increased from $7.7 \%$ in 2010 to $11.4 \%$ in 2014 and contributed $24.7 \%$ to electricity generation in 2014 compared with $19.2 \%$ in 2010 . Although hydropower remains the largest form of nonfossil fuel energy, wind power and solar power have had the biggest uptake in the last 5 years. ${ }^{4}$ Between 2010 and 2014, installed capacity increased from 216 gigawatts (GW) to $301 \mathrm{GW}$ for hydropower, from $29 \mathrm{GW}$ to $96 \mathrm{GW}$ for wind power, and from $0.8 \mathrm{GW}$ to $28 \mathrm{GW}$ for solar power. The total renewable generation capacity added during this period (184 $\mathrm{GW}$ ) exceeded the net increase in coal-based capacity of $115 \mathrm{GW}$.

Figure 3: Primary Energy Supply in the People's Republic of China, 2000-2014

\section{Million TCE}

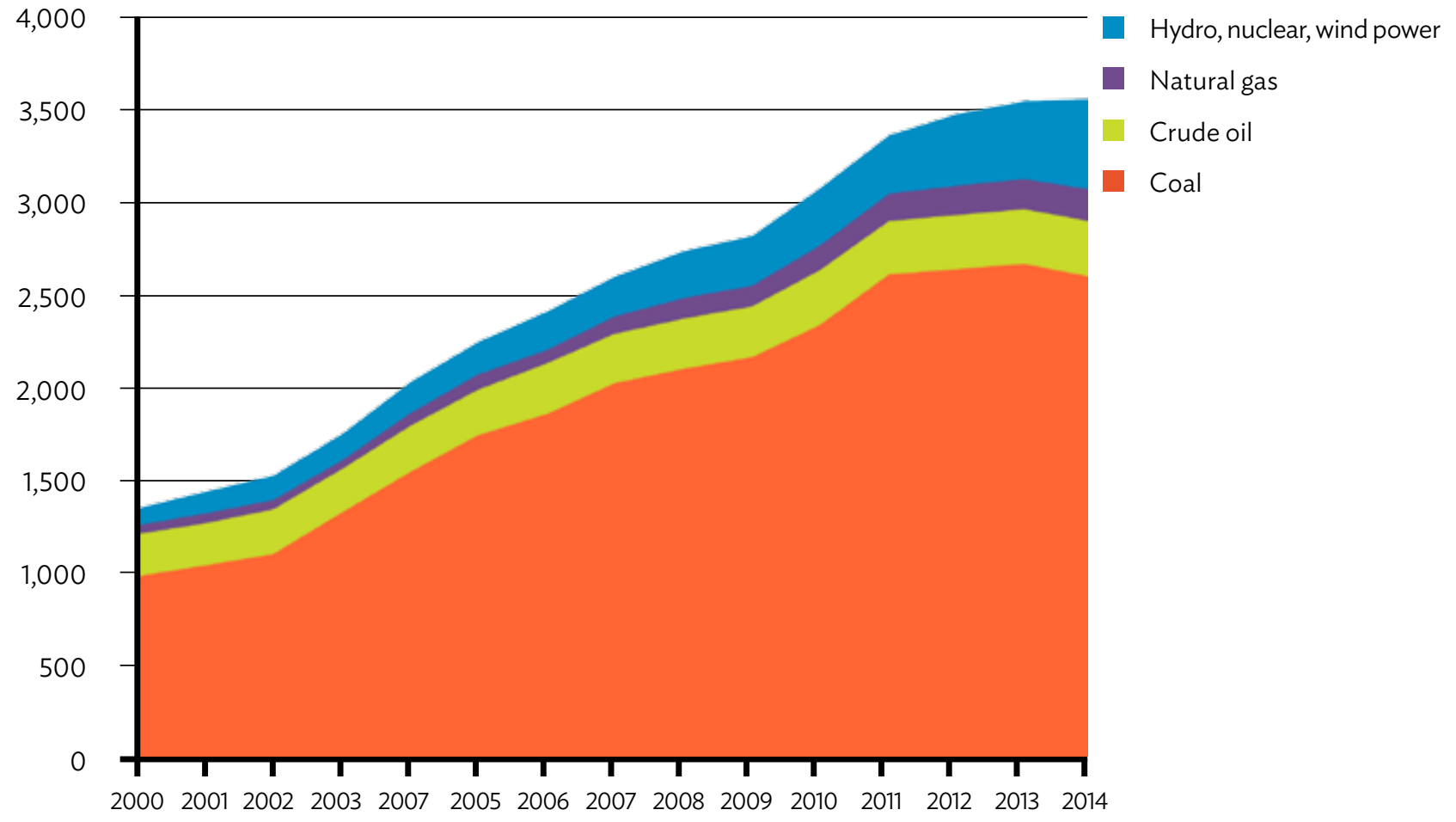

tce $=$ ton of coal equivalent.

Source: National Bureau of Statistics.

$4 \quad$ Electricity generation from wind and solar power increased by more than 3.5 times between 2010 and 2014, from 50 TWhs to 180 TWhs. 
The PRC has sufficient coal reserves, but because of production and logistic bottlenecks in the coal supply chain, it meets about $5 \%$ of its coal demand through imports (in 2015). However, coal imports are likely to decline with the slowing of demand for coal. The demand for oil, on the other hand, is increasing because of demand from the transport sector. At the same time, domestic production is decreasing. The PRC imported more than $60 \%$ of its oil consumption in 2015 , and is expected to overtake the United States (US) as the largest oil importer in the near future.

To reduce its dependence on coal, the PRC is aggressively expanding the consumption of natural gas. The PRC's dependence on gas imports has, however, increased as a result, to $30 \%$ in 2014. Natural gas pipelines and LNG terminals are being expanded and the PRC is likely to be a major recipient of piped natural gas from the Russian Federation and the Central Asian countries. Shale gas development is a significant opportunity to reduce emissions and improve energy security, but development has been rather slow in the early stages, primarily because of gaps in technology, concerns about water availability, weak gas distribution infrastructure, and a tightly regulated price for natural gas. The PRC is also investing in coal gasification and coal liquefaction to produce synthetic gas and liquid fuel. These technologies could lead to an increase in GHG emissions and in demand for water in water-stressed regions of the country.

Besides its significant share in the country's water withdrawals (about 10\%) and water pollution, the energy sector in the PRC is a major contributor to the worsening air pollution. Coal is burned in northern PRC to supply heat, and is used as industrial feedstock and energy source for industries. The Government of the PRC has begun implementing an action plan to shut down coal-fired power plants and boilers in urban areas and replace them with cleaner natural gas-fired combined heat and power (CHP) plants. New coal-fired power plants will incorporate strict pollution control measures, and existing coal-fired plants will be retrofitted to match the emission levels (excluding carbon dioxide emissions) of natural gas-fired power plants.

In parallel with efforts to contain energy demand, the government will strive harder to increase the share of nonfossil fuel energy in the PRC's energy supply mix and expand the use of low-carbon and cleaner fuel, such as natural gas. Natural gas is foreseen to meet $10 \%$ of primary energy consumption by 2020 (compared with $5.7 \%$ in 2014), when demand could reach $350 \mathrm{bcm}$. In addition, the PRC is expected to develop its untapped shale gas resources, the largest in the world. Shale gas production could reach $30 \mathrm{bcm}$ by 2020 (H. Guo, Y. Wang, and Z. Wang, 2016). The government is actively promoting the use of natural gas in urban areas for heat supply and cooling using $\mathrm{CHP}$ and distributed tri-generation plants.

\section{What Is Driving the Water-Energy Nexus?}

There is increasing realization that water and energy are tightly interlinked and interdependent, given the importance of water for producing energy, the impact of energy production and consumption on water quality and availability, and the demand for energy for water supply (Environment Protection Agency, 2014). The challenge of addressing this nexus in a mutually compatible manner is further heightened by several other developments that are occurring simultaneously in the PRC.

The unprecedented economic growth over the past 3 decades and the growth momentum of the economy indicate that the PRC's overall energy consumption will maintain its upward trajectory. Although energy intensity was decreased by $18 \%$ during the 5 years to 2015, and a similar reduction is projected for the subsequent 5 -year 
period, overall energy consumption is not likely to peak during the next 10-15 years, as the GDP growth rate is greater than the projected reduction in energy intensity.

Despite the impressive growth of renewable energy in the PRC's energy supply mix, the country's energy sector will continue to be dominated by coal, which requires a significant amount of water for extraction and for cooling coal-fired power plants. ${ }^{5}$ The coal-dominant energy sector in the PRC is likely to remain a significant user of water resources, especially in the water-stressed northern PRC, and the emerging coal chemical industry may further increase water consumption in the coal sector. Coal mining and processing and coal-fired power and coal-to-chemical plants have a major effect on the country's water consumption (L. Pan et al., 2011). IMAR, Shaanxi, and Shanxi-the primary coal production provinces in the PRC, accounting for most of the country's coal production-are in northern PRC, where water is in short supply. Altogether, more than $50 \%$ of the PRC's major coal reserves are in regions with high or extremely high water stress according to the Baseline Water Stress China Map of the World Resources Institute (WRI) (Figure 4).

Ongoing efforts to reduce air pollution in the PRC's first- and second-tier cities have prompted the gradual relocation of coal power plants to western PRC. Existing power plants in eastern PRC are being decommissioned, and new power plants are being built in western provinces like IMAR, Ningxia, and XUAR. The move is likely to raise the already high levels of water stress in these provinces. Nuclear power plants, on the other hand, are mostly in the coastal areas and use seawater for cooling.

In the search for possible replacements for petroleum use in transportation, coal gasification and coal-to-liquid (CTL) processes, which offer cleaner ways of using coal to produce electricity, are being considered, given the PRC's abundant supplies of coal and limited oil reserves. But the large water requirement of these processes suggests that water availability could be a constraint on their large-scale deployment in the PRC.

Modern water supply systems extract water from water sources, transfer water directly to end users (e.g., irrigation) or to a treatment plant when higher-quality water is required (e.g., for urban water supply), distribute treated water to consumers, and treat and possibly recycle wastewater before it is discharged into the natural environment. Every step in this cycle uses energy. Installing hydropower plants in places where there is sufficient elevation difference in water transfer channels could also produce energy. (Water in the West, 2013)

The regional disparities in water supply and the huge mismatch between water availability and demand, which are unlikely to be bridged by nearby water sources, have made long-distance water transfers an option for addressing water shortages in the PRC. In December 2014, the government launched the South-North Water Transfer Project to enable the transfer of $45 \mathrm{bcm}$ yearly from central and southwest PRC to northern PRC, augmenting the flow of the Yellow River and relieving the water supply problems of the Beijing-Tianjin region (T. Yannagi, 2008). Increasingly, the PRC is also resorting to desalination as a solution to water shortages in coastal regions in the north. The energy requirement for desalination is a function of salinity, water temperature, and the desalination technology adopted. Seawater desalination is usually more energy-intensive than the desalination of brackish water.

5 The PRC also intends to reduce the share of coal in primary energy supply from $66 \%$ in 2014 to $62 \%$ by 2020 . 
Although water intensity in agriculture is likely to continue the declining trend, increased water consumption in urban areas often accompanies urbanization and industrialization. International experience, however, suggests that water consumption will decrease after a certain level of economic development is reached, as affluent societies move away from primary industry and agriculture toward service-oriented, less water-intensive economic activities and can afford to adopt more expensive water conservation measures, such as wastewater recycling.

Climate change affects the hydrologic cycle through changes in precipitation and rainfall patterns, resulting in droughts and flooding, desertification, and saltwater intrusion into coastal water resources. It amplifies the already intense competition for water. Certain options for adapting to climate change, such as desalination of groundwater and long-distance water transfer, require additional energy consumption, which is likely to cause more GHG emissions and worsen climate change. On the other hand, certain technical options for mitigating climate change by reducing GHG emissions, such as a shift toward shale gas instead of coal, or to largescale carbon capture and storage, may be hindered by concerns about the possibility of groundwater contamination. 


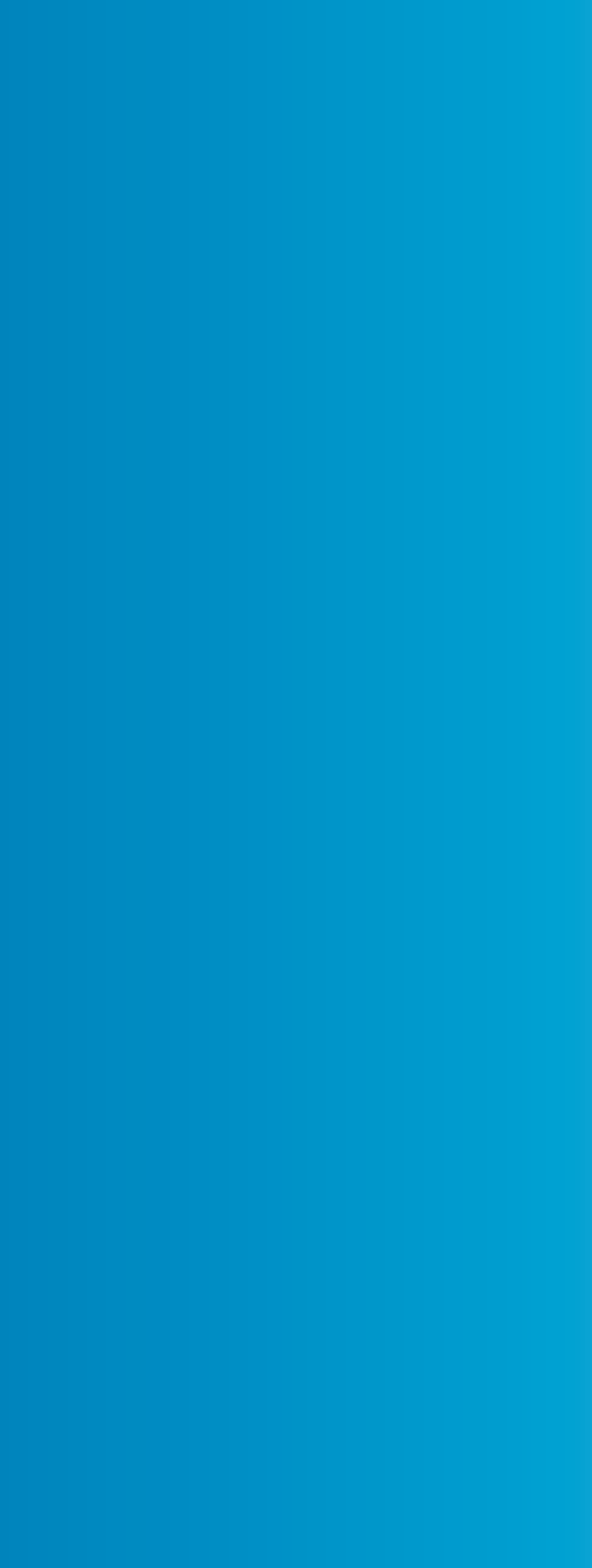




\section{Water Use in Coal Industry}

Three northern provinces-IMAR, Shanxi, and Shaanxi-dominate coal production in the PRC. IMAR and Shanxi each produce around 1 billion tons of coal yearly, more than the coal production of the US, the second-largest coal producer in the world. The coal production of Shaanxi Province, the PRC's third largest coal producer, matches that of Australia and Indonesia, the world's two biggest coal-exporting countries. Together, these three provinces represent over $65 \%$ of national coal production. Other provinces with an annual coal production of over 100 million tons are Yunnan, Hebei, Anhui, XUAR, Henan, Shandong, and Guizhou.

Coal production in the PRC has undergone geographic concentration, in parallel with the consolidation of ownership of coal mining companies. The 14 large-scale coal bases produced 3.36 billion tons in 2013 , over $90 \%$ of total output. Most of these coal bases are in IMAR (25.4\% of coal production in 2014), Shanxi (25.2\%), and Shaanxi (13.3\%), in the water-stressed north (China National Coal Association, 2014). Fortysix percent of coal mining regions experience severe water shortage according to WRI's Baseline Water Stress China map (Figure 4).

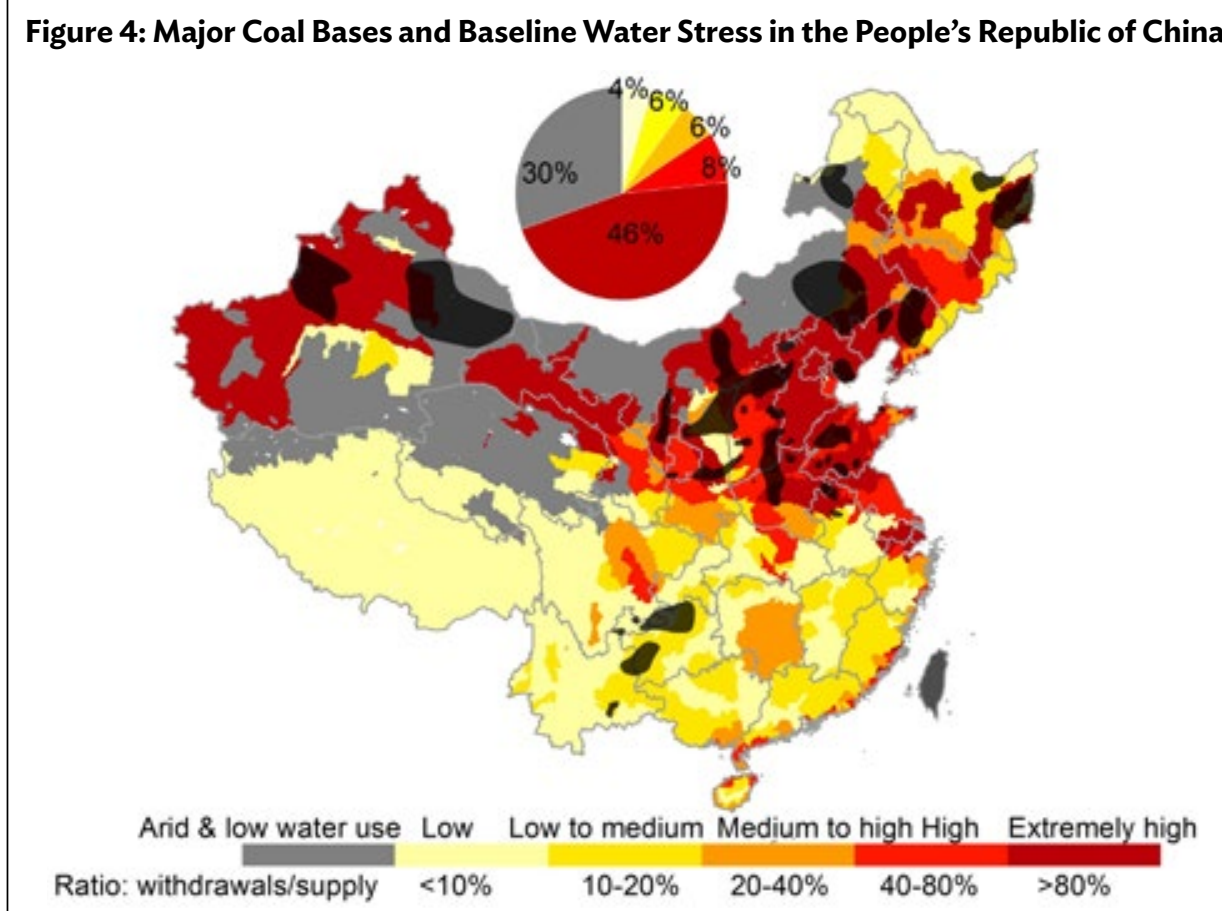

Sources: World Resources Institute’s Baseline Water Stress China; and Wang, et al., 2016. 


\section{Water Use in Coal Mining}

Water is used to extract and wash coal, and also to reduce dust and cool machinery (Figure 5). The main water-related concern is not the quantity of water used but the discharge of contaminated water, which could adversely affect natural bodies of water. Mine tailings could leach into groundwater, contaminants carried by runoff could taint surface water bodies, and polluted water could infiltrate into underground aquifers (Water in the West, 2013).

Water withdrawal in the PRC's coal mining sector ranges from $0.06 \mathrm{~m}^{3} /$ ton to $1.6 \mathrm{~m}^{3}$ / ton, depending on the extent of water recycling. The sector withdraws an average of $0.5 \mathrm{~m}^{3} /$ ton of groundwater, and up to $1.07 \mathrm{~m}^{3} /$ ton in Shanxi Province. Water withdrawn for coal mining totals about $2 \mathrm{bcm} /$ year $-3 \mathrm{bcm} /$ year ( $\mathrm{Li}$, et al., 2014). However, most of this water is returned to natural water bodies after treatment.

"Produced water" resulting from the dewatering of coal seams during the mining process is generally unsuitable for reuse (Box 2). If not properly treated before discharge, it can seriously pollute surface water and groundwater. The danger of contamination from untreated coal mining produced water is a bigger concern than the actual quantity of water used for coal mining.

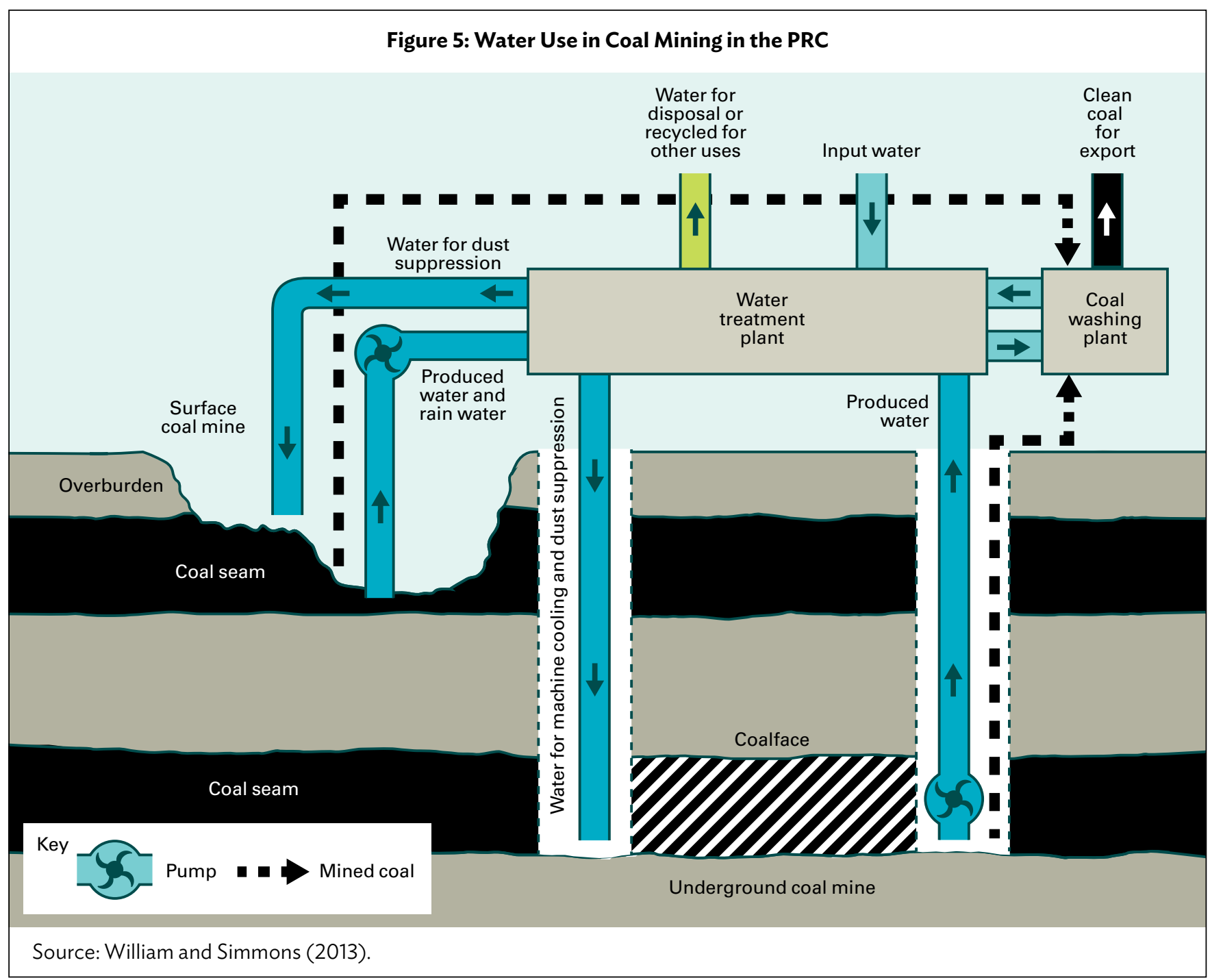




\section{Box 2: Classification of Produced Water in Coal Mining}

The "produced water" from coal mining can be classified into five categories according to water quality, as follows:

Clean mine water. This is uncontaminated groundwater meeting drinking water standards and sometimes containing beneficial trace elements. It can be turned into mineral water.

Mine water with suspended solids. This nontoxic water with salinity of less than $1,000 \mathrm{mg} / \mathrm{L}$ contains suspended solids and a small amount of metal ions, dissolved organic matter, and bacteria. It can achieve drinking water standards through flocculation, sedimentation, filtration, and disinfection.

Mine water with high salinity. This type of produced water, found mainly in mining areas in northern PRC, the western highlands, the North China Plain, and eastern coastal areas, contains sulfates, bicarbonates, chlorides, and calcium, potassium, sodium, and other salts, and has a total salinity level of 1,000-4,000 mg/L. It cannot be used without treatment. Mine water with high salinity can be treated by distillation, reverse osmosis, or electro dialysis desalination.

Acid mine water. This water results when a coal seam with high sulfur content is mined and the sulfide is converted into sulfuric acid through oxidation, making the water acidic. Coal and metal elements from surrounding rock can be easily dissolved in acidic water to produce highly saline hard water. If discharged untreated into the groundwater system, acid mine water will acidify the surface water, affecting aquatic life, as well as plants if used for irrigation. Acid mine water is often treated by chemical neutralization, through the addition of alkaline reagents, or filtration with limestone and dolomite.

Mine water with toxic pollutants. This water sometimes contains fluorine, radioactive and toxic trace elements and other hazardous elements, and oil. Fluorinated mine water is produced in mines located in areas with high fluorine content. Coal mine water in certain mines in northern PRC has a fluorine content of over $1 \mathrm{mg} / \mathrm{L}$.

$\mathrm{mg} / \mathrm{L}=$ milligram per liter PRC = People's Republic of China.

Source: E. Williams and J. Simmons (2013). www.bp.com.

To ensure the safety of mining operations and prevent flooding, produced water must be pumped out to ensure the safety of mining operation and prevent flooding. On average, $1.88 \mathrm{~m}^{3}$ of water is drained for every ton of coal produced. In 2010, about $6 \mathrm{bcm}$ of produced water from coal mining was drained. Produced water varies in amount and quality according to regional factors like local climate, groundwater conditions, coal production span, and mining method used. For instance, coal mines in southeast PRC drain up to $80 \mathrm{~m}^{3}$ of produced water for every ton of coal produced. In Shanxi Province in northern PRC, on the other hand, the amount of water drained is only about $0.24 \mathrm{~m}^{3}$ per ton of coal. 
Produced water from coal mining contains suspended coal particles and this has become a significant source of pollution. It must be treated before discharge. Historically, wastewater from coal mining, including produced water, was gathered behind tailings dams and then simply allowed to evaporate. This practice could impact natural water bodies due to leaking of mine tailings consisting of excavated material and runoff of contaminated water.

Recycling produced water could help reduce or even put an end to water withdrawal from external sources for mining operations. Facing a serious geographic mismatch between coal reserves and water resources-(i.e., over $70 \%$ of 96 key coal mining areas are in water-stress areas, and in $40 \%$ of these areas the water shortage is severe - the government has made water recycling mandatory for coal mining. In $2010,3.6 \mathrm{bcm}$ of produced water from coal mining, or about $60 \%$ of the produced water from coal mining, was treated and reused.

\section{Water Use in Coal Washing}

After extraction, coal must be processed further to remove the sulfur-bearing minerals and rocks that were mined along with it. This process of beneficiation or coal washing, during which the coal is fed into a cyclone with an aqueous suspension of magnetite (a naturally occurring magnet), reduces the transport cost of coal, increases its calorific value, and lowers the amount of ash it contains, especially its sulfur content. Some coal preparation technologies that do not use an excessive amount of water are suitable for water-stressed regions with a cold climate, such as northern PRC. But there are health and safety concerns: dry coal cleaning presents a higher risk of fire and explosion.

About $56 \%$ of the coal produced in the PRC goes through beneficiation, and over $94 \%$ of coal beneficiation is using the wet process. From 2005 to 2010 , the number of coal washing plants increased by $80 \%$, to 1,800 facilities, with a total washing capacity of 1.75 billion tons per year. On average, the water withdrawal for coal washing is 2.5 $\mathrm{m}^{3} /$ ton and water consumption is $0.2 \mathrm{~m}^{3} /$ ton. Water withdrawal for coal washing is about $5 \mathrm{bcm}$ and water consumption is about $0.4 \mathrm{bcm}$. About $85 \%$ of the water used for coal washing (about $4.25 \mathrm{bcm}$ ) can be recycled.

The wastewater from coal washing is highly polluted, and must be treated before discharge into natural water bodies. It is usually channeled into tailings ponds, where solids are allowed to settle and the water is recycled, evaporated, or treated further before discharge. The wastewater from coal washing and produced water from coal mining add up to about $4.5 \mathrm{bcm}$ that needs to be treated.

Although coal washing has many benefits, water scarcity is an important barrier to its increased application. On the other hand, coal washing plants, despite being equipped with wastewater treatment facilities, have not been fully effective in preventing the discharge of polluted wastewater into surface water, especially rivers.

\section{Water Use in Coal Gasification and Coal Liquefaction}

The possibility of using coal to replace petroleum use in transportation is highly attractive to the PRC with its abundant supply of coal and its limited reserves of oil and conventional natural gas. Coal gasification and coal liquefaction are believed to be cleaner ways of using coal in urban areas. However, water availability could constrain the adoption of these technologies in the PRC, given their large water requirement. 
Coal liquefaction needs significant amounts of water for three major processes:

(i) cooling gasifiers and reactors to maintain the desired temperature in the associated cooling towers, just like thermoelectric power plants; (ii) extracting hydrogen from water, to be used in converting coal into liquid hydrocarbons; and

(iii) handling solids (e.g., quenching ash, pelletizing sulfur, and treating sludge and gasifier ash) and controlling dust. Among these processes, hydrogen production and solid handling offer less scope for reducing water consumption, but air cooling and hybrid cooling can still reduce the water requirement by a significant amount compared with wet cooling (i.e., air cooling, by a factor of 4.1, and hybrid cooling, by a factor of 1.7).

The first commercial coal liquefaction plant using direct coal-to-liquid (DCTL) technology was commissioned by the Shenhua Group in Ordos, IMAR in 2008. Most CTL projects in the PRC apply indirect coal-to-liquid (ICTL) technology. The government has approved 11 major CTL projects with a total capacity of 21.22 million tons per year. These projects, except for the Shenhua Plant in Ordos, apply ICTL technology. Nine of the 11 CTL plants, with a total capacity of 14.22 million tons (67\% of the total approved capacity), are in IMAR, Ningxia, Shanxi, Shaanxi, and XUAR provinces, which are all under severe water stress. Water consumption per ton of liquid fuel product differs between the DCTL and ICTL technologies. The ICTL approach consumes more water than the $6 \mathrm{~m}^{3}-8 \mathrm{~m}^{3}$ that DCTL needs to produce a ton of liquid fuel.

\section{Water Use in the Production of Synthetic Natural Gas from Coal}

Coal can be converted into synthetic natural gas (SNG) through gasification and methanation. Coal-to-gas technologies are still in the development stage in the PRC. The first coal-to-gas pilot project, Datang Power's Keqi Project in IMAR, with a capacity of 4 billion $\mathrm{m}^{3}$ per year, was commissioned in December 2013. The total annual capacity of coal-to-gas plants could reach 15 billion-18 billion $\mathrm{m}^{3}$ by 2015 according to the 12th Five-Year-Plan of Natural Gas Development (National Development and Reform Commission [NDRC], 2012), and 200 billion $\mathrm{m}^{3}$ by 2030. The PRC government has approved SNG projects with a total capacity of $67 \mathrm{bcm}$ as of 2013 and further 54 projects with capacity $164 \mathrm{bcm}$ are at planning stage (Li et al., 2014). Most of the projects are in water-stressed IMAR and XUAR (Cornot-Gandolphe, 2014).

However, converting coal to natural gas is an extremely water-intensive process, requiring 6-10 liters of freshwater for producing $1,000 \mathrm{~m}^{3}$ of natural gas. To support the target of 200 billion $\mathrm{m}^{3}$ SNG production in 2030 , about $1.2 \mathrm{bcm}-2.0 \mathrm{bcm}$ of water will be consumed per year. The SNG plants now being constructed or planned are in arid and semiarid regions, such as IMAR and XUAR, and will consume about $0.5 \mathrm{bcm}-0.7 \mathrm{bcm}$ of freshwater per year. This amounts to, $20 \%$ of the region's total industrial water consumption. The plants would, therefore, significantly worsen water stress in areas already experiencing chronic water shortages (Wen et al., 2013).

Besides their high demand for water, coal-to-gas projects also produce highly polluted wastewater, with chemical oxygen demand (COD) of over 10,000 milligrams per liter $(\mathrm{mg} / \mathrm{L})$ and ammonia nitrogen $(\mathrm{NH} 3-\mathrm{N})$ of over $5,000 \mathrm{mg} / \mathrm{L}$. About $0.5 \mathrm{~m}^{3}$ $1.2 \mathrm{~m}^{3}$ of wastewater is produced per ton of coal gasified. It is also estimated that $0.5 \mathrm{bcm}-1 \mathrm{bcm}$ of wastewater will be produced from coal gasification by 2030 , if the PRC achieves the targeted capacity of 200 billion $\mathrm{m}^{3}$ of SNG production. 


\section{Recent Trends in Water Use in the Coal Sector}

The PRC must contend with overcapacity in the coal value chain. The overcapacity is present in coal mining and processing, coal power generation, and the coal chemical industry. The problem is symptomatic of the heavy dependence on coal for the growing energy demand. (L. Pan et al., 2011). The PRC also depends heavily on coal as the main feedstock for the production of a variety of chemicals and industrial products. The recent economic downturn has caused a decline in the demand for coal-based industrial products and significantly reduced growth in overall energy consumption and demand for coal-based electricity and heating. The increased output of renewable energy and efforts by the government to control the air pollution attributable to coal-based power generation and heat production may have contributed to this decline in demand.

As a result, the government has announced plans to decommission coal mining capacity of 60 million tons and to impose a moratorium on approvals of new coal mines in 2016-2018 (National Energy Administration, 2016). The approval and environmental monitoring requirements for coal mining and coal washing must be rigorously enforced to ensure that mining operations do not adversely affect water resources. Strict controls should be placed on water withdrawal, and water recycling should be maximized. Produced water from coal mining and oil and gas production should be recycled to the greatest possible extent to minimize freshwater withdrawal and to reduce the potential for contaminating natural water bodies. Local environmental protection agencies and other regulatory agencies must strictly monitor how produced water from mining operations is stored, recycled, and treated before being released back into natural water bodies.

The PRC has recently launched an ambitious program to expand the SNG production and coal chemical industries. There is valid economic justification for promoting the SNG industry for energy security and air pollution control, but it needs to be balanced against the high water intensity of these industrial processes. Moreover, SNG production increases GHG emissions. The policy of encouraging the coal chemical industry, therefore, needs urgent review in the context of the industry's contribution to increasing water stress and to $\mathrm{GHG}$ emissions. 


\section{Water Use in the Oil and Gas Sector}

Although the PRC is a net importer of oil, it is the world's fourth largest oil producer, accounting for $5 \%$ of global crude oil production. ${ }^{6}$ Total crude oil production in the PRC increased from 163 million tons in 2000 to 211 million tons in 2014 (National Bureau of Statistics, 2014), for an average annual growth rate of $2 \%$. Given the PRC's limited oil reserves, its conventional oil production is unlikely to increase significantly in the future. The major crude oil-producing provinces are Heilongjiang, Shaanxi, Shandong, Tianjin, and XUAR. All of these provinces are under high to extremely high water stress.

\section{Water Use in Crude Oil Production}

Conventional oil drilling requires water for preparing the drilling fluid, cleaning and cooling the drill bit, and maintaining oil well pressure. If the pressure in the oil well is insufficient, more water is pumped to increase the pressure (Water in the West, 2013).

The water used for preparing the drilling fluid and pressurizing the oil well is entirely consumed, as it cannot be reused. A considerable amount of water is required for the effective operation of a conventional oil field, but there is generally little need for freshwater. As an oil field matures, a variety of enhanced oil recovery techniques are used to extend its economic life. These techniques involve injecting water combined with chemical additives, hydrocarbon gas, or carbon dioxide into the reservoir. The injected water may be seawater, recycled produced water from oil drilling, municipal wastewater, or brackish water (William and Simmons, 2013, www.bp.com).

The fluids coming out of the production well contain considerable amounts of water (produced water). Generally, the ratio of water to oil tends to increase as the oil field matures. Most of the produced water is separated from the oil in a separator at the wellhead. The produced water contains soluble mineral salts from the reservoir, chemicals used in oil field operation, and very fine rock particles, as well as dissolved hydrocarbons. The volume of produced water could be as high as three times the volume of the oil produced. Although produced water and used drilling fluids can be reused to pressurize the oil wells, these substances are highly polluted and contain harmful chemicals, and must be treated properly before being discharged into natural water bodies. Alternatively, the produced water can be evaporated or injected into disposal wells, while ensuring that local aquifers are not contaminated (William and Simmons, 2013, www.bp.com). 
If most of the produced water were reused, the net water consumption would be equal to the volume of oil produced, as the same volume of water as the oil produced would have to be pumped back into the oil well to maintain pressure. But as the produced water is not fully reused, producing 1 barrel of oil consumes roughly 1.5 barrels of water. Therefore, about $0.2 \mathrm{bcm}-0.3 \mathrm{bcm}$ of water is consumed in oil production in the PRC (Figure 6) (William and Simmons, 2013, www.bp.com).

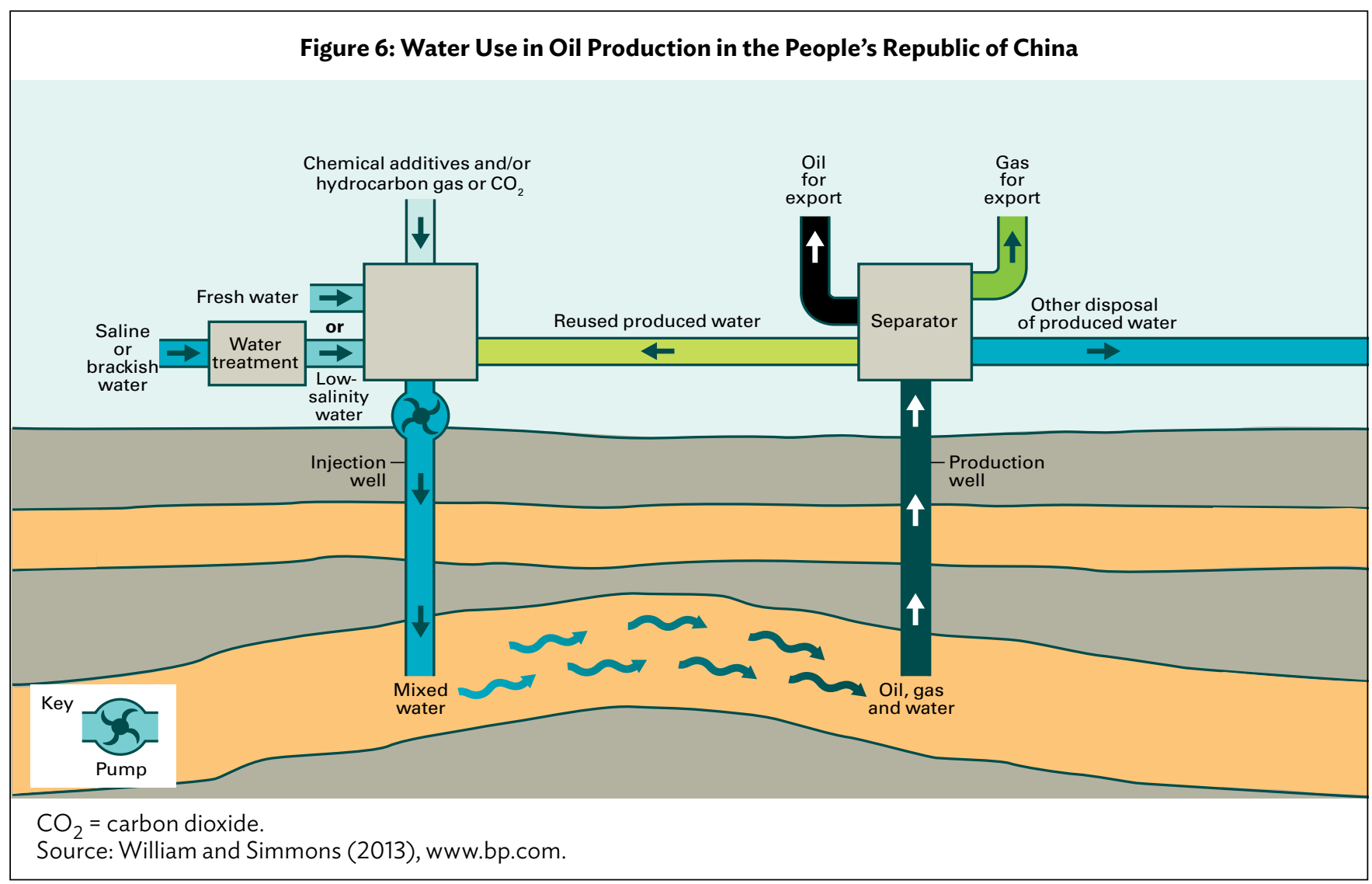

\section{Water Use in Oil Refineries}

The production capacity and output of petroleum refineries in the PRC exceed the country's crude oil production. The refineries have therefore become increasingly dependent on imported crude oil. In 2000-2014, refinery output increased from 204 million tons to 502 million tons, whereas crude oil output increased from 163 million tons to 211 million tons. ${ }^{7}$ The refineries are in coastal provinces like Guangdong, Jiangsu, Liaoning, Shandong, Shanghai, and Zhejiang, as well as inland provinces producing crude oil, such as Shaanxi (Meyers, 2012).

Water consumed in oil refineries serves as coolant for chemical processes, as feedstock for the production of steam for various chemical processes, and also as a source of hydrogen. Cooling water does not have to be of high quality, but hardness and salinity may have to be controlled to avoid scaling. Seawater and brackish water can be used for cooling after salinity is reduced to some extent. The quality required for process water, including water used to generate process steam, varies depending on where in the refining process the water is required. Demineralized water is used in cracking and other chemical processes, while recycled water can be used to remove salts from crude oil (Figure 7) (William and Simmons, 2013, www.bp.com). 


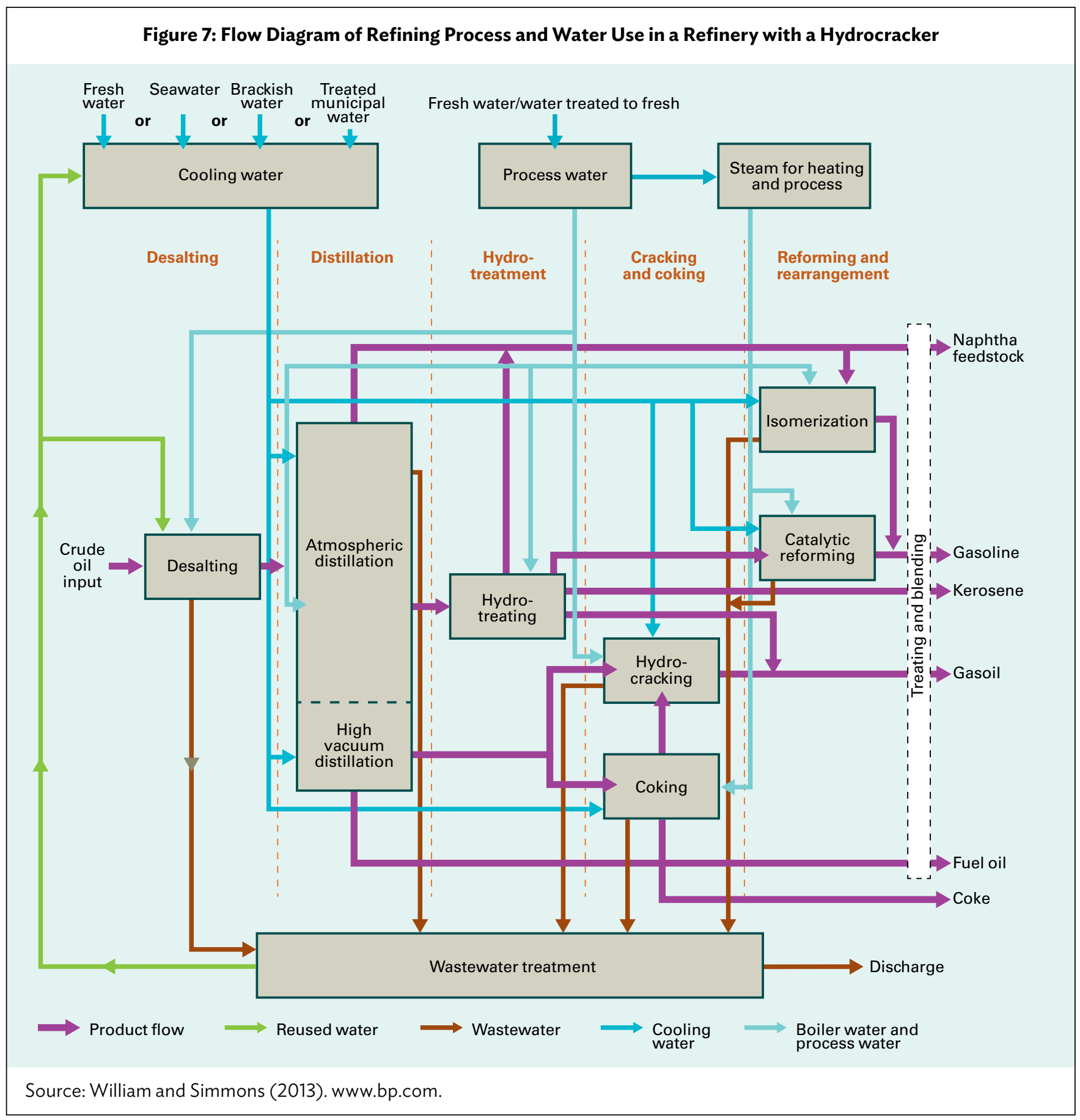

Refinery design and upgrades include the choice of cooling systems, water sources, and extent of water recycling and reuse. If cooling water is not recycled, water withdrawals average $11 \mathrm{~m}^{3}$, and water consumption $0.5 \mathrm{~m}^{3}$, per ton of output (E. Williams and J. Simmons, 2013, www.bp.com). Most refineries in the PRC use closed-loop (wet tower) cooling or saltwater cooling, and freshwater withdrawal intensity is much smaller than these figures. There are many opportunities to improve the efficiency of water use in refineries, and increase water recycling and use of lower-quality water for most requirements. Adopting these measures can reduce freshwater and potable water use by as much as $45 \%-90 \%$ in a typical refinery. 
The disposal of process and cooling water, contaminated with organic compounds, sulfur, and heavy metals, is a major concern. Water and steam used for cooling and heating do not come into contact with the oil. But water and steam used in chemical processes are likely to be contaminated with pollutants, and must be treated before they are released into surface water bodies. Water used to desalt oil contains dissolved chlorides and dissolved hydrocarbons, while process water used in the cracking process may contain sulfur compounds and phenols (Water in the West, 2013).

\section{Water Use in Conventional Natural Gas Production and Processing}

The consumption of natural gas, considered a clean and low-carbon fuel compared with coal, is rapidly increasing in the PRC. The government has recently taken steps to replace coal with natural gas in urban areas with heavy air pollution, importing piped gas and LNG to supplement the country's limited conventional gas reserves. Banking on the PRC's substantial reserves of unconventional gas (mainly shale gas reserves, believed to be the world's largest, and coal-bed methane), the government has also set ambitious targets and is starting to exploit these resources ( $\mathrm{H}$. Guo, Y. Wang, and Z. Wang, 2016).

The PRC produced 128 billion $\mathrm{m}^{3}$ of conventional natural gas in 2014. Conventional natural gas requires relatively modest amounts of water for preparing the drilling fluids, and little or no water for processing. About $0.256 \mathrm{bcm}$ of water is consumed during conventional natural gas drilling, at current production levels (Water in the West, 2013).

Natural gas processing usually result in produced water due to the separation of water vapor mixed with the gas. The produced water containing aromatic hydrocarbons is discharged into underground injection wells or reused in natural gas processing. Natural gas processing involves the separation of water and heavier hydrocarbons in gravity separators and dehydrators.

Water is required to cool the separation towers and other machinery, such as compressors, and to generate the process steam needed for amine scrubbing to remove carbon dioxide and hydrogen sulfide from the gas streams. Even low-quality water can be used for cooling, but water for producing steam must have low salinity. (E. Williams and J. Simmons, 2013, www.bp.com)

In addition to domestically produced natural gas, the PRC also imports significant quantities of $L N G$. Water is required for regasification of $L N G$ to vaporize the $L N G$ in a heat exchanger by transferring thermal energy from water to LNG. As most of the LNG terminals are coastal installations, seawater is usually used for this purpose.

\section{Prospects for Shale Gas Exploration in the PRC and Implications for Water}

The PRC has abundant shale gas resources, mainly in arid and water-stressed regions such as XUAR and the highly water competitive region in Sichuan Province. In 2012, the Ministry of Land Resources estimated the PRC's continental available shale gas resources at 134.4 trillion $\mathrm{m}^{3}$, of which 25 trillion $\mathrm{m}^{3}$ are exploitable (China Energy Net, 2014). By 2013, the Ministry of Land Resources had awarded two shale gas exploration concessions to state-owned petroleum companies. Shale gas output amounted to 25 million $\mathrm{m}^{3}$ in 2012 and to 1.3 billion $\mathrm{m}^{3}$ in 2014 (China Energy Net).

Shale gas exploration in the PRC has taken place mostly in the Sichuan Basin and in the Tarim Basin in XUAR . During the 12th Five-Year Plan period (2011-2015), 19 shale gas explorations were carried out in Anhui, Chongqing, Guizhou, Henan, Hubei, 
Hunan, Jiangsu, Jiangxi, Liaoning, Shaanxi, Sichuan, XUAR, and Yunnan. The PRC's first large-scale shale gas field, Sinopec's Fuling Field, began commercial operations in 2014 , and is expected to reach a production capacity of 10 billion $\mathrm{m}^{3}$ by 2017.8

Shale gas extraction requires horizontal drilling and hydraulic fracturing, which uses significant amounts of water. In hydraulic fracturing, fluid consisting of water and sand with chemical additives is pumped at high pressure into shale formations to crack the rock and release the trapped gas. After fracturing, the water pressure is reduced to allow fracturing fluids to flow back to the wellhead, followed by shale gas. A significant portion of the water used in hydraulic fracturing is consumed in the process (Figure 8) (World Resource Institute, 2014).

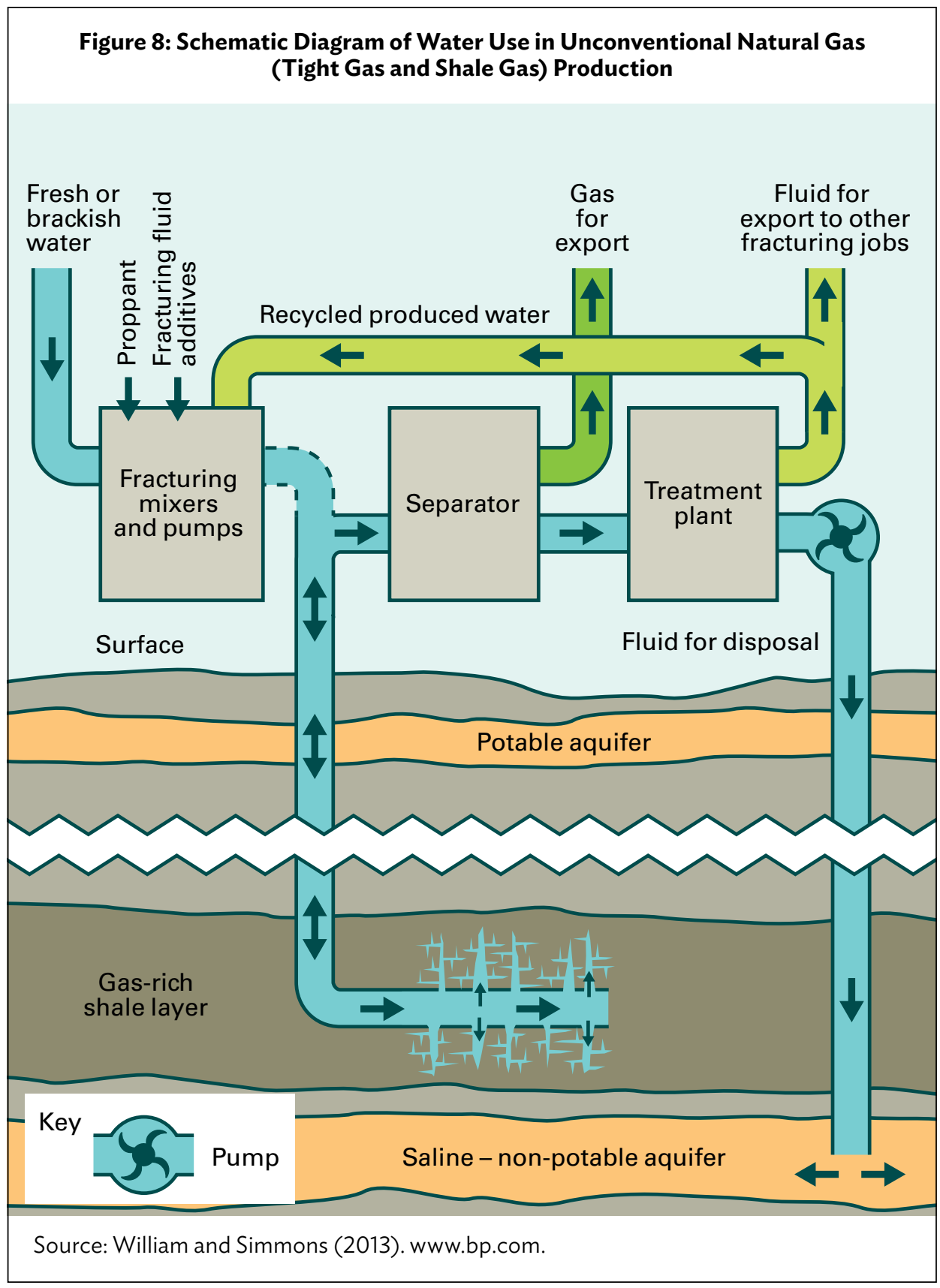

8 http://business.sohu.com/20140421/n398575009.shtml. 
Highly contaminated flow back water makes up about $10 \%-75 \%$ of the fracturing fluid originally injected. It contains the chemicals used for fracturing and must, therefore, be treated before being discharged into natural water bodies. It can also be recycled and reused for fracturing. If not managed properly, flow back water from hydraulic fracturing can significantly degrade surface water and groundwater resources. Ensuring that the fracturing fluid and the flow back water do not enter the groundwater aquifers is also critical. As the shale formations lie beneath the groundwater aquifers, the wellbores must be properly engineered to avoid any possibility of leakage (J.J. Anthony et al., 2016).

The reinjection of flow back water into deeper geologic formations and the evaporation of the wastewater and disposal of the residual sludge as solid waste are two options being considered for the disposal of the flow back water. However, the former option carries the risk of groundwater contamination and the latter, is energyintensive (World Resources Institute [WRI], 2014).

The amount of water required to complete a shale gas well varies from well to well and from basin to basin, making estimates of water demand for shale gas development uncertain. The water requirement varies, depending on the geology and the well characteristics. For example, the length of horizontal sections and the depth, porosity, and permeability of the shale base determine the water requirement. Instead of freshwater, brackish water and recycled water can be used for fracturing. The water intensity of shale gas production is about 10 times that of conventional gas production, according to data from the US (WRI, 2014).

The government is preparing the master plan for shale gas development to confirm the volume of the country's recoverable shale gas resources. Although shale gas exploration in the PRC has made some progress in the Sichuan Basin, large-scale shale production has yet to be realized. Preliminary estimates indicate that the PRC would be able to produce 60 billion-100 billion $\mathrm{m}^{3}$ of shale gas by 2020 and 150 billion- 180 billion $\mathrm{m}^{3}$ by 2030 , compared with its conventional gas output of 106 billion $\mathrm{m}^{3}$ in 2013. Water resources of about 0.04 bcm by 2020 and $0.08 \mathrm{~m}^{3}$ by 2030 are likely to be required for this.

About $40 \%$ of the PRC's shale resources are in areas of high to extremely high baseline water stress and in arid locations (Figure 9). The Sichuan shale basin is in a region of high water stress due to high water demand in relation to the available supply. Shale gas development is likely to exacerbate this situation. The Tarim Basin in XUAR is subject to extremely high baseline water stress in arid conditions, including extremely high groundwater stress and seasonal variability (WRI, 2014).

\section{Ensuring Sustainable Water Use in the Oil and Gas Sector in the PRC}

Fossil fuel production contributes to about $1.5 \%$ of annual freshwater withdrawals in the PRC. But the fossil fuel sector can be a major source of contamination of groundwater and surface water resources. Locating major coal mining bases and potential shale gas exploration zones in the water-stressed north and northwest region of the country makes the situation even more serious.

While the conventional oil and gas sector in the PRC is not a major water user and does not significantly contribute to water pollution at present, shale gas exploration is likely to become a significant water user in water-stressed regions and a potential source of groundwater contamination. Strict measures must, therefore, be adopted from the outset to minimize water use in shale gas exploration by promoting the reuse of fracking fluids and by preventing possible leaks of fracking fluid into groundwater aquifers. 


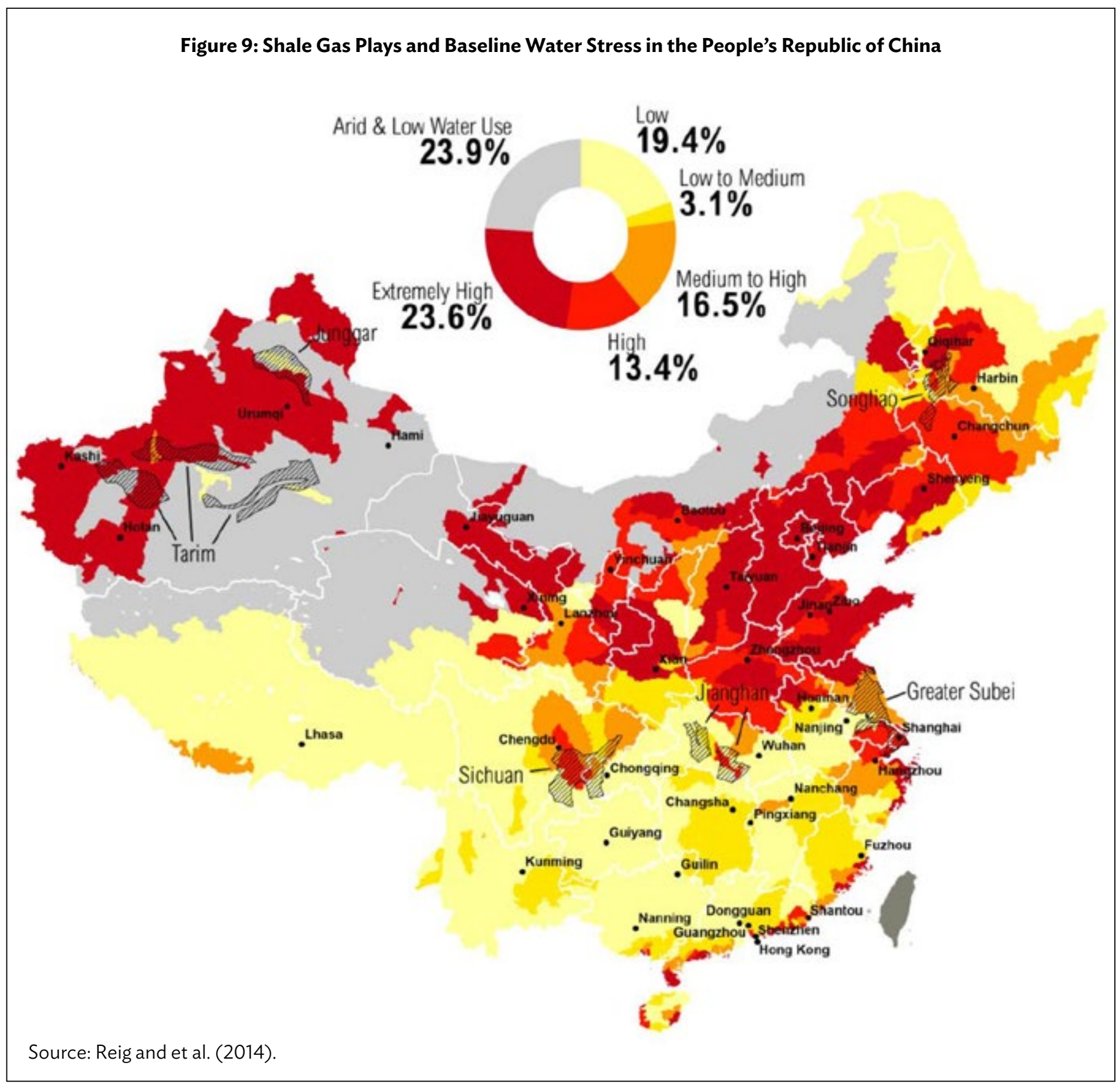




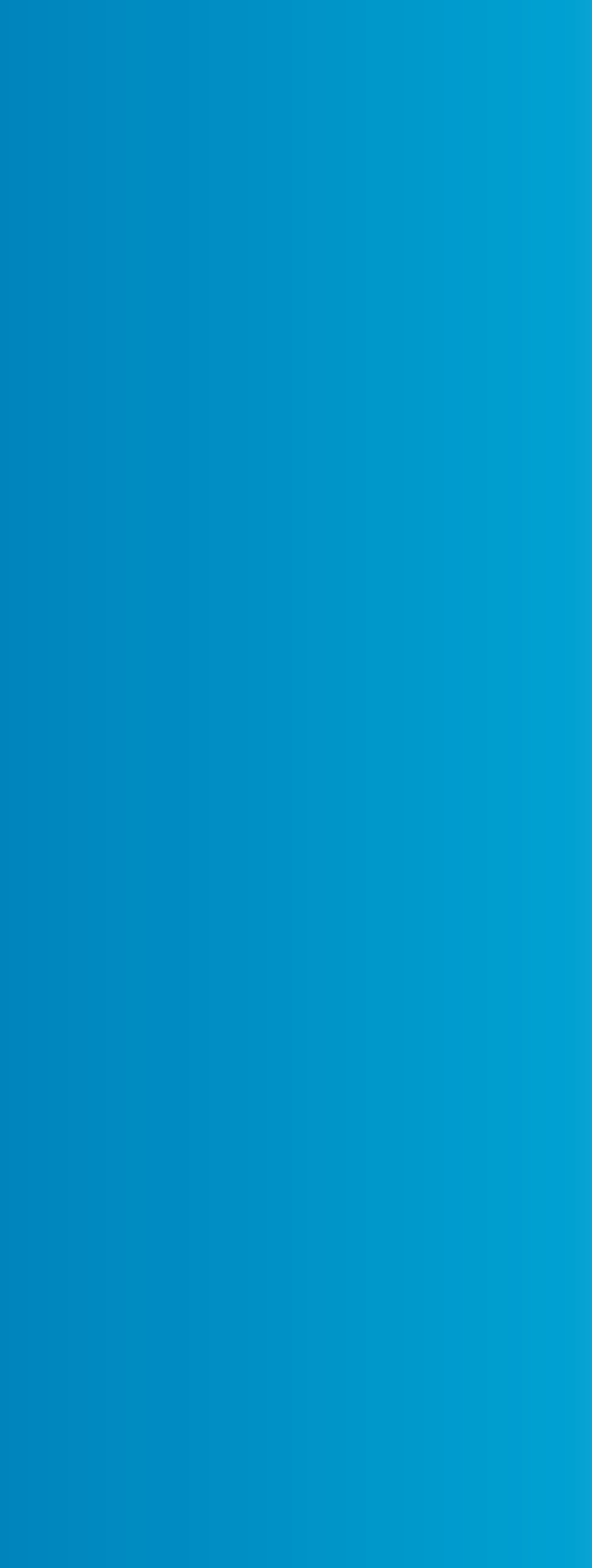




\section{CHAPTER 4}

\section{Water Use in Electricity Generation}

As a rapidly developing country, the $\mathrm{PRC}$ is still in the process of building up its power generation infrastructure. The PRC increased its generation capacity from $962 \mathrm{GW}$ in 2010 (China Electricity Council [CEC], 2011) to 1,360 GW by 2014 (CEC, 2015a). Projected installed capacity ranges from $1,700 \mathrm{GW}$ to $1,850 \mathrm{GW}$ by 2020 , and from $2,100 \mathrm{GW}$ to $2,350 \mathrm{GW}$ by 2030 . The recent economic slowdown and industrial transformation could affect the demand for new generation capacity. Although the share of nonwater-consuming technologies, such as wind and solar, are expected to increase, growing power generation capacity will further expand water withdrawal and consumption for power generation.

The share of thermal power in installed capacity decreased from $73.4 \%$ in 2010 to $67.3 \%$ in 2014 , and that of coal power from $67.3 \%$ to $60.4 \%$. The share of coal-based power is expected to drop to $59 \%$ by 2020 and to $51 \%$ by 2030 as the PRC strives to fulfill its commitment to expand the contribution of nonfossil fuel energy. In 2014, the electricity output of coal-fired power plants experienced negative growth for the first time in 40 years (CEC, 2015b). However, the rate of increase in freshwater withdrawal and water consumption for power generation continues to be determined by the cooling technologies adopted by coal-fired power plants.

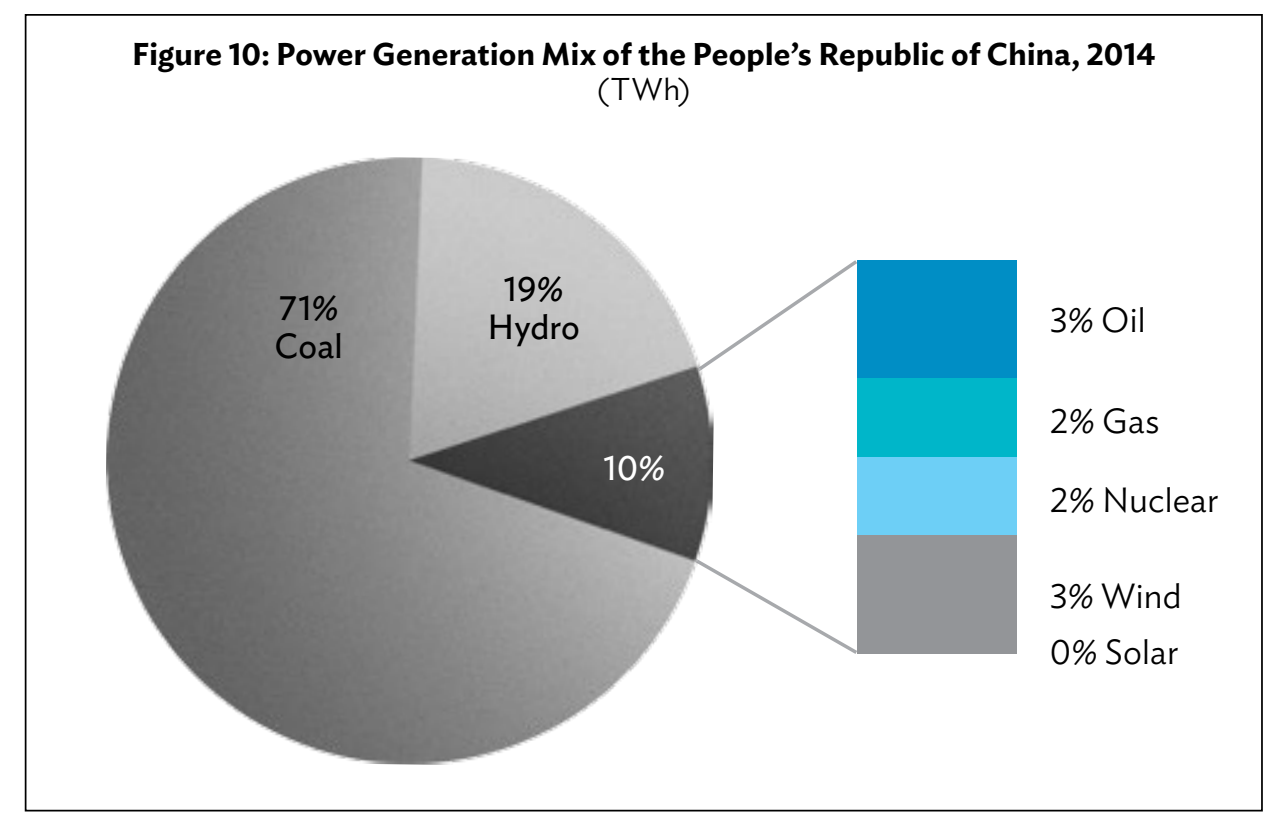


About $82 \%$ of electricity generation capacity in the PRC requires water for cooling or, as in the case of hydropower, for electricity generation. All thermal power plants, including nuclear power plants that use steam turbines to generate electricity, need cooling, mostly with water. However, nuclear power plants now in operation or to be commissioned by 2030 are in the coastal areas and depend on seawater for cooling.

Although hydropower is also a major water user, most of the water withdrawn is returned to the same river basin, or to a different river basin in the case of transbasin hydropower plants, with little impact on water quality. (J. Melilo, T. Richmond, and G. Yohe, 2014). Renewable energy-based electricity-generation technologies, such as wind power and solar photovoltaic generation, have minimal water requirements. On the other hand, the cooling requirement of concentrated solar photovoltaic and biomass-based electricity generation is comparable with that of other thermal power plants.

The installed capacity of coal-fired power plants increased from $660 \mathrm{GW}$ in 2010 to 825 GW in 2014. Given the government's commitment to reduce coal consumption, the installed capacity of coal power plants is expected to peak at around $960 \mathrm{GW}$ by 2020, and then continuously decrease to $920 \mathrm{GW}$ by 2030 (Cornot-Gandolphe, 2014).

Most coal-fired power plants, installed in the last 10 years, deploy the latest technologies, such as ultra-supercritical and supercritical steam technologies, and have a unit size of more than 600 megawatts (MW), especially among the recently installed plants (B. Ali and A. Kumar, 2015). The government is also encouraging the decommissioning of smaller (less than $100 \mathrm{MW}$ ) coal-fired plants. Over $95 \mathrm{GW}$ of small plants have already been decommissioned since 2006, and most coal-fired power plants with a capacity of less than $200 \mathrm{MW}$ are likely to be decommissioned by 2020 or converted into CHP plants.

To meet the growing demand for electricity for economic development, the PRC is promoting the new energy strategy of moving coal-based electricity generation to sparsely populated western provinces that are rich in coal resources. The new coal power plants will be closer to the large-scale coal mining bases, and long-distance ultra-high-voltage electricity transmission links are being built to link these power plants to the load centers in the coastal provinces (C. Zhang et al., 2016). This policy is driven by the need to control air pollution in densely populated coastal provinces in eastern PRC. But the northwest region of the PRC, where most coal reserves are found, is under high or extremely high water stress (Cornot-Gandolphe, 2014).

\section{Cooling Technologies Used in Thermal Power Plants in the PRC}

In thermal power plants using steam turbines (coal-fired power plants, combinedcycle gas turbines with a steam cycle, nuclear power plants, and concentrated solar power plants), the steam from the turbine must be cooled further to achieve maximum thermal efficiency. The choice of cooling systems has the greatest impact on the water requirements of a thermal power plant. With a heat transfer capacity four times that of air, water is a much more effective coolant when it is available in sufficient quantities. Water (wet) cooling systems can be configured as once-through (open-loop) or closed-loop cooling systems. In water-scarce locations, dry (air) cooling and hybrid cooling systems that use a combination of wet and dry cooling are adopted (Box 3) (G.Thopi and A. Pouris, 2016.). 


\section{Box 3: Cooling Technologies Used in Thermal Power Plants in the People's Republic of China}

Once-through (open-loop) cooling systems use an ample supply of water from natural water bodies, such as seas, rivers, lakes, or cooling ponds, to pass through the steam condenser (heat exchanger) of the power plant. Water is returned to the water body $10^{\circ} \mathrm{C}-20^{\circ} \mathrm{C}$ warmer than when it was extracted. Most of the water withdrawn is returned (about $99 \%$ of the water is returned; the rest is lost to evaporation), without significant impact on water quality except for an increase in water temperature. Open-loop systems require significant amounts of water withdrawal and are, therefore, vulnerable to droughts, and compete for water with other users. In addition, the discharge of high-temperature water into natural water bodies may affect aquatic ecosystems. In spite of its low cost and low water consumption, open-loop cooling using freshwater is not widespread in the PRC because of a lack of suitable surface water bodies in close proximity to coal-fired power plants. However, in coastal areas, the use of seawater in open-loop cooling systems is common among coal-fired power plants and nuclear power plants. A typical $500 \mathrm{MW}$ coal power plant using open-loop cooling withdraws $0.5 \mathrm{bcm}$ of water per year and consumes 0.0029 bcm per year (Meldrum et al., 2013).

Closed-loop (wet) cooling systems differ from open-loop systems in that the water used for cooling the steam turbine exhaust is recirculated after cooling instead of being discharged into natural water bodies. The heated water is cooled by being passed through a wet cooling tower, cooling pond, or surface water body (e.g., river) before it is recycled. Although water consumption due to evaporation is roughly 10 times higher than that for open-loop cooling systems, water withdrawal is about 100 times lower. In addition, the capital costs of closed systems are 40\%-50\% higher than the capital costs of open-loop systems. In the PRC, closedloop systems with cooling towers are preferred because of their lower water withdrawal requirement and environmental impact compared with open-loop systems. A typical $500 \mathrm{MW}$ coal power plant using closed loop wet cooling systems withdraws $0.01 \mathrm{bcm}$ of water and consumes $0.0084 \mathrm{bcm}$ of water per year.

Dry cooling systems are similar to closed-loop wet cooling systems, but use air instead of water to condense the steam. 
These systems require minimal amounts of water, and are appropriate for dry and arid regions in northern PRC. However, they affect power plant efficiency because of the lower cooling capability of air compared with that of water, and the electricity used to maintain the airflow. The efficiency loss is about $2 \%-7 \%$ but can be as high as $25 \%$ on hot summer days. Moreover, the capital cost of dry cooling systems is as high as three to four times that of closed-loop wet cooling systems and 10 times more than that of open-loop wet cooling systems. Power plants using dry cooling still require water for air pollutant scrubbing, steam cycle boiler makeup, and handling of coal ash, amounting to about $25 \%$ of water consumption in power plants using closed-loop cooling.

Hybrid cooling systems use a combination of wet and dry cooling systems, allowing the separate or simultaneous use of wet and dry cooling equipment, depending on the ambient temperature and water availability. These systems can reduce the efficiency loss resulting from dry cooling on hot summer days while reducing the water withdrawal and consumption associated with wet cooling. However, hybrid systems are more complex and expensive.

$\mathrm{bcm}=$ billion cubic meter, $\mathrm{m}^{3}$ = cubic meter, $\mathrm{MW}=$ megawatt .

Source: Water in the West. 2013.

The cooling water requirement of thermal power plants also depends on overall thermal efficiency (Figure 11). More efficient ultra-supercritical coal-fired power plants convert larger fractions of thermal energy to electricity and have a lower cooling requirement than low-efficiency subcritical coal-fired power plants. Similarly, operating coal-fired power plants as CHP plants by using the waste heat of the turbine exhaust steam in a heat exchanger to heat the return water from district heating supply systems can substantially reduce the cooling water requirement during the winter months. In the PRC, most new coal-fired power plants are ultra-supercritical plants and a significant number of coal-fired power plants in northern PRC operate as CHP plants. 


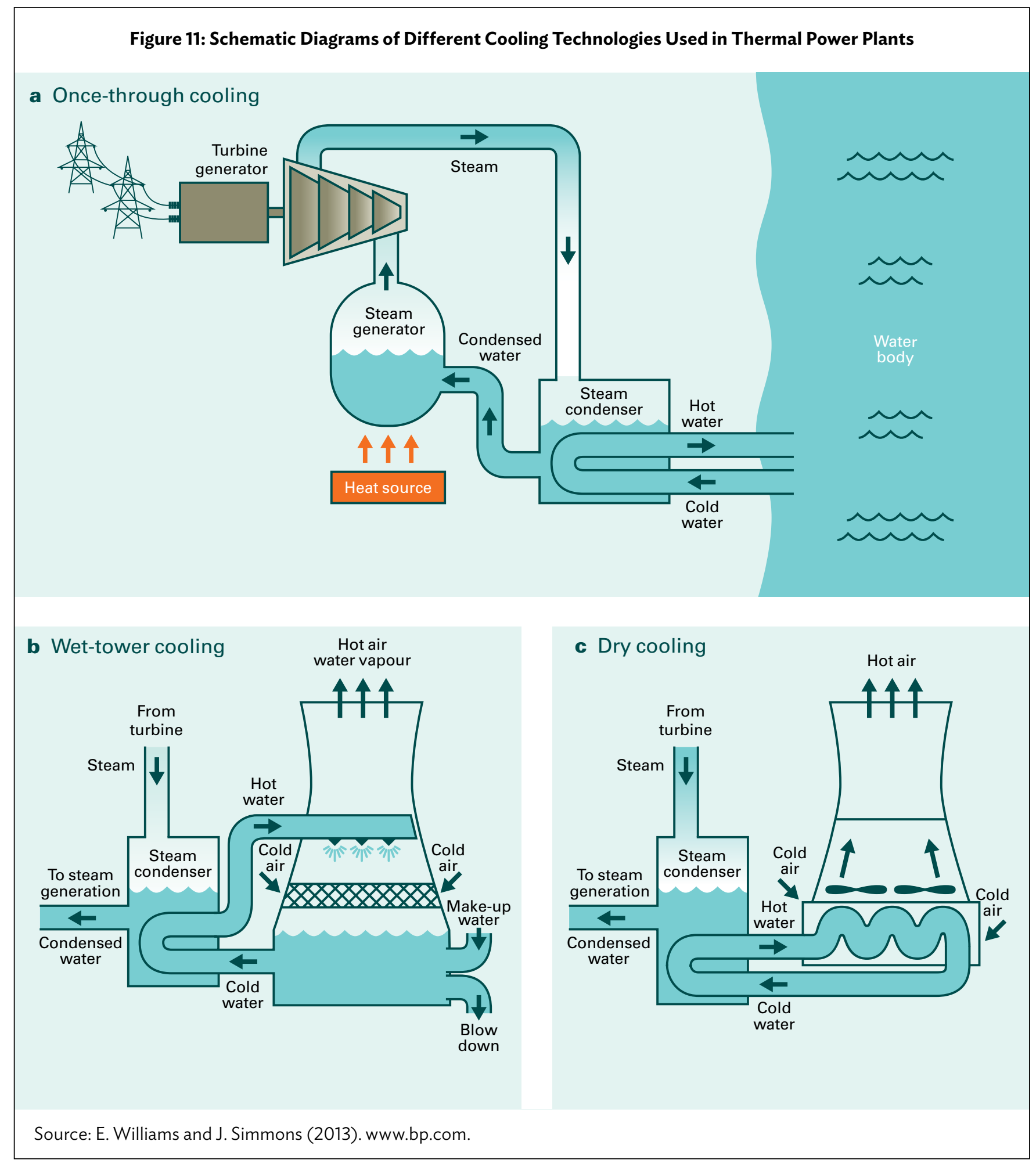




\section{Water Withdrawal and Consumption for Thermal Power Generation}

Since 2007, water withdrawal for the cooling of thermal power plants has grown more slowly than the overall growth rate of thermal power generation, and started to decline in 2013 as recently commissioned power plants increased their water efficiency and older and water-inefficient plants closed down (Figure 12).

Figure 12: Trends in Power Generation and Associated Water Withdrawal in the People's Republic of China, 2000-2014

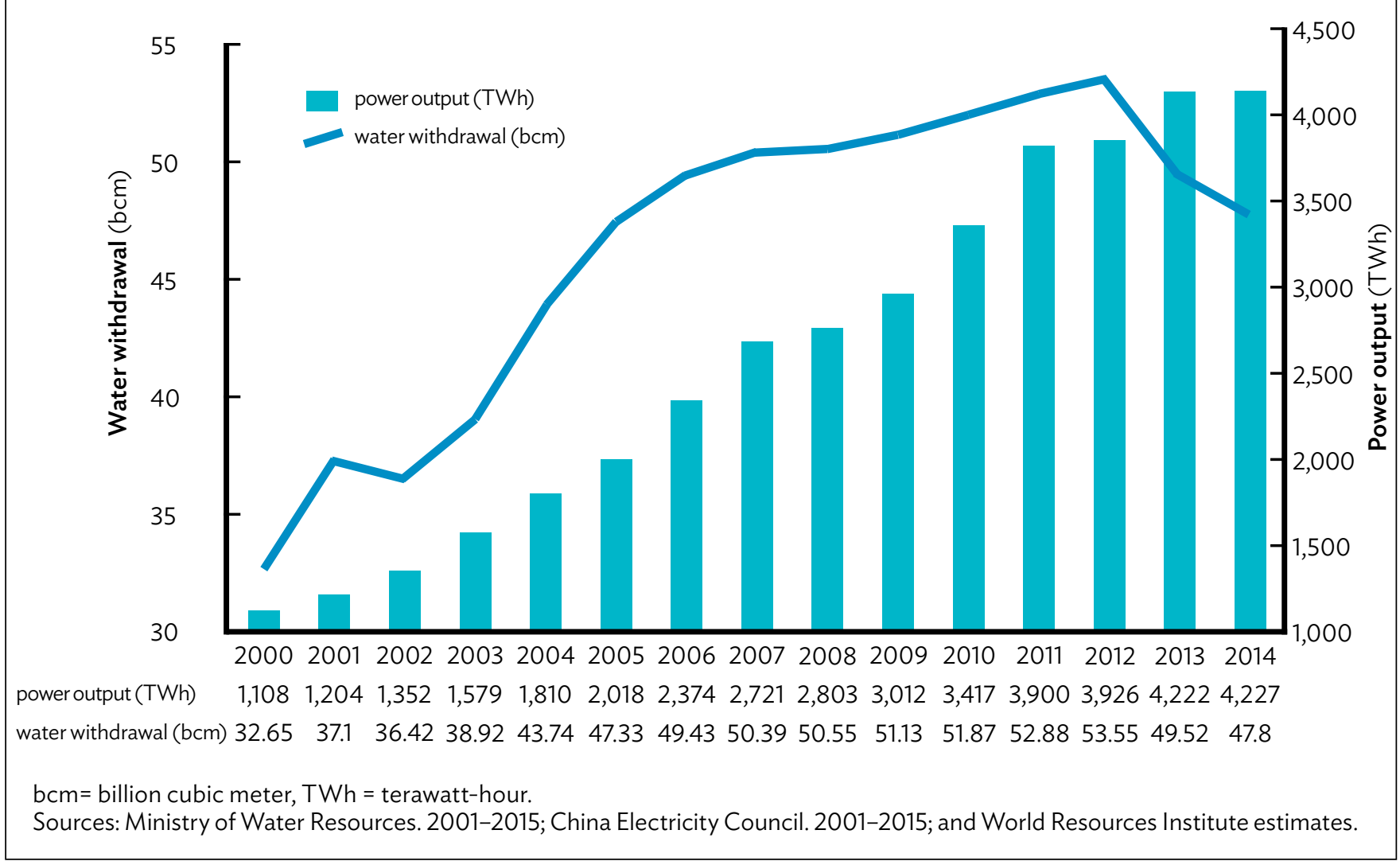

In 2014, freshwater withdrawals for thermal power generation in the PRC amounted to about $48 \mathrm{bcm}$, or roughly $8 \%$ of the country's total water withdrawals (MWR, 2015). The power sector is the largest industrial water user. Despite the increasing water efficiency of thermal power plants, the share of thermal power in overall industrial water withdrawals increased from $29 \%$ in 2000 to $39 \%$ in 2012, before decreasing to $35.2 \%$ by 2014. Of the total water withdrawn by the power sector, $85 \%$ is for open-loop cooling.

The water withdrawal factor, an indicator showing the amount of water withdrawn per megawatt-hour (MWh) of electricity produced, decreased from $29.5 \mathrm{~m}^{3} / \mathrm{MWh}$ in 2000 to $11.3 \mathrm{~m}^{3} / \mathrm{MWh}$ in 2014. In addition, the wastewater factor (the amount of wastewater discharged per MWh of electricity produced) improved more dramatically, plummeting from $1.38 \mathrm{~m}^{3} / \mathrm{MWh}$ in 2000 to $0.1 \mathrm{~m}^{3} / \mathrm{MWh}$ in 2012 (Figure 13). These developments highlight the gains in water efficiency and water recycling in coal-fired power plants in recent years.

Water use in thermal plants depends largely on the cooling technology used (Figure 14). Open-loop cooling systems require the withdrawal of large amounts of water but consume very little, while closed-loop systems have a low water withdrawal requirement but high water consumption because of evaporation (J. Melilo, T. Richmond, and G. Yohe, 2014). 
Figure 13: Water Withdawal and Wastewater Factors for Power Plants in the People's Republic of China, 2000-2012

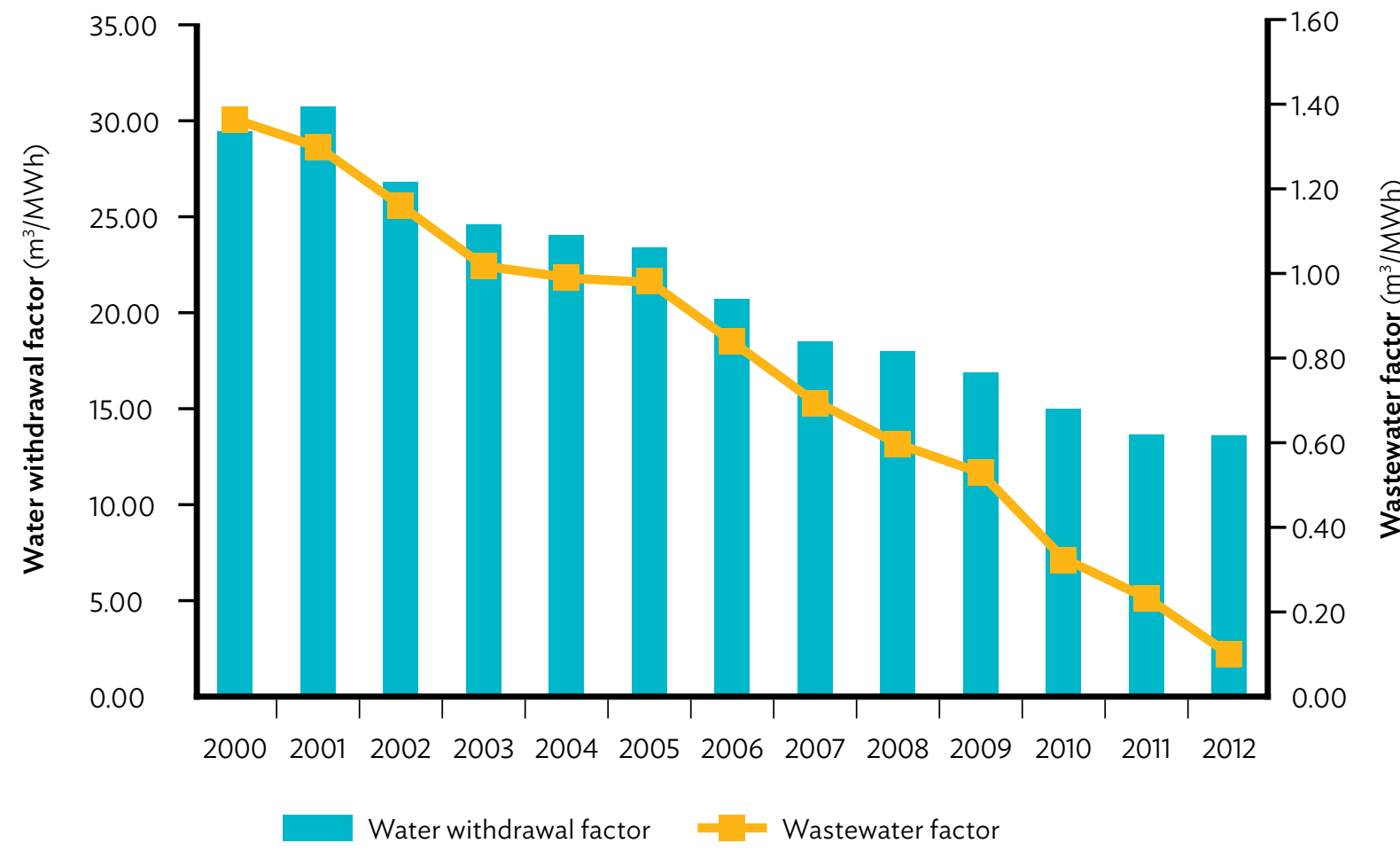

$\mathrm{m}^{3}=$ cubic meter, $M W h=$ megawatt-hour.

Sources: China Electricity Council. 2000-2012; and World Resources Institute analysis.

Figure 14: Cooling Technologies in the People's Republic of China Power Sector

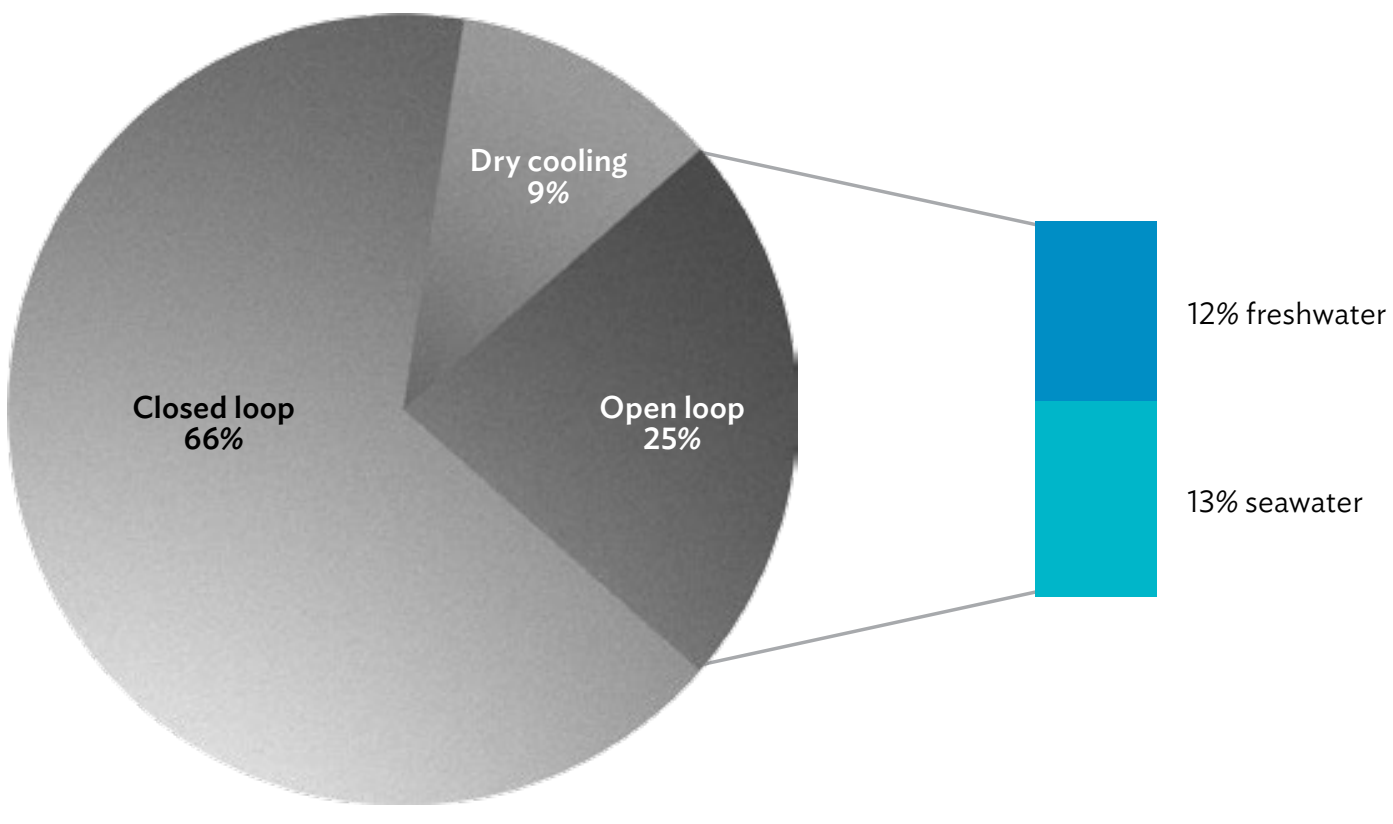

Source : World Resources Institute analysis. 
The cooling technologies used in the PRC's thermal power sector closely reflect water availability (Figure 15). Although closed-loop cooling predominates in both the south and the north, over $95 \%$ of power plants using open-loop cooling are in southern PRC, where surface water is relatively abundant or access to seawater is convenient. Power plants in the PRC's arid northwest rely exclusively on closed-loop systems or dry cooling. Dry cooling accounts for $24 \%$ of the region's thermal power capacity.

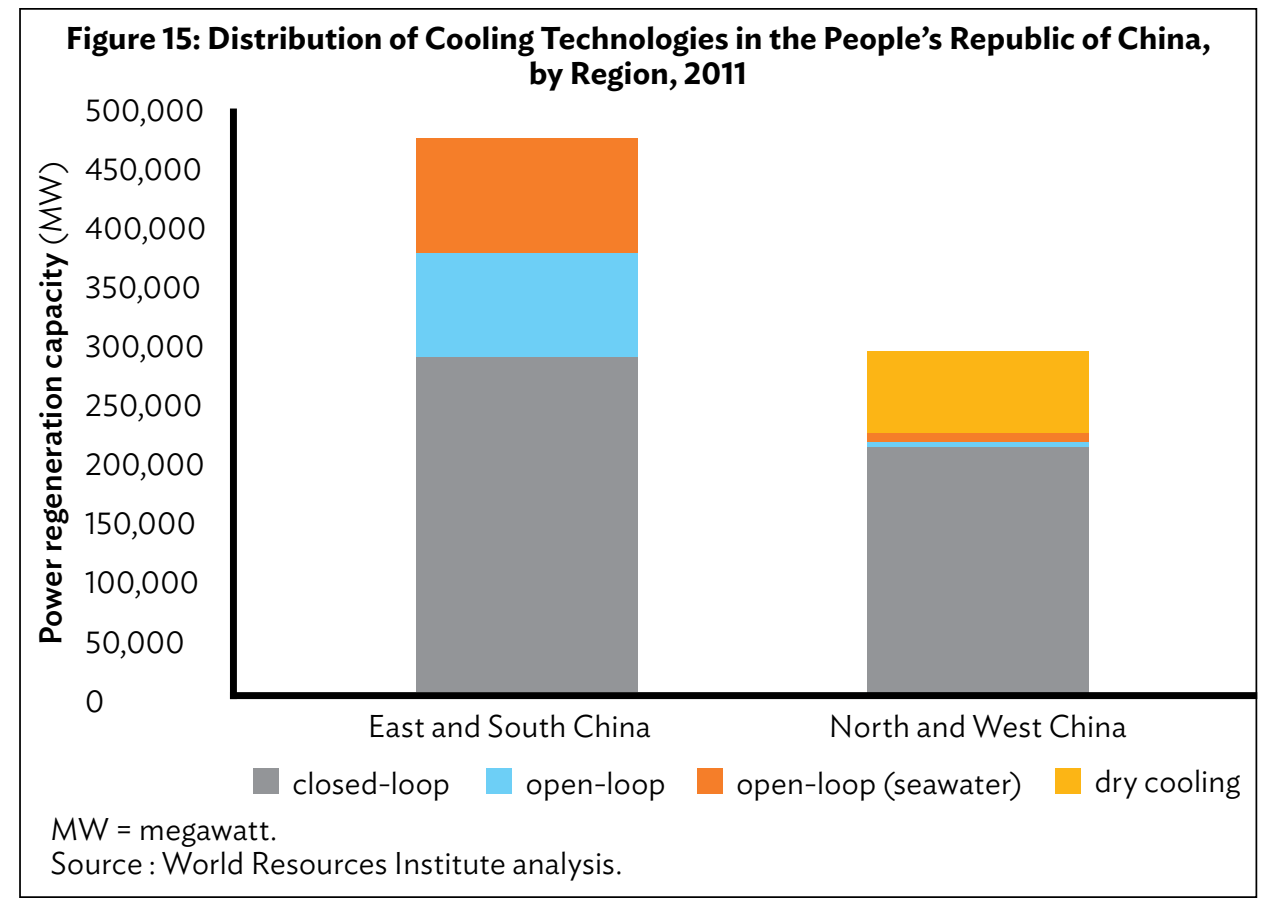

Thermal power plants with closed-loop cooling systems generated $65.2 \%$ of the country's electricity generation in 2011 while representing 16\% of water withdrawals and $90.8 \%$ of water consumption (Figure 16) in the power sector. On the other hand, thermal power plants using open-loop cooling and contributing $11.8 \%$ of power generation were responsible for $83.2 \%$ of water withdrawals in the power sector. While a major share of water withdrawals is due to power plants using open-loop cooling, water consumption takes place mostly in power plants using closed-loop cooling.

Figure 16: Share of Power Production, Water Withdrawal, and Consumption in People's Republic of China Totals, by Cooling Type, 2011

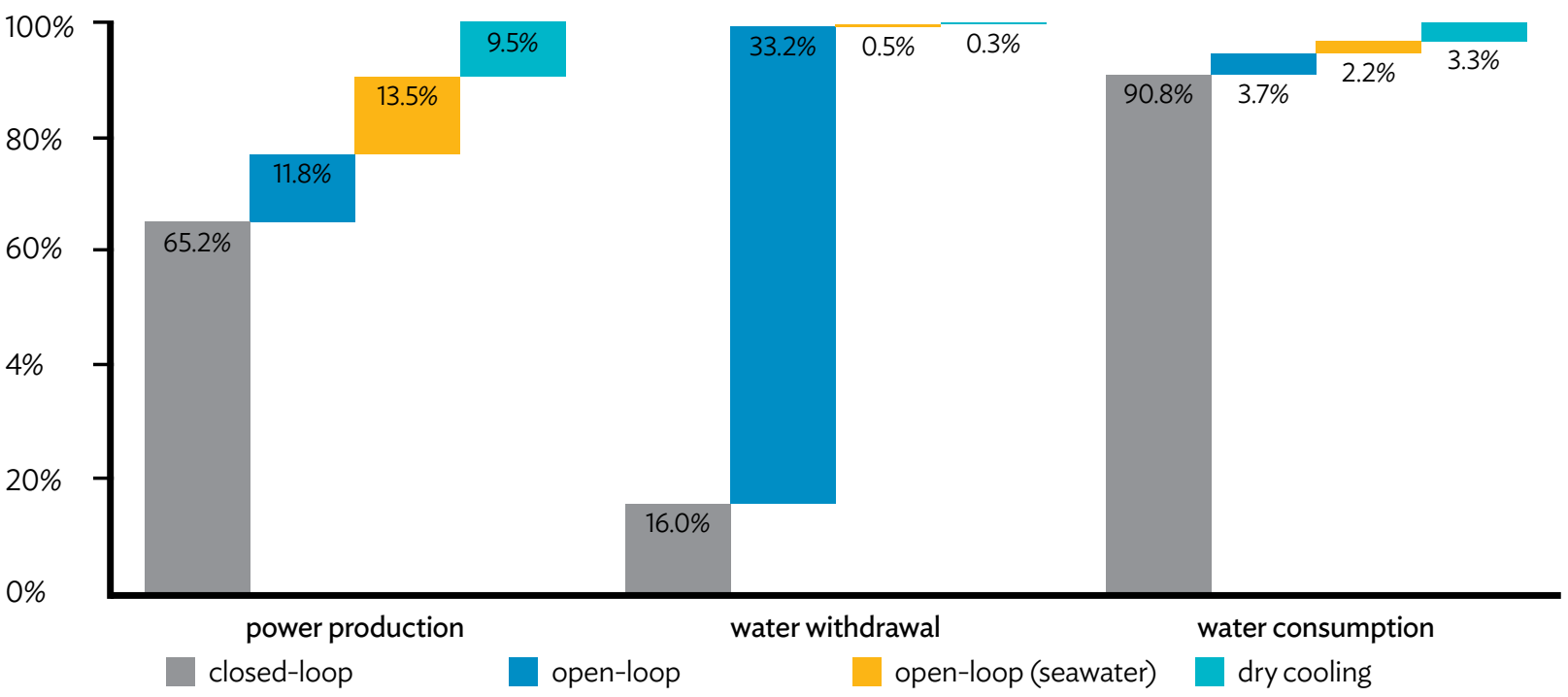

Source: World Resource Institute analysis. 
Freshwater withdrawals by the PRC's power sector in 2014 was 48 bcm, close to the average annual runoff of the Yellow River ( $58 \mathrm{bcm} / \mathrm{year}$ ) (Yellow River Conservancy Commission, n.d.). Withdrawals by Jiangsu province (in the east) alone accounted for $27 \%$ of this total. Most provinces with significant water withdrawals are in eastern and southern PRC, particularly along the Yangtze River (Figure 17). Provinces with a high level of water withdrawals also have a larger share of power plants using open-loop cooling. Shanghai, where openloop cooling is highly prevalent, has the highest water withdrawal intensity (water withdrawal per unit of electricity produced), while Tianjin has the lowest. Shanghai's water withdrawal intensity is 45 times that of Tianjin due to the high prevalence of open loop cooling.

\section{Figure 17: Water Withdrawal Intensity in the People's Republic of China, by Province, 2011}

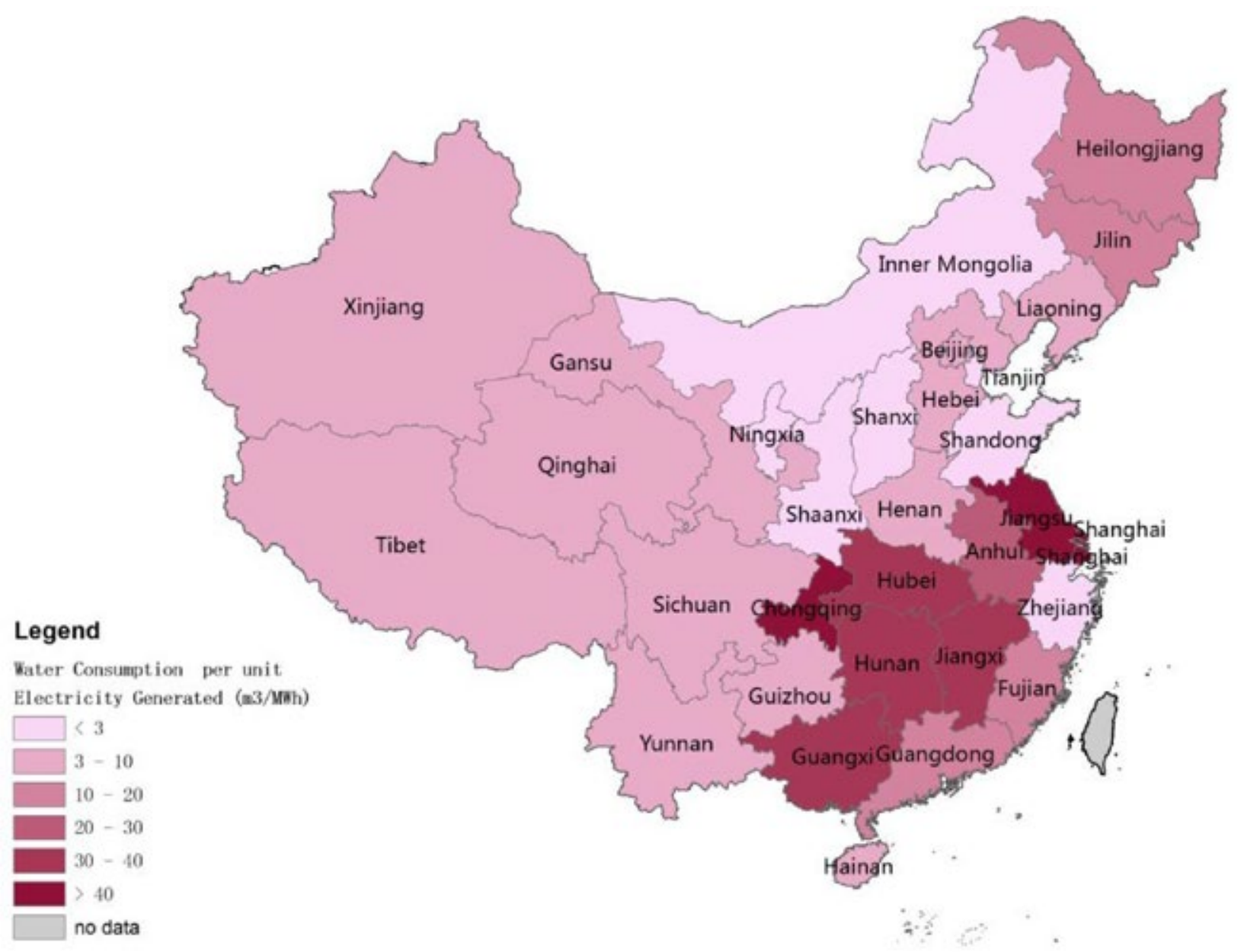

Source: World Resources Institute analysis.

Total water consumption in thermal power generation in 2011 was $7 \mathrm{bcm}$, or about $13 \%$ of water withdrawals by the power sector. There is a noticeable geographical difference between water consumption intensity and water withdrawal intensity. Coastal provinces like Guangdong, Tianjin, and Zhejiang generally have a larger share of thermal power plants using open-loop cooling with seawater, and therefore their freshwater consumption intensity is lower. But the inland provinces such as IMAR and Shaanxi also have low water consumption intensity because a significant share of thermal power plants in these provinces are of recent vintage and employ dry cooling. 
Figure 18: Water Consumption Intensity in the People's Republic of China, by Province, 2011

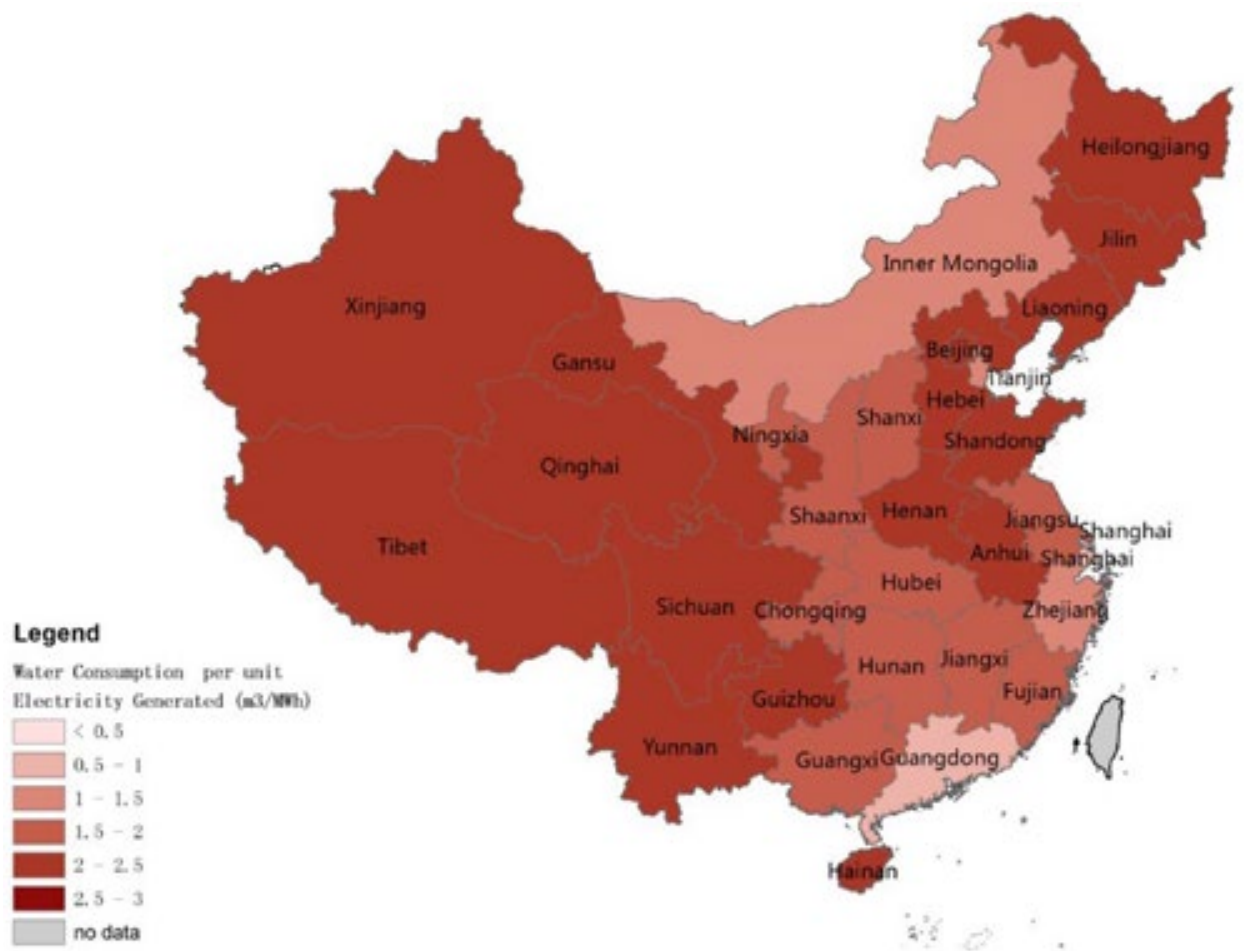

Source: World Resource Institute analysis.

The PRC's provinces and municipalities differ in power production and associated water use (Figure 19). Plants in the east and south generally withdraw more water for each unit of electricity produced than plants in other regions, where more power plants have been fitted with open-loop cooling systems. However, the water consumption in eastern and southern provinces are low compared with their power generation. On the other hand, in northern and northwestern provinces, the water withdrawal is less in comparison with the power generation while water consumption is more. This is due to the high prevalence of closed-loop cooling systems in this region.

\section{Figure 19: Share of Power Production, Water Withdrawal, and Consumption in the People's Republic of China, by Region, 2011}

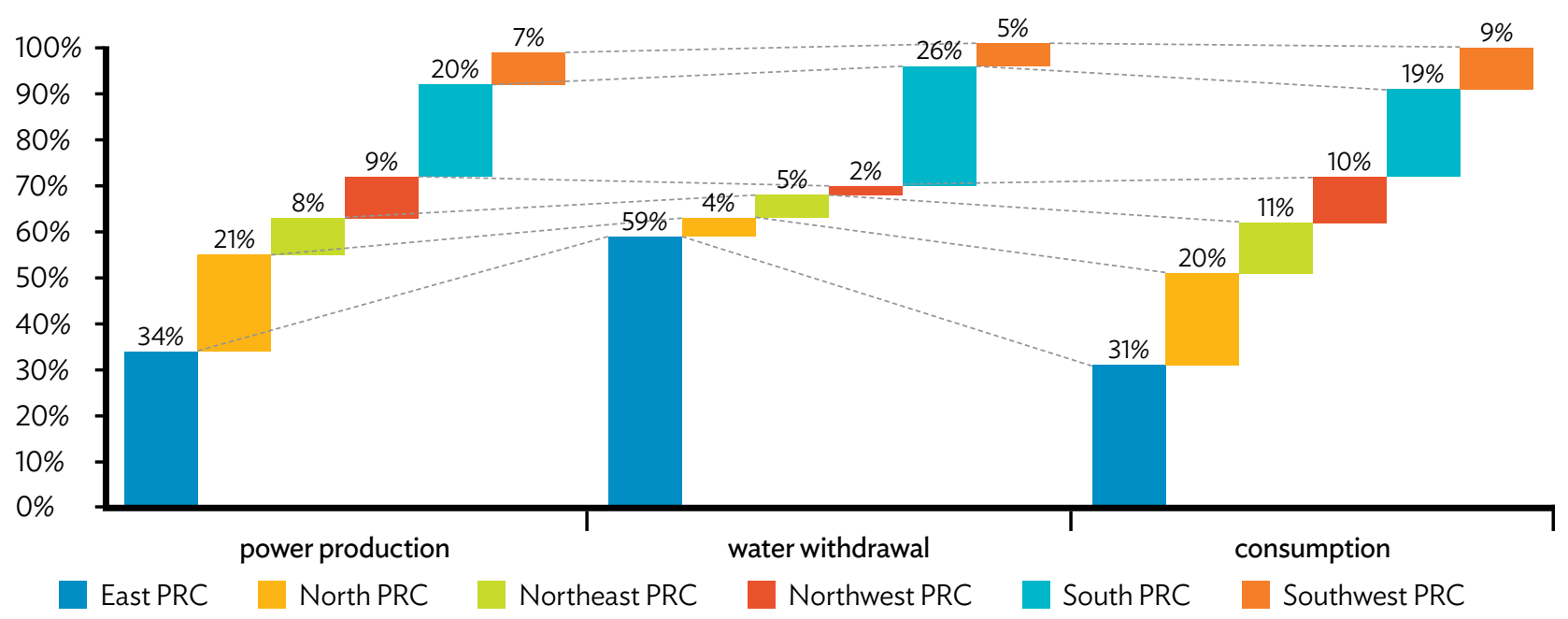

PRC $=$ People's Republic of China

Source: World Resource Institute analysis. 


\section{Water Use Projections for the Thermal Power Sector}

The projected water consumption for power generation takes the Three Red Lines policy into account. The government has defined strict water resource management requirements, setting mandatory limits on water withdrawal, efficiency, and water quality. (IEA Greenhouse Gas R\&D Programme Information Paper, 2009-2015). The national water quantity limit is $670 \mathrm{bcm}$ for 2020 and $700 \mathrm{bcm}$ for 2030 (State Council, 2012). Although the exact amount of water that will be available to the power sector has not yet been released, a freshwater withdrawal allocation of $67,000 \mathrm{~m}^{3}$ in 2020 and $70,000 \mathrm{~m}^{3}$ in 2030 can safely be assumed for thermal power generation, given its current $10 \%$ share of national water withdrawal.

The future water withdrawal of the power sector is projected under four different scenarios with different assumptions about the cooling technologies used (Box 4 and Figure 20).

\section{Box 4: Reference Scenarios for Water Withdrawal} by the Power Sector in the People's Republic of China

\section{Scenario 1: Status quo}

New plants follow the same distribution of cooling technologies (66\% with closed-loop cooling, $13 \%$ with seawater open-loop cooling, $12 \%$ with freshwater open-loop cooling, and $9 \%$ with dry cooling)

\section{Scenario 2: Increased closed-loop cooling in new plants}

2015-2020: 88\% with closed-loop cooling, 3\% with seawater open-loop cooling, and $9 \%$ with dry cooling

2021-2030: 81\% with closed-loop cooling, 10\% with seawater open-loop cooling, and $9 \%$ with dry cooling

\section{Scenario 3: Increased dry cooling in new plants}

2015-2020: 67\% with closed-loop cooling, 3\% with seawater open-loop cooling, and $30 \%$ with dry cooling

2021-2030: 50\% with closed-loop cooling, 10\% with seawater open-loop cooling, and $40 \%$ with dry cooling

\section{Scenario 4: Retrofitting scenario ( $20 \mathrm{GW}$ of existing freshwater open-loop cooling capacity retrofitted with closed-loop or dry cooling every 5 years)}

2015-2020: 67.5\% of new plants with closed-loop cooling, 2.5\% with seawater open-loop cooling, and 30\% with dry cooling

2021-2030: 51.5\% of new plants with closed-loop cooling, 8.5\% with seawater open-loop cooling, and $40 \%$ with dry cooling

$\mathrm{GW}$ = gigawatt

Source: World Resource Institute analysis. 


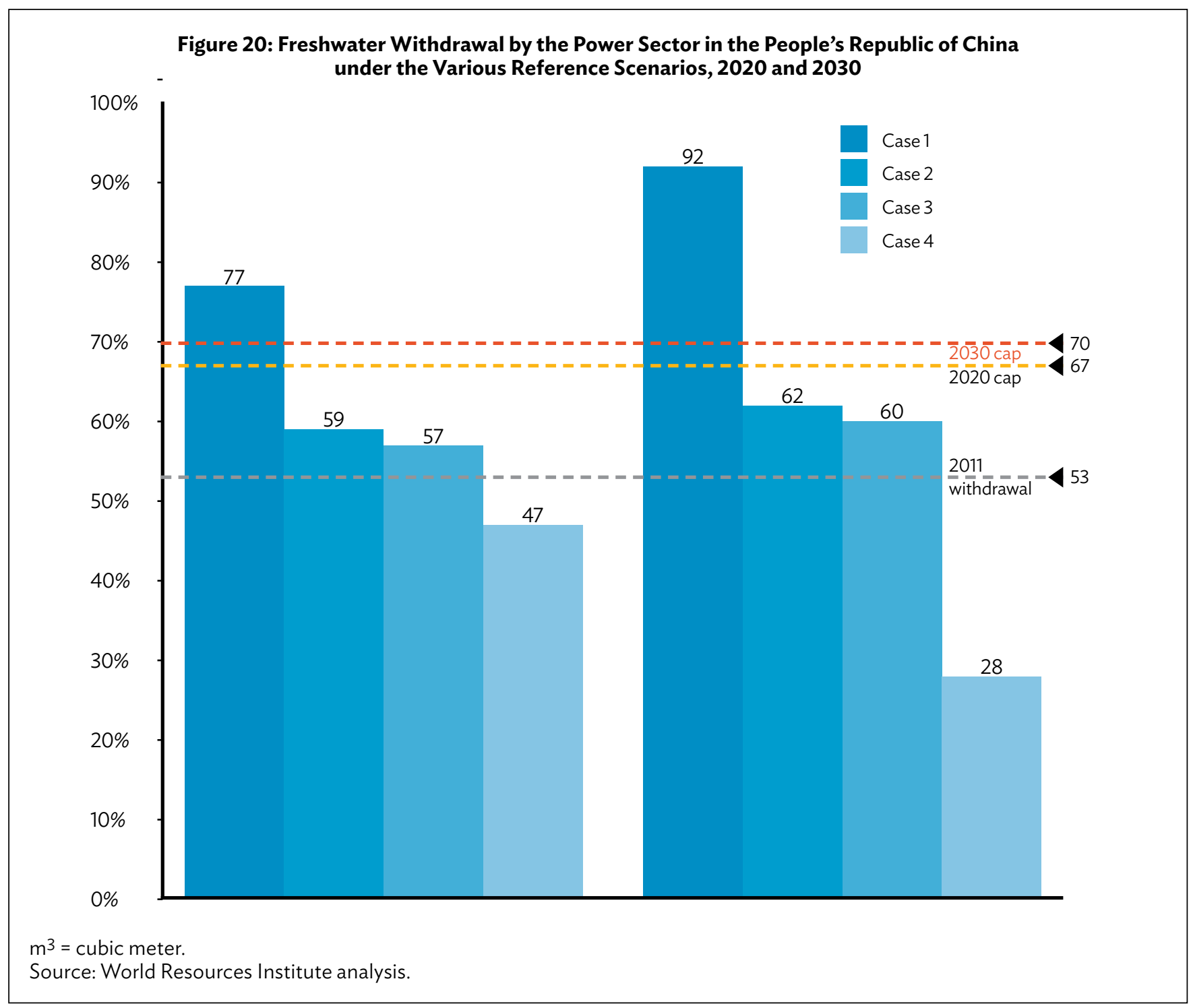

The water withdrawal projections for the power sector in 2020 range from $47 \mathrm{bcm}$ to $77 \mathrm{bcm}$, depending on assumptions about the cooling technologies to be used by the new coal-fired power plants, and the retrofitting and decommissioning of existing plants. If the new plants retain the present distribution of cooling technologies (scenario 1), water withdrawals will increase to $77 \mathrm{bcm}$ by 2020 and to $92 \mathrm{bcm}$ by 2030 , from $48 \mathrm{bcm}$ in 2011 . But if dry cooling is increased to $30 \%$ of the newly installed plants by 2020 and to $40 \%$ by 2030 (scenario 3), water withdrawals can be capped at $57 \mathrm{bcm}$ by 2020 and at $60 \mathrm{bcm}$ by 2030 .

The analysis also shows that, unless a sizable number of new power plants adopt dry cooling, water withdrawals for power generation could reach about $15 \%$ of the national total by 2030 , compared with $10 \%$ in 2015 . Keeping total withdrawals below 700 bcm by 2030 would be difficult and water scarcity in northwestern PRC, where large coal-fired power bases are being developed, would worsen.

As closed-loop cooling accounts for the bulk of water consumption, increasing its share in new plants (scenario 2) would increase consumption (Figure 21). But increasing the share of dry cooling while maintaining closed-loop cooling at $67 \%$ of new plants until 2020, and at 50\% between 2020 and 2030, would result in a slight decrease in water consumption. 


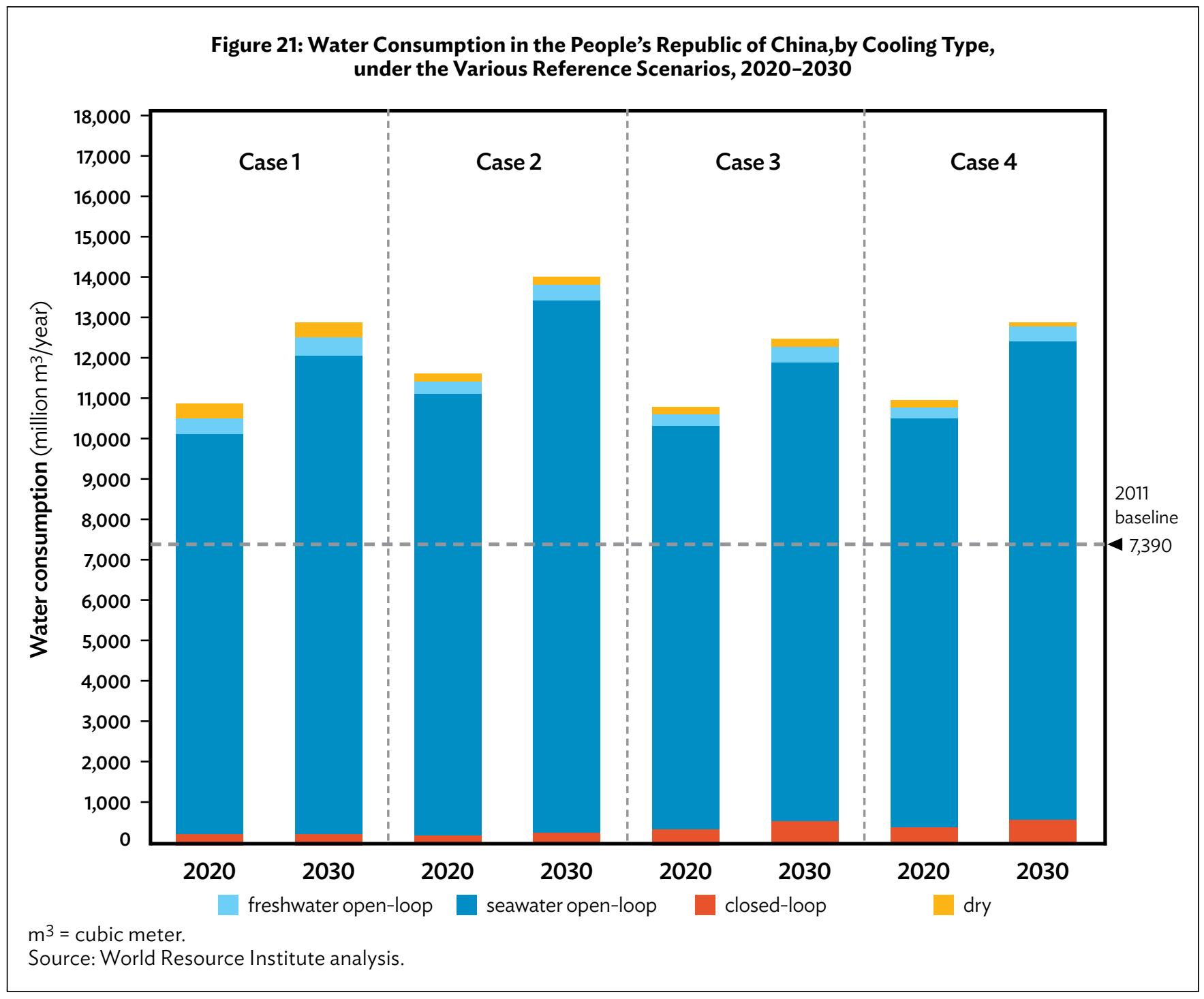

In summary, while increasing the share of closed-loop cooling will result in a reduction of water withdrawal, it will increase the water consumption in the thermal power sector. For regions under severe water stress in northern and western PRC, closedloop cooling may not be the most appropriate cooling technology. More and more, these regions will have to depend on dry cooling. Dry cooling, however, reduces the thermal efficiency of power plants by adding to auxiliary power consumption, and could further increase the carbon footprint of the PRC's thermal power sector.

Closed-loop cooling can still be deployed in interior provinces of southern and central PRC with moderate water stress. In coastal provinces, open-loop cooling based on seawater should be the preferred option. But open-loop cooling based on freshwater bodies (rivers and lakes) could be deployed selectively, as its use could increase the water temperature of natural water bodies, with adverse impact on aquatic biodiversity and water quality.

\section{Evolving Policy Regime for Water Use Regulation in the Thermal} Power Sector

In December 2013, the Ministry of Water Resources (MWR) released the Guidelines for Water Resource Planning for Large Scale Coal Power Base Development to ensure 
the sustainable development of coal bases. According to the guidelines, regional water resource availability should be considered in the design of coal bases, which should strictly conform to the regional targets under the Three Red Lines policy.

The coal bases must "save water before using water", and limit the use of groundwater. In administrative districts where water withdrawal reaches or exceeds the Three Red Lines, they should improve water efficiency or transfer water rights from other water users to meet water demand ceilings, instead of increasing groundwater withdrawal. The guidelines call for a detailed water appraisal to determine the predicted water demand of the coal base and its impact on water resource availability and on other water users, and for compensation plans for the affected parties.

The guidelines also require coal-fired power plants in water-scarce areas to use drycooling systems and to consume less than $0.1 \mathrm{~m}^{3}$ of water per gigawatt-hour of power generated. (C. Zhang et.al., 2016). In addition, the government is pilot-testing a water right transfer scheme to encourage industrial enterprises, including thermal power plants, to invest in water conservation projects (Box 5).

\section{Box 5: Ningxia Water Right Transfer Scheme (Case Study)}

The Yellow River Water Transfer Plan, developed by the Ningxia Department of Water Resources (DWR) in 2004, allows specific transfers of water from agricultural to industrial uses. The DWR has signed contracts with industrial enterprises, including thermal power plants, committing the latter to invest in water conservation in agriculture (e.g., reducing water loss in irrigation canals), and has transferred water rights to the industries taking part in the scheme.

The amount of water transferred is roughly equal to the water savings achieved through the investments made by the enterprises. The water right transfer price depends on the total cost of the water conservation project, its duration, the quantity of water transferred, and the location of the project.

Even as the potential for water conservation through canal systems has steadily diminished, the prospects for water right transfers have improved. By June 2013, Ningxia had implemented nine water transfer projects involving a total of 88 million cubic meters $\left(\mathrm{m}^{3}\right)$ of water (Y. Chen, 2014), and was expecting up to 425 million $\mathrm{m}^{3}$ in total transfers by 2020 (Ministry of Water Resources, 2004).

The Ningxia Lingwu power plant was the first water right transfer project in the PRC. Plant authorities signed a water transfer agreement with the Irrigation Management Bureau of the Ningxia DWR. Under the agreement, the plant authorities undertook to invest CNY40 million (about $\$ 6.5$ million) in a canal water-saving project for the Qingtongxia irrigation area, in exchange for water rights of 14.4 million $\mathrm{m}^{3} /$ year (C. Hu 2014). 
Besides administrative measures, the PRC has adopted a water resource fee to promote water conservation in the energy sector. The Water Law of 1988 directed the government to impose a water resource fee, but the measure did not become compulsory until 2006.9 Coal-fired power generation plants also had to pay for freshwater used as cooling water, but could use desalinated or recycled water free of charge. This requirement effectively encouraged power plants to turn to nontraditional water sources for cooling. By 2012, the use of desalinated water had reached 66 million $\mathrm{m}^{3}, 2.5$ times the amount used in 2006 (MWR ,2013).

During the 12th Five-Year Plan period, the government further improved the mechanism for imposing and collecting water resource fees. The Notice on Water Resource Fee Collection classified water resource fees into five categories and set a higher rate for water withdrawals in excess of the quota assigned to a user. In addition, the 31 provinces were expected to collect water resource fees at the tariff levels set by the NDRC at the end of 2015.10 The provinces where large coal bases are located, except for Ningxia, Shandong, and Shanxi, must raise their water resource fees to comply with the NDRC's tariff requirement.

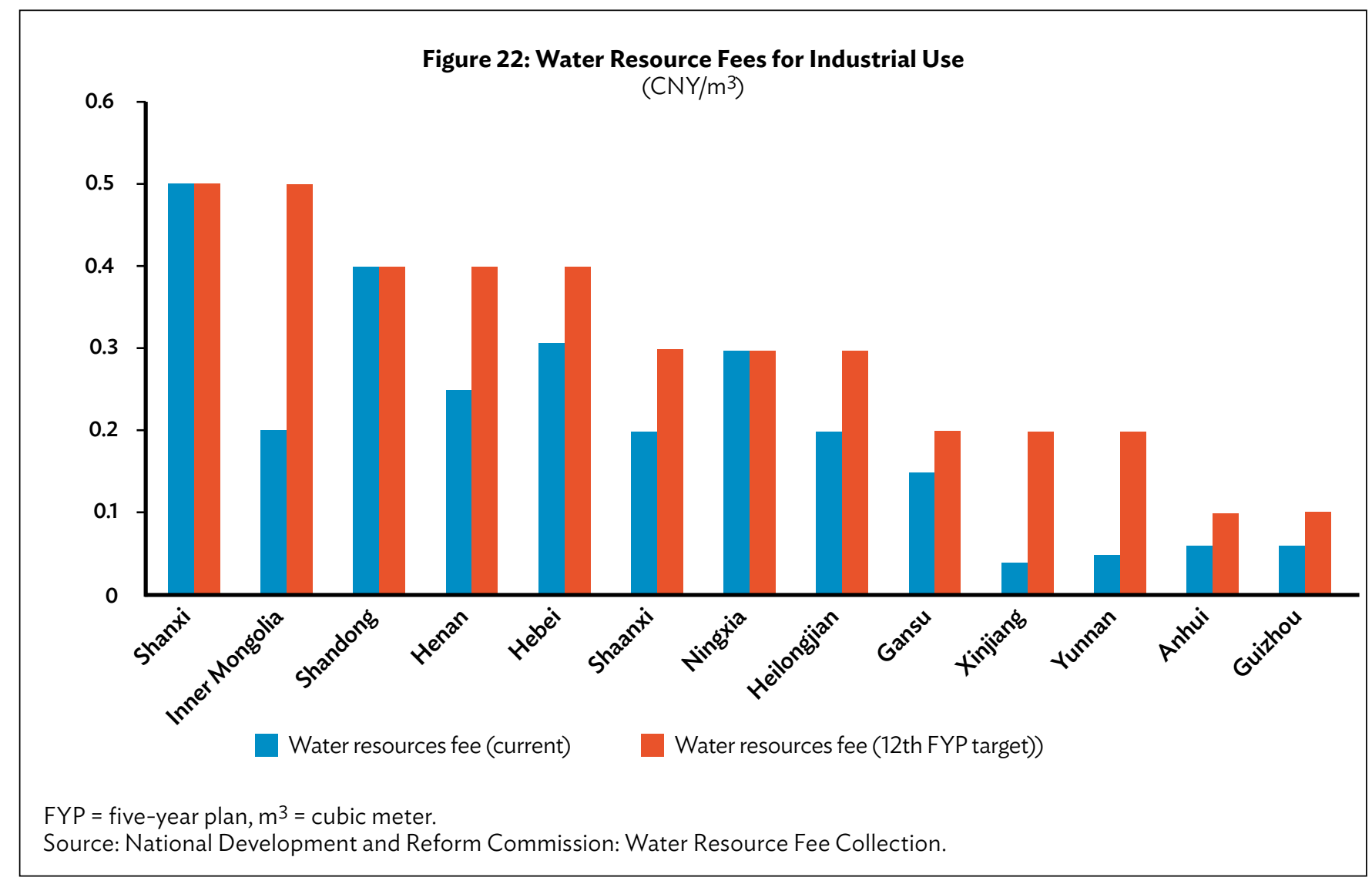

9 In 2006, the State Council published the Regulations on Water Withdrawal Permit and Water Resources Fee Collection, in which the water resources fee became a compulsory fee for water users.

10 Water resource fees were initially set at the lowest level by the NDRC for the 31 provinces, autonomous districts, and cities in the Notice on Water Resource Fee Collection. These areas were required to raise their water resources fees at least to the level prescribed in the notice by the end of 2015 . 


\section{Ensuring Sustainable Water Use in Thermal Power Generation}

Despite a rapid increase in renewable sources of electricity generation and ambitious targets set by the government for increasing the share of nonfossil fuels in the country's energy supply mix, coal-based thermal power will remain the major source of electricity generation. Since the thermal power sector contributes about $10 \%$ of freshwater withdrawals and an increasing number of thermal power plants are in highly water-stressed northern and northwestern parts of the PRC, it is imperative to reduce the freshwater withdrawals and freshwater consumption by the thermal power sector.

This would require the strict enforcement of a water resource assessment that must be made during the planning of new thermal power plants to ascertain their water-related impact, including the competition for water resources with existing water users, such as the agriculture sector, and the effect on water quality and water temperature. Drycooling technology must be deployed in regions where water stress is severe because of lack of freshwater resources and high demand for water.

In addition, water right transfer mechanisms that call for power plants to purchase water rights from local communities by investing in water conservation should be encouraged, with appropriate regulations for the strict enforcement of the obligations of the contracting parties. It is necessary to ensure that local communities and farmers are not deprived of access to water simply because thermal power plants can afford to pay a higher price for this limited resource.

As dry cooling systems are more expensive to build and operate, coal-fired power plants using this technology are likely to have a higher levelized cost of electricity. It is necessary to fully account for the higher levelized cost of electricity of coal-fired power plants using dry cooling during when investment decisions are made and subsequent dispatching of such power plants. Capturing the cost of water-related externalities would encourage the commissioning and use of less water-intensive electricity-generation technologies. 


\section{Water Use Implications of Hydropower}

Hydropower is the most widely used form of renewable energy in the PRC. In 2014, it accounted for $19.2 \%$ of the country's electricity generation and $22.2 \%$ of its installed electricity generation capacity. The PRC has the largest installed hydropower capacity in the world, exceeding the installed hydropower capacity of Brazil, Canada, and the US combined. The government has set the targets of increasing the share of nonfossil fuel energy in primary energy supply to $15 \%$ by 2020 and to $20 \%$ by 2030 . Hydropower has an important role in meeting these targets and ensuring energy security (Ecofys, 2015). Installed hydropower capacity exceeded $300 \mathrm{GW}$ in 2014 and is expected to reach 380 GW by 2020 and 450 GW by 2030 (China Energy Net, 2016).

Although hydropower uses the energy of flowing water, most of the water that passes through hydropower plants can later be put to other uses. Hydropower plants are often associated with large dams and reservoirs storing water for future electricity generation and for other purposes, such as irrigation and flood protection.

The point of release of stored water for hydropower generation is not the same as the point of extraction, since hydropower depends on the height difference between the point of extraction and the point of release. Often, the water is released into the same river several kilometers downstream from the point of extraction. More complex hydropower plants release the water into a different river system. Run-ofriver hydropower plants even release water into the same river without significantly changing the water flow downstream of the point of release. Despite the significant amount of water withdrawal associated with hydropower, the water consumption of hydropower is limited to seepage and evaporation losses from the reservoirs. The reservoirs created for hydropower may also replenish groundwater sources. The water consumption of run-of-river hydropower plants is negligible, as evaporation is negligible in the absence of water storage.

From a water management perspective, the impact of hydropower pertains to the timing and location of water release, as hydropower plants with storage may cause temporal and spatial water shortages for other users. The impact is more severe when hydropower involves trans-basin water transfers, and appropriate water management regulations are required to balance the competing demands of different water uses. The environmental impact of hydropower is mainly due to the fragmentation of river systems, disrupting the integrity of aquatic ecology and resulting in biodiversity loss due to the obstruction of fish migration along the river systems. The regulation of river flows to suit the need of hydropower generation can alter seasonal floods, and may adversely affect downstream floodplains, wetlands, and groundwater recharge. 
In addition, hydropower dams are likely to block sediment flows and affect soil fertility and agricultural productivity downstream.

\section{Status of Hydropower Development in the PRC}

Since 2000, the government has placed increasing emphasis on fully exploiting the vast hydropower potential in response to increasing demand for electricity, growing air pollution problems, and climate change impact associated with coal-based electricity generation and energy security concerns. As a result, the installed capacity of hydropower has increased, from 79 GW in 2000 to 300 GW in 2014.

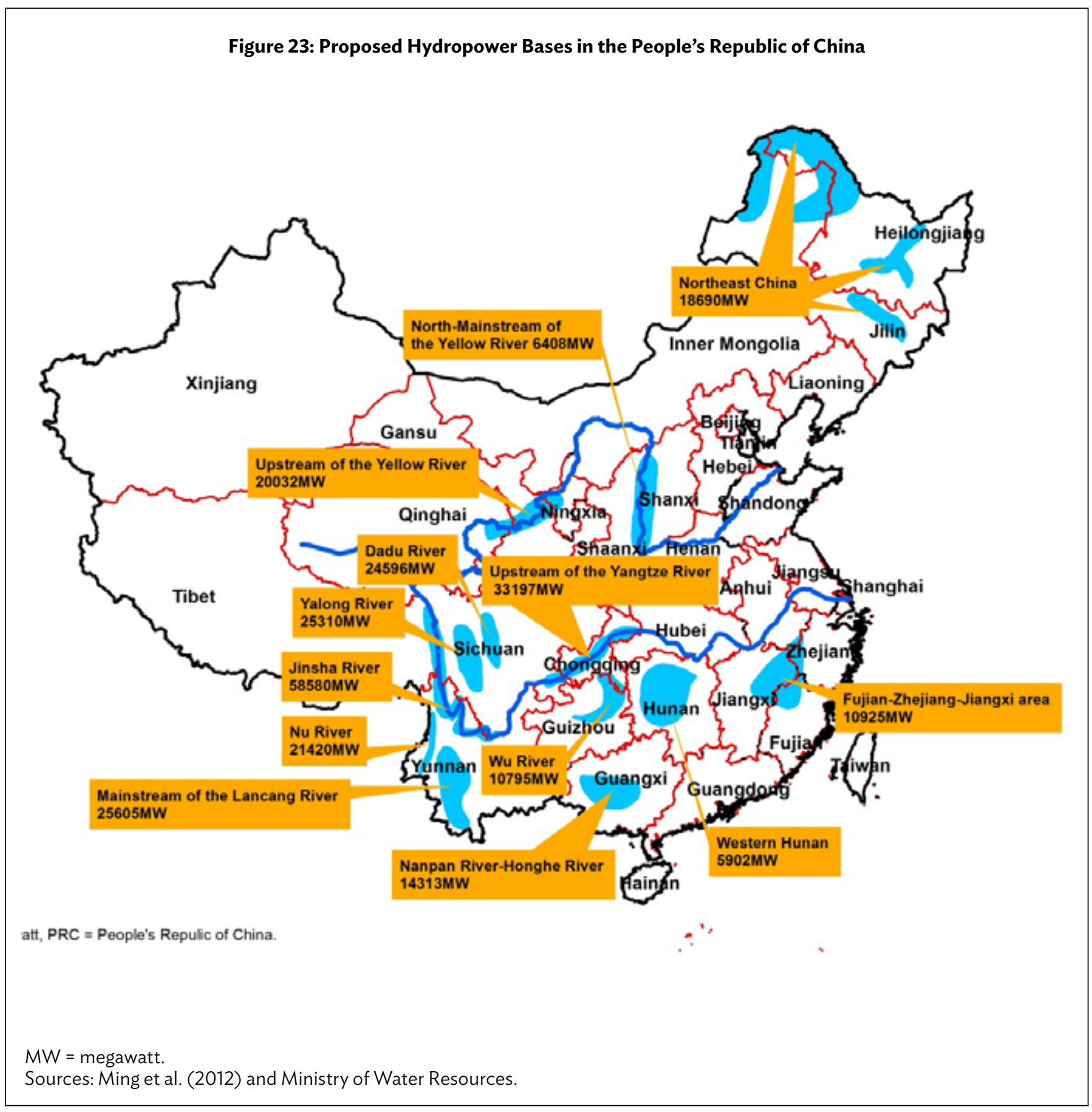


The geographic distribution of hydropower development in the PRC closely mirrors water resource availability across the country. In the southwest region, which accounts for over $65 \%$ of hydropower potential in the PRC, over $120 \mathrm{GW}$ of hydropower capacity had been developed by 2013 and an additional $35 \mathrm{GW}$ is under construction. Eastern and central-southern PRC have about $117.8 \mathrm{GW}$ of technically feasible hydropower potential and, by 2014 , over $80 \%$ of this had been developed. The northwest and northeast, on the other hand, have limited potential for hydropower; about one-third of this potential had been developed by 2014 .

The government has identified 13 hydropower development bases along the Jinsha, Yalong, Dadu, Wu, Hongshui, and Nu rivers; upstream of the Yangtze and Yellow rivers; mainstream of the Lancang River; north mainstream of the Yellow River; and in Hunan Province, in the Fujian-Zhejiang-Jiangxi area, and in northeastern PRC (Figure 23). Except for the two hydropower bases along the Yellow River and a hydropower base in the northeast, most of the hydropower bases are in the south. Estimates suggest that the total planned and installed hydropower capacity of these 13 hydropower bases ( $276 \mathrm{GW}$ ) would account for $51 \%$ of the technically feasible hydropower capacity in the PRC (G. Li, 2007).

The National Energy Administration plans to increase the total installed hydropower capacity to $420 \mathrm{GW}$ by 2020 , with conventional hydropower at $350 \mathrm{GW}$ and pumped-storage power stations at $70 \mathrm{GW}$. During the 12th Five-Year Plan period, the total installed capacity of all hydropower projects increased by $160 \mathrm{GW}$.

The PRC has some of the largest hydropower plants in the world (Table 3), including the Three Gorges hydropower plant with a capacity of $22.5 \mathrm{GW}$ (Box 6). Extra-large hydropower plants with a capacity of over $1.2 \mathrm{GW}$ contribute to over $50 \%$ of installed capacity in the country.

Table 3: Hydropower Plants in the People's Republic of China, by Capacity

\begin{tabular}{|lcc|}
\hline Scale of Hydropower Station & Number & Installed Capacity (GW) \\
\hline Large, type I $(\geq 1.2 \mathrm{GW})$ & 56 & 154.86 \\
Large, type II $(\geq \mathrm{I} \mathrm{MW}$ and $<1.2 \mathrm{GW})$ & 86 & 51.78 \\
Medium $(\geq 1 \mathrm{MW}$ and $<300 \mathrm{MW})$ & 477 & 52.42 \\
Small, type I $(\geq 10 \mathrm{MW}$ and $<50 \mathrm{MW})$ & 1,684 & 34.61 \\
Small, type II $(<10 \mathrm{MW})$ & 19,887 & 33.62 \\
Installed capacity $(<500 \mathrm{~kW})$ & 24,568 & 5.59 \\
Total & 46,758 & 332.88 \\
\hline
\end{tabular}

$\mathrm{kW}=$ kilowatt, $\mathrm{MW}=$ megawatt, $\mathrm{GW}=$ gigawatt .

Source: Ministry of Water Resources (2013b). 


\section{Box 6: The Three Gorges Hydropower Plant}

The Three Gorges Dam is a hydroelectric dam that spans the Yangtze River by the town of Sandouping in Yiling District, Yichang, Hubei Province. The hydropower plant is the world's largest power station in terms of installed capacity ( $22.5 \mathrm{GW})$. The dam is 181 meters high and 2,335 meters long. It has created the Three Gorges reservoir, which has a surface area of 1,045 $\mathrm{km}^{2}$ and extends upstream from the dam for about $600 \mathrm{~km}$ (G.S.R. Murthy, K.G. Murty, and G. Raghupathy, 2014).

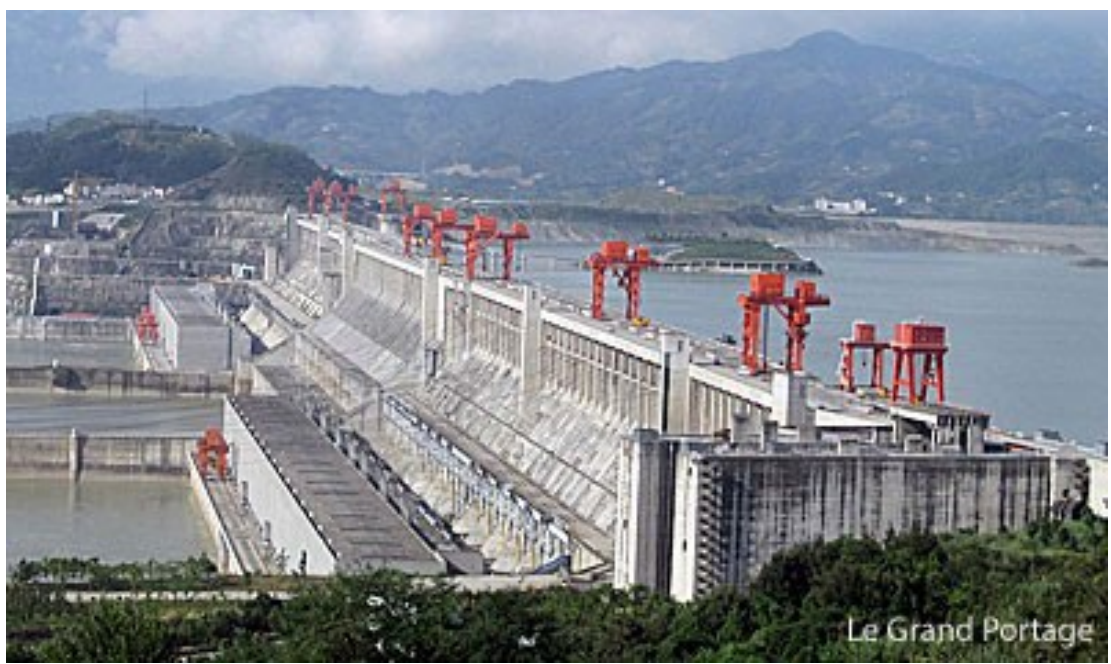

The plant was completed and fully functional as of 4 July 2012. In addition to producing electricity, it is intended to increase the Yangtze River's shipping capacity and reduce flood risks by increasing water storage during the wet season.

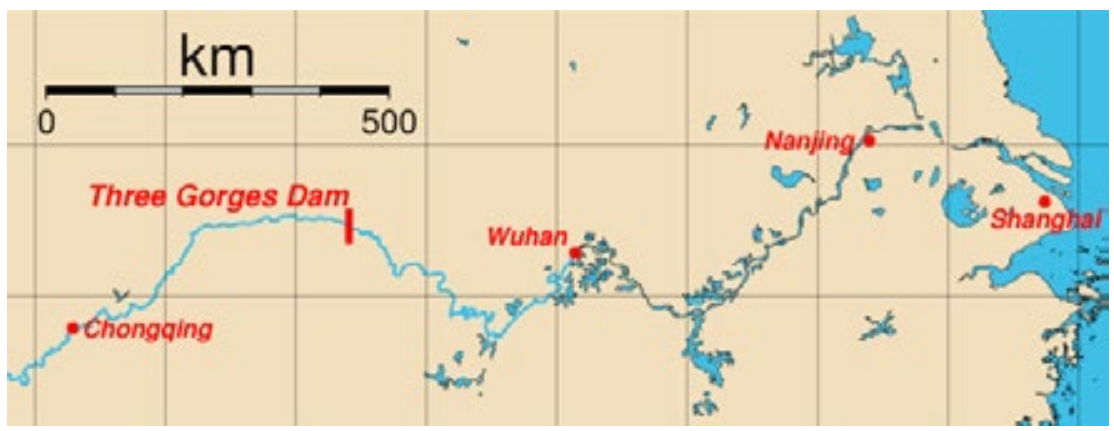

\section{Power Generation of the Three Gorges Dam}

Three Gorges is the world's largest capacity hydropower station with 34 generators - 32 main generators, each with a capacity of $700 \mathrm{MW}$, and two smaller generators with $50 \mathrm{MW}$ each. Of the 32 main generators, 14 are installed on the north side of the dam, 12 on the south side, and the remaining six are in the underground power plant. The expected annual electricity generation is over $100 \mathrm{TWh}$. In 2014, the electricity generation of the Three Gorges hydropower plant (98.4 TWh) exceeded the total electricity generation of the Philippines.

$\mathrm{GW}=$ gigawatt, $\mathrm{km}=$ kilometer, $\mathrm{km}^{2}$ = square kilometer, $\mathrm{MW}=$ megawatt, $\mathrm{TWh}=$ terawatt-hour.

Source: https://en.wikipedia.org/wiki/Three_Gorges_Dam. 


\section{Role of Pumped-Storage Hydropower in the PRC's Electricity System}

Pumped-storage hydropower (PSH) plants (Figure 24) can play an important role in providing the required flexibility to the generation supply mix in the PRC, and particularly in the northern part of the country, in facilitating wind power absorption, and in reducing wind power curtailment. The operating principle of PSH plants is fairly simple. The plants store electrical energy in the form of gravitational potential energy of water stored at a higher elevation compared with the lower reservoir. This potential energy is converted to electricity by releasing the stored water through turbines to the lower reservoir during the time peak period when the marginal cost of electricity is high. The water is pumped back from the lower reservoir to the upper reservoir when the marginal cost is low or when there is surplus electricity generation.

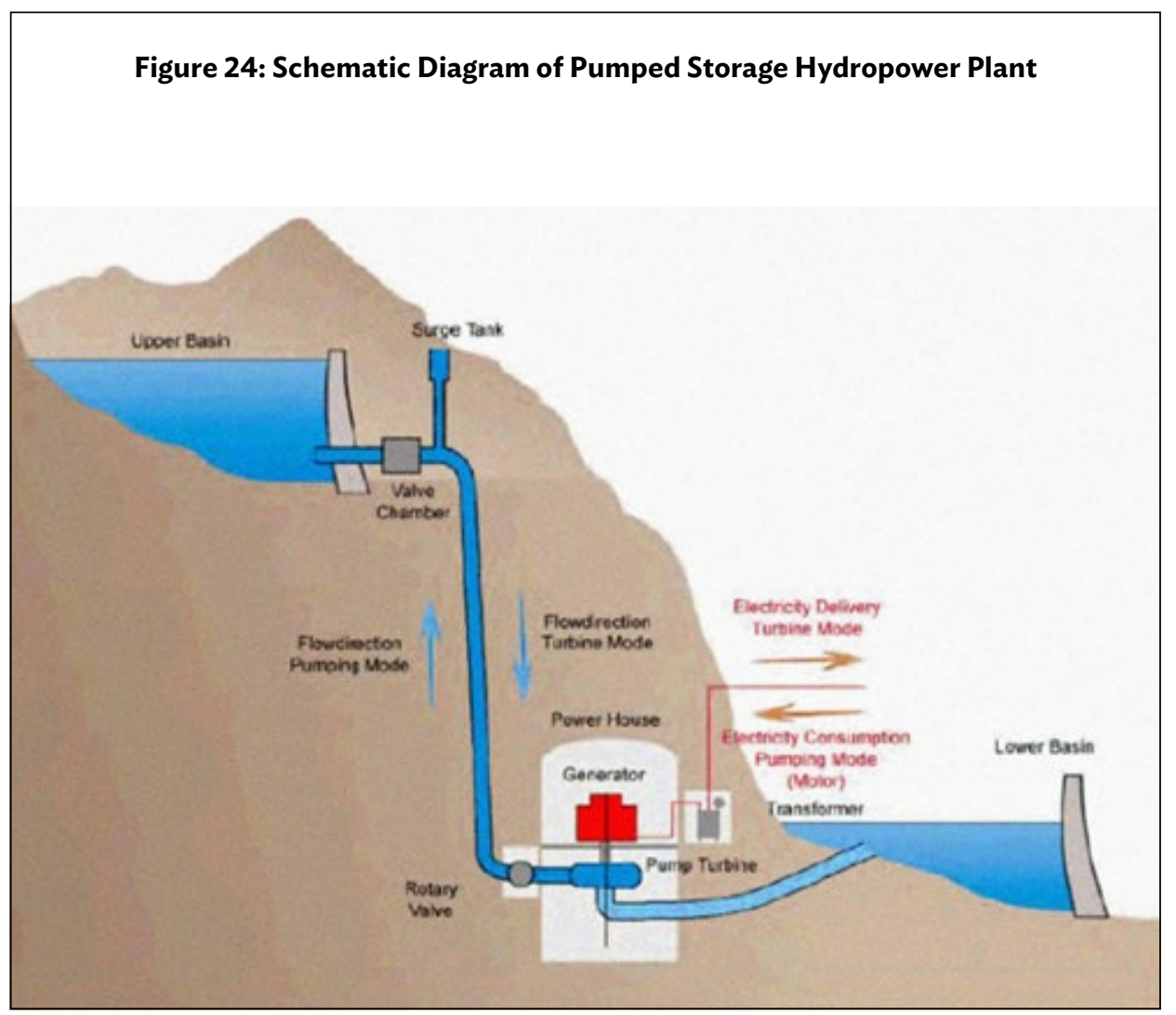

The majority of existing pumped-storage plants are physically connected to natural river systems (usually on a tributary of a river), and the operation of the PSH plant disrupts the natural flow of the river. As water is recycled in PSH plants between the upper reservoir and the lower reservoir, the plants do not require large-scale water storage or water diversion as in the case of conventional hydropower. However, water flows downstream of the PSH plant may still be affected by the operational requirement of the plant.

A relatively recent approach to designing PSH plants is to locate the reservoirs in areas that are physically separated from river systems. These projects are termed "closedloop" pump storage because they have minimal or no impact on river systems. By avoiding existing complex aquatic systems, these types of PSH plants have the potential to greatly reduce the most significant aquatic impact associated with hydropower. After the initial filling of the reservoirs, the only additional water requirement is minimal operational makeup water to offset evaporation or seepage loss. 
By the end of 2012, the cumulative installed capacity of PSH in the PRC had reached $20.7 \mathrm{GW}$, with eight PSH plants amounting to $8.9 \mathrm{GW}$ under construction (Chen and Bai, 2013). It is important to note that only $5.9 \mathrm{GW}$ (28.5\%) of the PRC's installed PSH capacity and $1.2 \mathrm{GW}$ of PSH capacity under construction are in the three northern regions, where more than $87 \%$ of the PRC's wind power capacity is located. Since these northern provinces predominantly depend on coal power and the presence of a larger share of coal-fired CHP plants, the PSH plants can play a significant role in reducing wind power curtailment by increasing the flexibility of the power system. It is, therefore, necessary to have an appropriate regulatory regime and incentive structure to encourage investments in PSH plants in the province with high wind power penetration.

\section{Hydropower Development in the PRC: Major Issues}

The Energy Development Strategy Action Plan (2014-2020) issued by the State Council in 2014 highlights the importance of increasing the share of clean energy in the PRC's energy mix. However, hydropower development, in particular the construction of large dams, has adverse environmental and ecological impact. Historically, the exploration of hydropower in the PRC did not fully take into account its impact on the environment and on ecosystems.

Disruption of ecosystem continuity. Hydropower development usually disrupts the natural flow of water in a river system because of the construction of dams and weirs, as well as the diversion of water. Sedimentation levels are affected, as sediment tends to accumulate in reservoirs and deprives downstream areas of sediment flow. Seasonal flooding can also be reduced and the fertility of floodplains may be affected. In addition, hydropower dams can cause the complete drying of riverbeds downstream of the dam unless small amounts of water are released from the bottom of the dam to maintain the ecosystem's integrity (Gulbenkian Think Tank on Water and Future of Humanity, 2013). Some hydropower plants developed in the PRC in the past did not provide for this.

Effects on aquatic life and biodiversity in river systems. The construction of high dams and large reservoirs can also change the water temperature and level of dissolved oxygen, leading to a stratification phenomenon with variations in water quality at different levels. The water released from the bottom of the reservoirs tends to have a lower temperature and low levels of dissolved oxygen, which may affect the aquatic life downstream of the dam. The construction of dams may also disrupt fish migration along the river systems and prevent spawning, resulting in a drastic reduction of the fish population and extinction of endangered fish species. On the other hand, the reservoirs built for hydropower may provide opportunities for commercial aquaculture.

Environmental impact during construction. The submersion of vegetation during the impounding process may result in short-term water quality deterioration and eutrophication, as well as the release of climate change-causing methane into the atmosphere. Cleaning the reservoir bed of biomass before it starts the impounding process can keep this from happening. The construction of hydropower plants likewise results in quarrying, soil borrowing for fillings, and disposal of construction waste. Terrestrial animals and the local environment may be affected. For this reason, the project developers and contractors must take appropriate precautions. 
Effect on rural indigenous communities. The formation of man-made reservoirs may also result in inundation of forestland and farmland, as well as cultural relics, and may require the resettlement of rural communities. Some of the affected communities may consist of socially vulnerable groups of indigenous peoples with unique sociocultural practices, especially in southwestern PRC, in provinces such as Guangxi and Yunnan. It is necessary to restore the livelihoods of affected communities in a culturally sensitive manner without adversely affecting their traditional cultural norms. The government has issued specific policies and guidelines for the resettlement of people displaced by hydropower development in the 1990s, increasing the compensation payments and subsidies to affected people.

\section{Ensuring the Sustainable Development of Hydropower}

Hydropower remains a vital and significant source of electricity generation without contributing to climate change or to air pollution. Hydropower is also an indigenous source of energy and enhances the energy security of the PRC. However, hydropower has certain harmful environmental and social effects and must be developed in a sustainable manner. Identifying the harmful impact at the planning stage and introducing appropriate remedial measures would make it economically and technically feasible to develop further the remaining hydropower resource in the PRC in an environmentally and socially sustainable manner. Some of these remedial measures are as follows:

Strategic approach to hydropower development at river basin level. It is necessary to take a river basin-wide approach to hydropower development and undertake integrated planning with regard to hydropower development in a river basin. The water use profile of the river basin, competing uses of water, and the need for a minimum flow to maintain the ecological integrity of the river basin should be taken into account in deciding on the development strategy of hydropower. A strategic environmental assessment (SEA) or cumulative environmental impact assessment at the river basin level is also recommended to identify the environmental impact of the cascade development of hydropower in the river basin.

The SEA may recommend keeping certain sections or tributaries of the river free from hydropower development and identify the river sections for hydropower development with the least impact on the environment. The SEA allows selection criteria to optimize the configuration of hydropower plants to minimize impact, including the effects on biodiversity hotspots and the fragmentation of sensitive ecosystems, and guidelines for operating the hydropower cascade to balance the conflicting objectives of maximizing electricity generation, minimizing the impact on the aquatic ecological environment, and meeting the water demand of different users.

\section{Environmental and social considerations prioritized in the design of hydropower} plants. As hydropower can have significant and long-lasting environmental impact, a comprehensive environmental impact assessment is critical. Hydropower projects that affect sensitive biodiversity hotspots and the spawning grounds of endangered fish species, and deprives local communities of water resources by diverting river flows, should be avoided. At the same time, possibilities for win-win solutions should be explored by promoting hydropower projects with multiple benefits, such as flood control, irrigation, and secure water supply, in addition to electricity generation. 
Some project-specific measures to be incorporated in the design of hydropower projects are:

- Measures to enable fish migration. Fish migration aids for upstream and downstream migration at dam structures give migrating fish species access to their habitats and spawning grounds. The design of these structures must take into account specific hydraulic requirements and fish behavior.

- Measures to ensure ecological flow. To preserve the river ecosystem in the event of significant water diversion or abstraction for hydropower, an ecologically optimized river flow reflecting ecologically important aspects of the natural flow regime, including a relatively constant flow and more dynamic flow at certain periods, must be maintained downstream of the dam or water extraction point for hydropower.

- Measures to ensure sediment transport. Sediment is deposited upstream of a dam and in a reservoir, resulting in a reduction in sediment flow downstream of the reservoir. This adversely affects the ecological function of sediment in downstream sections of the river, such as stabilizing the riverbanks and maintaining the fertility of alluvial flood plains. It is also necessary to extract the sediment to maintain the storage capacity and flood protection capacity of the reservoir. The hydropower plant operators need to carry out reservoir flushing at regular intervals in a controlled manner.

- Measures to minimize hydro peaking. Hydro peaking, defined as the fluctuation of the downstream water level with a change in the output of a hydropower power plant, must be kept within certain limits to reduce the adverse impact. The mitigation measures may include controls on ramping rate, the building of downstream regulatory ponds, the improvement of riverbank structures, and the coordinated operation of hydropower cascades.

Benefit-sharing with local communities and ecological compensation. The upper watershed of river systems containing hydropower plants must be protected to ensure the long-term sustainability of the hydropower development. Degraded watersheds cause heavy flows of sediment, which may fill the reservoirs quickly. On both commercial and sustainability grounds, it makes sense for hydropower developers to allocate a certain share of their revenues for ecological sustainability, terrestrial and aquatic wildlife protection, water quality improvement, and watershed protection. This may be implemented in a socially inclusive manner by involving the local communities and compensating them for investing in watershed protection. 


\section{Energy for Water}

Modern water supply systems consist of extracting water from water sources, transferring the water directly to an end user (e.g., irrigation) or to a treatment plant when higher-quality water is required (e.g., for urban water supply), distributing the treated water to consumers, and treating the wastewater after use and before it is discharged into the natural environment. It may also be possible to recycle the used water after treatment, before it is eventually discharged into the environment. Every step in this water cycle involves a considerable amount of energy. While energy is required to transfer water from a lower elevation to a higher elevation, energy can be produced when water is transferred from a higher to a lower elevation using gravity, if hydropower plants are built (Water in the West, 2013).

\section{Energy for Groundwater Extraction}

Although little or no energy is required to gain access to surface water, the energy consumed in the course of extracting water from underground sources can be significant, depending on the depth of the groundwater source. With increasing groundwater extraction from deeper aquifers in northern PRC due to the lowering of the water table, energy consumption for groundwater extraction is likely to increase. The major users of groundwater in the PRC are small-scale farmers (for agriculture), industries, and public water utilities (for residential and commercial uses).

Given the large number of groundwater users, especially in agriculture, it would be difficult to regulate and accurately estimate the energy consumption for groundwater extraction. There is also a great deal of variation in types of groundwater pumps, ranging from electric and diesel power to solar pumps (Water in the West, 2013).

Although the PRC does not subsidize electricity and diesel for groundwater extraction, the extent of groundwater extraction and associated energy consumption is showing an increasing trend on account of water shortages in northern PRC. The energy requirement of groundwater extraction depends on the depth, type of pump, pumping efficiency, and volume of extraction. Intensive groundwater extraction is causing the further deepening of the groundwater level (L. Xi, L. Jie, and Z. Chunmiao, 2016).

Electric, diesel, and manual pumps are used for groundwater extraction in the PRC; only diesel and electric pumps require energy. Wang et al. (2012) investigated pumps in 366 villages and found diesel pumps account for $24 \%$ of groundwater extraction; electric pumps, for about $76 \%$. Diesel pumps have a pumping efficiency of about $15 \%$; 
for electric pumps, the pumping efficiency is about $40 \%$. Estimates based on these assumptions place average energy consumption at $0.433 \mathrm{kWh} / \mathrm{m}^{3,11}$ and total energy consumption for groundwater extraction at 40 terawatt-hours (TWh)/year.

\section{Surface Water Conveyance and Distribution}

In view of the disparity in water availability and water demand in the PRC, especially the water scarcity in northern PRC and the relative abundance of water supply in southern PRC, long-distance water transfer is seen as an option for addressing water shortages (Box 7). Local surface and groundwater resources for rural communities are being depleted as urbanization proceeds, the commercial and industrial sectors in northern PRC expand, and megacities thrive. The growing water demand is unlikely to be met from nearby water sources.

Water transfer systems consist of reservoir networks, canals, tunnels, pumps, and hydropower plants. Historically, gravity was used as the source of energy for water transfer from higher to lower altitudes and there was no need for an external source of energy. Modern water transfer systems depend on external sources of energy, primarily electricity, since gravity alone is no longer sufficient. Nevertheless, the elevation difference between the source and the destination is an important determinant of energy intensity of a water transfer system. Geographic characteristics determine whether a particular system is a net energy consumer or a producer. Sometimes there is a conflict between whether the available water should be stored for future use at a reservoir, or if it could be released for use in hydropower plants (Water in the West, 2013).

\section{Box 7: The South-North Water Transfer Project in the People's Republic of China}

The South-North Water Transfer Project is the world's largest interbasin water diversion project. Planned for completion in 2030, its aim is to eventually divert $45 \mathrm{bcm}$ of water annually from the Yangtze River in southern PRC to the more arid and industrialized north through three canal systems (South-North Water Transfer Project Office). The central routes and the first phase of the eastern route have started operation, while the western route is still in the planning stage (South-North Water Transfer Project Office, 2015).

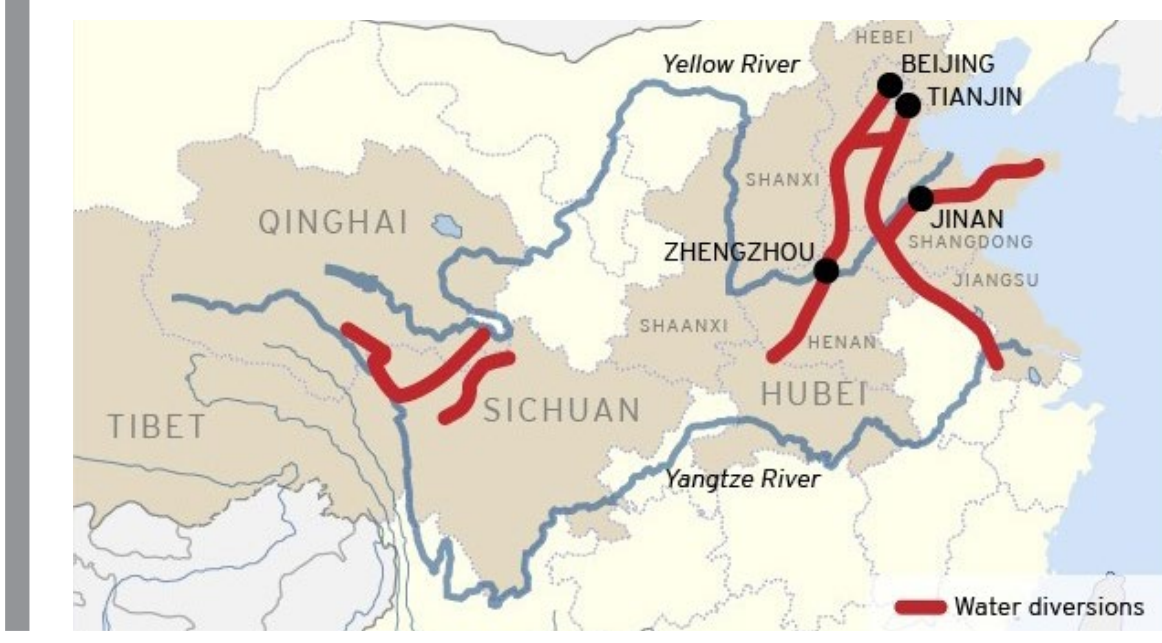

11 According to Wang et al. (2012), the total groundwater pumped for irrigation was estimated at $93 \mathrm{bcm}$. 


\section{Three routes of the South-North Water Transfer Project}

The eastern route is based on the course of the Grand Canal. Water from the Yangtze River will be pumped by 13 stations along the Grand Canal to the Dongping Lake and then delivered to Tianjin and the Shandong Peninsula through aqueducts. Energy is required to raise the transferred water by 65 meters.

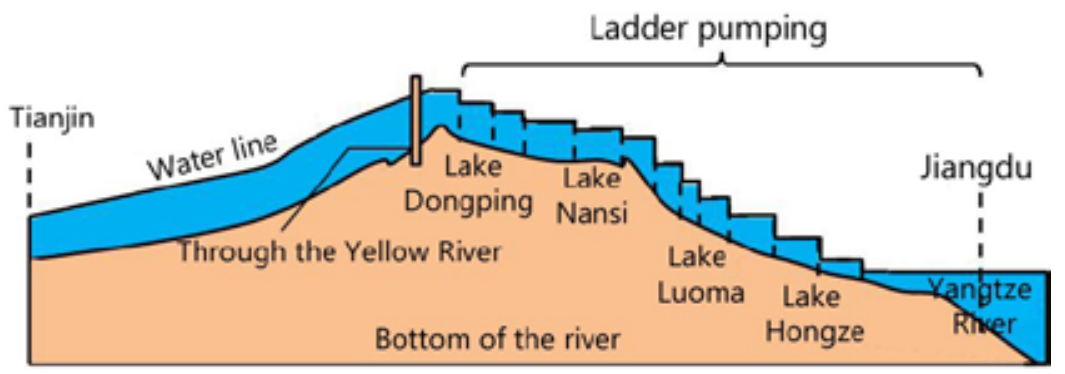

\section{Schematic diagram of water pumping along the eastern route from Yangtze River to Tianjin}

Meng and Wang (2005) estimated the electricity cost for the eastern

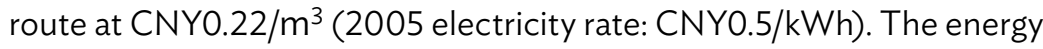
consumption of $0.44 \mathrm{kWh} / \mathrm{m}^{3}$ is $5-10$ times higher than that for pumping water from a nearby river or reservoir. With regard to energy intensity, the south-north water transfer system in the PRC could be comparable with that of brackish water desalination.

bcm, billion cubic meter, $\mathrm{kWh}=$ kilowatt-hour, $\mathrm{m}^{3}$ = cubic meter.

Source: Scott Moore (http://www.brookings.edu/research/papers/2013/02/waterpolitics-china-moore); and Ministry of Water Resources.

Besides energy consumption in water extraction and long-distance transfer, urban water distribution systems also consume energy. The amount of energy consumed during distribution depends on the topography and size of the city, the population, and per capita water consumption.

Variable-speed-drive pumps, which are more efficient at low loads, can reduce electricity consumption in water transfer and distribution. Using larger-diameter pipes and lining the pipes to reduce the frictional losses of water distribution can also decrease electricity consumption. In addition to reducing the total electricity consumption, the contribution of water pumping to peak electricity demand can be lowered by doing it during off-peak times.

The energy consumption for surface water conveyance and distribution depends on the hydraulic design, the length of the conveyance system, and the height difference between the water source and the point of use. While interbasin water transfer systems, such as SNWT in the PRC consume up to $0.45 \mathrm{kWh} / \mathrm{m}^{3}$, simple water conveyance schemes may require only $0.10 \mathrm{kWh} / \mathrm{m}^{3}$. On average, about $0.15 \mathrm{kWh} / \mathrm{m}^{3}$ is required for water supply from surface water sources in the PRC (Gao, 2012).The 
total energy consumption for surface water conveyance of $495 \mathrm{bcm}$ is in the range of 80 TWh, with water supply for the agriculture sector consuming about $50 \mathrm{TWh}$, compared with about 40 TWh for extracting just over $93 \mathrm{bcm}$ groundwater.

\section{Desalination and Energy Consumption}

Northern PRC is increasingly resorting to desalination as a solution to water shortages in coastal regions. Total desalination capacity increased from $10,000 \mathrm{~m}^{3} /$ day in 2000 to about $925,000 \mathrm{~m}^{3} /$ day by 2014 (State Oceanic Administration, 2015), and 112 desalination plants were built in the PRC in 2014. The desalination plants in the PRC are in nine coastal provinces (Fujian, Guangdong, Hainan, Hebei, Jiangsu, Liaoning, Shandong, Tianjin, and Zhejiang). The government expects to increase its desalination capacity to 3 million $\mathrm{m}^{3} /$ day by 2020 , including a massive desalination plant of 1 million $\mathrm{m}^{3} /$ day to supply a third of the water requirement of Beijing. The northeastern cities of Qingdao and Tianjin are also expanding their desalination capacity.

\section{Desalination Technologies}

Thermal systems. These rely on boiling water in a partial vacuum (low pressure) at a temperature below $100^{\circ} \mathrm{C}$. Thermal systems require energy in the form of electricity to maintain the low pressure and the pumping as well as thermal energy. Most desalination plants using thermal systems are adjacent to thermal power plants to allow the use of waste heat from the plants. There are two main thermal methods:

- Multistage flash distillation. Hot water is passed through a series of chambers, each with a lower pressure than the previous one to cause flash evaporation. Water boils at a lower temperature in each successive chamber and the steam is condensed in cooling tubes to produce freshwater.

- Multieffect distillation. This method is somewhat similar to multistage flash distillation except that the saline water is preheated with the steam produced at later stages of the process. Multieffect distillation systems operate at a lower temperature than flash distillation.

Membrane systems. This is the most popular desalination technology, with an energy requirement lower than that of thermal systems. Membrane systems entail more pretreatment of saline water than thermal systems.

- Reverse osmosis is the most common membrane-based desalination technology. Semipermeable membranes are used to retain salts and let water through. Pressure differences are maintained across membranes with the help of high-pressure electric pumps. The requisite pressure difference, as well as the electricity consumption, increases with the salinity of water. Reverse osmosis is suitable for water with total dissolved solids of more than 3,000 parts per million.

- Electrodialysis. Instead of using pressure to force water through the membrane, this method uses an electric field to attract charged ions across the membrane, leaving the desalinated water behind.

Source: Williams and Simmons. 2013. www.bp.com.

(Water in the West, 2013) 
Desalination is the most energy-intensive water option, with an energy requirement ranging from $3 \mathrm{kWh} / \mathrm{m}^{3}$ to $18 \mathrm{kWh} / \mathrm{m}^{3}$ (Wen et al., 2014). The energy requirement for desalination depends on the salinity and temperature of the water and on the desalination technology adopted. Energy costs range from 35\% to 50\% (PUB) of the total cost of desalinated water. Brackish water is a mixture of freshwater and seawater, more saline than freshwater, but less saline than seawater. Therefore, the desalination of brackish water is usually less energy-intensive than the desalination of seawater (Water in the West, 2013).

The dominant desalination technologies deployed in the PRC are reverse osmosis and multieffect distillation (MED). About $65 \%$ of the plants use reverse osmosis, and $35 \%$ use MED. Desalination capacity in 2014 was $600,000 \mathrm{~m}^{3} /$ day for reverse osmosis, and 320,000 $\mathrm{m}^{3} /$ day for MED.

Membrane processes are less energy-intensive than thermal processes (Table 4 and Box 8). The energy requirement of membrane systems depends on the quality of the water treated. Highly saline seawater needs more energy to desalinate than brackish water, which has low salinity. The energy consumption of thermal systems, on the other hand, does not depend on water quality.

The higher energy intensity of thermal processes is due to the high energy requirement for evaporation. Using waste heat from $\mathrm{CHP}$ plants can reduce the cost of energy. Because of its relatively low temperature requirement, MED can be powered by waste heat or recovered process heat to lower electricity consumption.

Table 4: Energy Requirement of Different Desalination Technologies

\begin{tabular}{|c|c|c|c|}
\hline \multicolumn{2}{|c|}{ Technology } & $\begin{array}{l}\text { Electrical Energy } \\
\qquad\left(\mathrm{kWh} / \mathrm{m}^{3}\right)\end{array}$ & $\begin{array}{c}\text { Thermal Energy } \\
\qquad\left(\mathrm{MJ} / \mathrm{m}^{3}\right)\end{array}$ \\
\hline \multirow{2}{*}{ Thermal } & $\begin{array}{c}\text { Multistage flash } \\
\text { distillation }\end{array}$ & $2.5-5$ & $70-280$ \\
\hline & $\begin{array}{l}\text { Multieffect } \\
\text { distillation }\end{array}$ & $1-3$ & $32-72$ \\
\hline \multirow{2}{*}{ Membran } & $\begin{array}{c}\text { Reverse osmosis } \\
\text { (seawater) }\end{array}$ & $2.2-8.5$ & Not required \\
\hline & $\begin{array}{l}\text { Reverse osmosis } \\
\text { (brackish water) }\end{array}$ & $1.0-2.5$ & Not required \\
\hline
\end{tabular}

$\mathrm{kWh} / \mathrm{m}^{3}=$ kilowatt-hours per cubic meter, $\mathrm{MJ} / \mathrm{m}^{3}=$ megajoules per cubic meter. 


\section{Box 8: Energy Consumption in Water Supply for Qingdao}

Qingdao, in the southern part of the Shandong Peninsula, has a population of 8.7 million people, $65 \%$ of whom are urban residents. It is one of the coastal cities suffering from severe water stress. Qingdao has a water resource availability per capita of $171 \mathrm{~m}^{3}$, less than that of many waterscarce Middle East countries. The long term sustainable water supply potential from local water sources is only $1.1 \mathrm{bcm}$ consisting of $-0.64 \mathrm{bcm}$ of surface water and $0.46 \mathrm{bcm}$ of groundwater resources. This total is less than Qingdao's projected water demand by 2020, which is expected to reach $1.48 \mathrm{bcm}$, with industry contributing $20 \%$, agriculture $33 \%$, and domestic use 39\% (Wen et al., 2014). Several options for meeting the projected demand have been considered.

Water supply from local surface water bodies. In 2011, water supply from local rivers contributed $66 \%$ (about $0.8 \mathrm{bcm}$ ) of Qingdao's total water supply, exceeding the sustainable level of surface water use. ${ }^{15}$ After the water extraction from local rivers, water it is conveyed to water treatment plants, thus using the advantage of natural height differences in elevation. In 2013, the average electricity consumption in the course of water extraction from local surface water sources and its distribution and delivery was about $0.43 \mathrm{kWh} / \mathrm{m}^{3}$ (Wen et al., 2014).

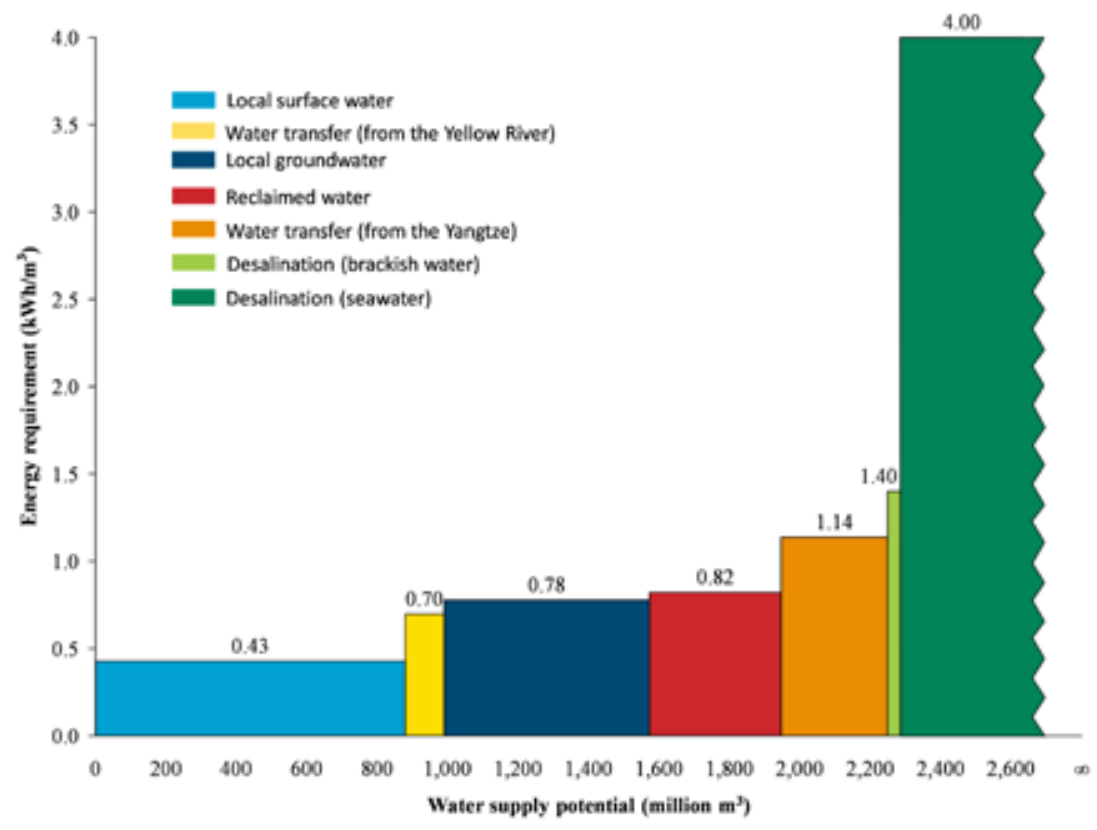

Energy Requirement of Water Supply for Qingdao, by Water Type 
Water supply from interbasin transfers. Qingdao receives $100 \mathrm{~m}^{3}$ from the Yellow River, and is also expected to receive up to $300 \mathrm{~m}^{3}$ from the Yangtze River by 2020, as part of the South-North Water Transfer Project. The energy consumption for water transfer from the Yellow River to Qingdao is $0.7 \mathrm{kWh} / \mathrm{m}^{3}$. Future transfers from the Yangtze River (South to North Water Transfer Project) are expected to consume $0.76 \mathrm{kWh} / \mathrm{m}^{3}$. The total energy consumption for water supply from the Yangtze River, including water treatment and distribution, will range from $1.1 \mathrm{kWh} / \mathrm{m}^{3}$ to $1.2 \mathrm{kWh} / \mathrm{m}^{3}$.

Water supply from groundwater sources. Groundwater in Qingdao is used mainly in irrigation and as drinking water for livestock. Only a small amount is put to municipal, domestic, and industrial use. Water extraction from groundwater consumes about $0.40 \mathrm{kWh} / \mathrm{m}^{3}$ of energy if the water is to be used only in agriculture (no water treatment is required), and $0.78 \mathrm{kWh} / \mathrm{m}^{3}$ if it is intended for municipal uses (requiring water treatment).

Water supply from desalination. Qingdao meets part of its water demand through the desalination of seawater. The two reverse osmosis desalination units in Qingdao consume $3.5 \mathrm{kWh} / \mathrm{m}^{3}-5 \mathrm{kWh} / \mathrm{m}^{3}$ of energy. As the salinity of brackish water in Qingdao is only about $25 \%$ of seawater salinity, the energy consumption for brackish water desalination is only about $1 \mathrm{kWh} / \mathrm{m}^{3}$.

Water supply from recycled water. The recycling potential of water used in Qingdao's residential and commercial sectors is estimated at $0.36 \mathrm{bcm}$. The energy consumption of water treatment for reuse depends on the treatment process, the required quality of recycled water, and the degree of pollution of used water. The treatment of urban wastewater using biochemical treatment processes consumes about $0.8 \mathrm{kWh} / \mathrm{m}^{3}$.

bcm = billion cubic meter, $\mathrm{kWh} / \mathrm{m}^{3}=$ kilowatt-hour per cubic meter.

Source: Wen et al. (2014).

\section{Energy for Water Treatment}

Given the wide range of contaminants, such as dissolved chemicals, animal waste, pesticides, and naturally occurring substances, no single treatment process serves all water treatment needs. At the same time, most urban water supply systems treatment processes do not distinguish between drinking water and water used for other purposes.

The energy required for water treatment depends on the extent of pollution of the water source: the cleaner the water, the less treatment and energy are required. The water treatment process usually involves rapid mixing with alum, iron salts, and polymeric materials for flocculation and coagulation to separate dissolved and suspended particles and form them into larger aggregates that can be removed; settling in a sedimentation tank; oxidation with chlorine to kill pathogens and break down organic pollutants; and filtration through gravel and sand filters. Groundwater can usually be treated with simple chlorination for disinfection (Water in the West, 2013).

In addition to these simple treatment processes, chemically contaminated water sources may require additional treatment, including $\mathrm{pH}$ adjustment to remove acidity 
or alkalinity; removal of ions and other dissolved substances through the addition of ion exchange resins or through electrode ionization; membrane filtration; ozone disinfection; and ultraviolet disinfection (Figure 25). These processes, especially membrane filtration, ozone disinfection, and electrode ionization, are much more energy-intensive $\left(0.5 \mathrm{kWh} / \mathrm{m}^{3}-1 \mathrm{kWh} / \mathrm{m}^{3}\right)$ than more traditional water treatment methods (less than $0.5 \mathrm{kWh} / \mathrm{m}^{3}$ ). The average energy consumption for water treatment in the PRC is about $0.3 \mathrm{kWh} / \mathrm{m}^{3}$.

The PRC's total freshwater withdrawal is $610 \mathrm{bcm}$, about $375 \mathrm{bcm}$ of this for agriculture and $48 \mathrm{bcm}$ for the cooling of thermal power plants. Water used for these purposes requires minimum or no treatment. Only water for residential $\left(61 \mathrm{~m}^{3}\right)$ and commercial/industrial uses $\left(131 \mathrm{~m}^{3}\right)$ needs to be treated before use (Figure 25). About 56 TWh of energy is consumed for the treatment of residential and commercial/industrial water.

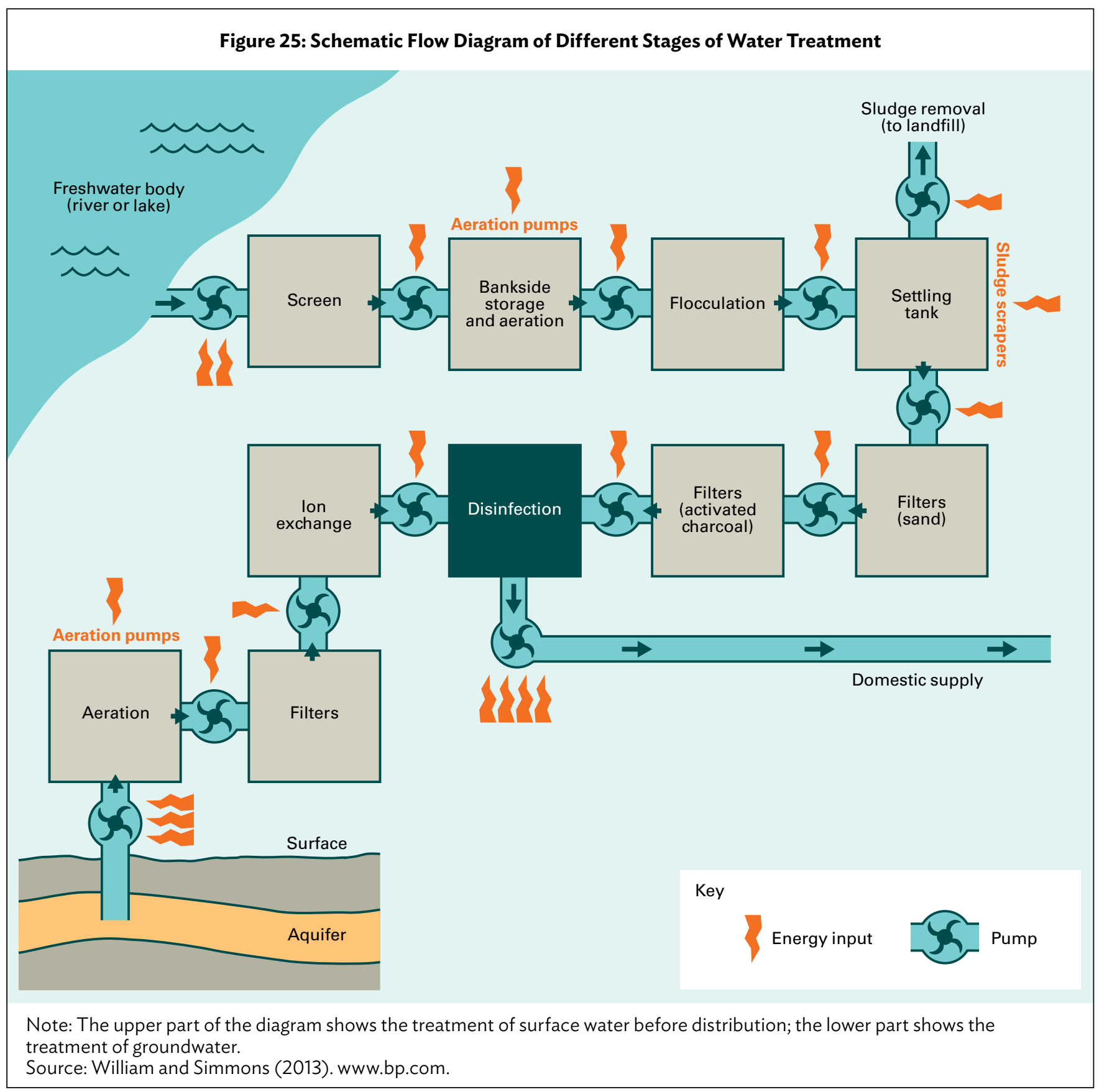




\section{Energy for Wastewater Treatment}

The release of polluted water into natural water bodies has emerged as one of the most serious environmental issues facing the PRC. Wastewater treatment, unless it is for recycling used water for human consumption, differs from water treatment, as the objective of wastewater treatment is to prevent the release of harmful substances into natural water bodies. Large water users, such as industries, power plants, and large commercial establishments, are required to have in-house facilities for treating wastewater before it is discharged into municipal systems or natural water bodies (Figure 26). These wastewater treatment facilities may use different processes to remove chemical pollutants specific to the industry concerned. However, nonpoint water users, such as residential users and farmers, usually release the used water into public wastewater systems without treatment.

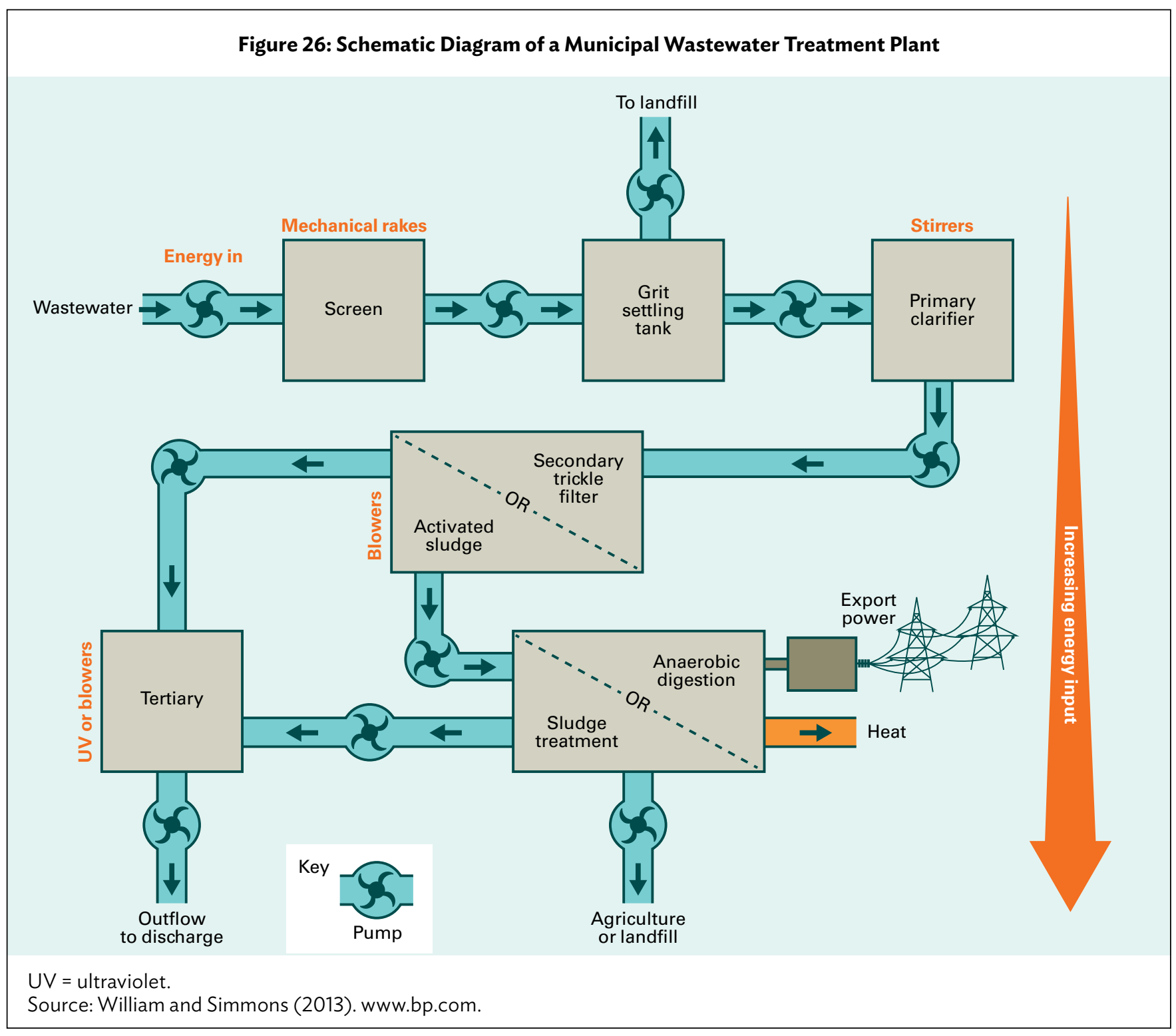

Wastewater treatment is closely related to the extent of the pollution and the standards set for the effluent quality to be discharged into natural water bodies or for the recycling of treated water. Wastewater is treated in the following stages: 
- Primary treatment consists of sedimentation to remove large suspended debris and sludge that have settled to the bottom of sedimentation tanks, and the skimming of floating material. No energy is required.

- Secondary treatment removes organic matter and remaining suspended particles through biological treatment. This is carried out by microbes and requires aeration with oxygen. The provision of oxygen for these biological processes is the most energy-intensive part of secondary water treatment. The wastewater can also be digested anaerobically (in the absence of oxygen) by microorganisms to produce biogas (a mix of oxygen and methane). Energy may be needed to maintain the optimal temperature, but this requirement can be offset by the use of biogas to produce electricity in CHP plants.

- Tertiary treatment, usually applied when wastewater is recycled for human consumption, can be highly sophisticated and energy-intensive. It may involve chlorine and ozone disinfection, ultraviolet disinfection, and depth filtration, among other advanced treatment technologies.

As an energy-intensive industry, the wastewater treatment sector in the PRC has witnessed a sharp growth in energy consumption in recent years, particularly since the implementation of stricter water quality and wastewater standards following the 11th Five-Year Plan period (2006-2010). Because of the increase in the volume of wastewater treated and the higher standards set for effluent water quality, the total energy consumption of the PRC's urban wastewater treatment plants in 2014 was triple the 2007 level, and energy consumption per ton of wastewater treated was $14 \%$ higher. ${ }^{12}$ Energy consumption is one of the largest expenses in wastewater treatment plant operations, generally accounting for $60 \%-90 \%$ of operation and maintenance costs. ${ }^{13}$

The energy requirement of wastewater treatment is associated with a range of factors, such as treatment capacity, inflow water quality, effluent quality, treatment process, and operating mode. Most of the energy is used in aeration, pumping, and sludge treatment. With the requirement for effluent water quality becoming increasingly stricter, the wastewater treatment sector must constantly retrofit or upgrade its technology, often leading to an increase in energy consumption. Efforts to improve energy efficiency in this sector will, therefore, have an important role in reducing GHG emissions.

According to the Ministry of Housing and Urban-Rural Development, in 2014 there were 3,998 urban wastewater treatment utilities in operation across the PRC, with a designed treatment capacity of 160 million $\mathrm{m}^{3}$ per day.

As of 2014, the average energy consumption of wastewater treatment plants in the PRC was around $0.27 \mathrm{kWh} / \mathrm{m}^{3}$, and energy efficiency was $14 \%$ higher than in 2007. In addition to technology and scale, the energy requirement of a wastewater treatment facility depends on geologically related variables, such as average annual temperatures and precipitation (W. Mohammad et al., 2016). The average energy consumption of wastewater treatment facilities in southern and central PRC is relatively low, at $0.21 \mathrm{kWh} / \mathrm{m}^{3}$ and $0.22 \mathrm{kWh} / \mathrm{m}^{3}$, respectively (X. Fu and L. Zhong, 2014). However, the PRC is still far behind the developed countries in terms of energy efficiency in wastewater treatment. 


\section{Addressing Energy Consumption in Water Supply: Policy Implications and Challenges}

Although the water sector's share of electricity consumption in the PRC is only about $4 \%$, the electricity consumed accounts for a significant share of water supply and wastewater treatment and can be as high as 25\%-40\%. Energy consumption by the water sector depends on the volume of water supplied, water supply options and technologies adopted, and the operating efficiency of water supply and water treatment facilities. Therefore, measures such as water conservation, water loss prevention, efficient use of water in agriculture and irrigation, and water recycling will reduce energy consumption in water supply.

The government has set targets for improving the efficiency of water use in irrigation and industry, to be achieved by 2020 and 2030, and an overall cap on water withdrawal (Three Red Lines). Reaching the irrigation water efficiency target will reduce irrigation water demand by $63 \mathrm{bcm}$ (more than the total amount of water withdrawn for energy production). The water leakage rate in urban water supply in the PRC was estimated at $17 \%$ in 2011 . This implies that $17 \%$ of the energy consumed for water extraction, treatment, and distribution that year was lost (L. Xi, L. Jie, and Z. Chunmiao, 2016).

Achieving this level of improvement in water conservation requires concerted efforts by many stakeholders and appropriate incentives from the government, backed by regular monitoring. Appropriate water tariffs and a market-based water right allocation regime may have to be established. Water recycling, which generally consumes less energy than groundwater extraction and long-distance water transfer, can also reduce energy consumption in water supply. However, the prevailing incentives are not adequate to promote the required level of investment in water recycling.

Energy consumption for water pumping is the main component of energy consumption in water supply. Therefore, pumping efficiency, not only for groundwater extraction but also for surface water conveyance, must increase if energy efficiency in water supply is to improve. In addition, energy intensity for water treatment (including desalination and wastewater treatment) can vary significantly depending on the technology used and the quality of feed water, and on water quality standards for effluents. Water quality standards should be set at appropriate levels to minimize energy consumption in water treatment (L. Xi, L. Jie, and Z. Chunmiao, 2016).

Energy consumption in water supply depends on the choice of water supply source. For instance, groundwater extraction, long-distance water transfer, and desalination are more energy-intensive options compared with the use of treated surface water or water recycling. Although the selection of water supply source is based on water resource availability, greater attention must be paid to selecting the water supply source that requires the least amount of energy, since energy accounts for a significant proportion of water supply cost and that share is likely to increase further in the future. In assessing different water supply options, the lifetime cost of energy, including externalities, must be taken into account (W. Mohammad et al., 2016). 


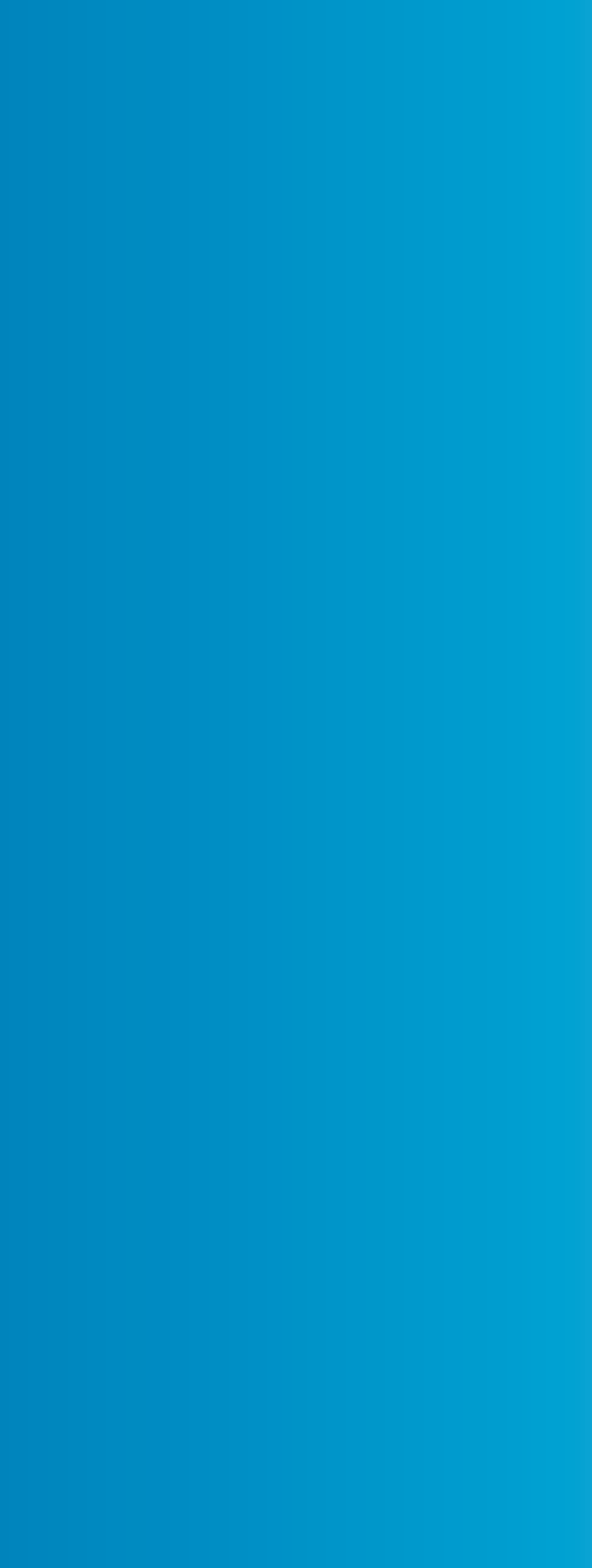




\section{Conclusion}

\section{Challenges}

Water resources in the PRC are unevenly distributed. In contrast with the water-rich south, parts of northern PRC, including heavily populated urban regions like Beijing, are under severe water stress. The country must also deal with the inefficient use of water in agriculture and the serious water pollution in most rivers in northern PRC. Moreover, the energy sector, especially coal-fired electricity generation, is a significant contributor to freshwater withdrawals (about 10\%), and coal mining is responsible for much of the groundwater pollution in some areas of the country.

According to the World Resources Institute's Baseline Water Stress China Map (Figure 4), 9 out of 13 provinces ${ }^{14}$ where key national energy bases are located face high or extremely high water stress, and over $50 \%$ of total proposed power-generation capacity under the 12th Five-Year Plan, 77\% of synthetic natural gas production capacity approved in 2013, and the country's shale gas reserves are all in waterscarce regions. Rapid urbanization, climate change, industrialization, and agricultural production will exert increasing stress on the shrinking "water pie."

\section{Opportunities}

The Government of the PRC, at the highest levels, is committed to promoting "ecological civilization," which calls for prioritizing natural resources conservation and protection while shifting economic growth onto a more resource-efficient, greener, and low-carbon path. The efficient and sustainable use of water, the most fundamental element of life and growth, is a core objective. In the past, the PRC depended on energy, and coal in particular, to underpin its rapid economic growth. But now there is an urgent need to decouple economic growth from increased use of carbon-intensive energy (Y. Che and Z. Shang, 2015).

The government already acknowledges that the current energy- and waterintensive economic structure is unsustainable over the long term because of the deteriorating air quality attributed to fossil fuel use-the PRC's contribution to climate change-water stress in northern PRC, groundwater depletion, and water quality issues. It has, therefore, taken steps to reduce the PRC's dependence on fossil fuels, and is promoting energy and water conservation, water recycling, and improvements in water use efficiency. The close links between the water and energy sectors, and the increased emphasis placed by the authorities on ecological civilization, provide opportunities to minimize the impact of energy production, conversion, and consumption on water supply in a more holistic way.

14 The 13 energy provinces are Anhui, Gansu, Guizhou, Hebei, Heilongjiang, Henan, IMAR, Ningxia, Shaanxi, Shandong, Shanxi, XUAR, and Yunnan. 
Integrate water and energy planning at the macro level. Traditional water and energy sector investment planning in the PRC is fragmented and poorly coordinated. Energy planners tend to consider water as a resource available to the energy sector, and pay scant attention to the impact of such resource use on other water users. They assume that energy sector development makes a greater contribution to overall economic development. Water stress, especially in the energy-rich but water-poor northern PRC, has worsened as a result; other sectors, especially agriculture, have been deprived of adequate water supply; and energy sector development has been suboptimal.

The PRC, on the threshold of achieving upper middle-income status, must take a more balanced approach to allocating its limited water resources among the different sectors, including energy. The ecological civilization concept and its goal of balanced and sustainable development based on resource conservation already provide the necessary political space. Interministerial coordination is needed to derive the most benefit from integrated water and energy sector planning. Decisions about energy supply options and the location of large energy-producing or energy-processing plants, such as coal bases and coal chemical plants, could thus be made after due attention is paid to the availability of water resources and the impact of their use in the energy sector on other water users.

A policy document issued by the Ministry of Water Resources (MWR) prescribes water use efficiency and water discharge standards for proposed coal bases and directs coal power plants at those bases to submit their water allocation plans for approval. This approach, however, deals with water use implications at the level of the individual power plant or coal base, not at the macro level, where decisions are made regarding whether these coal bases should be developed and where. The PRC must also critically assess how shale gas development or the aggressive promotion of CTL and coal-to-gas options will affect the water sector. The choice among water supply options, such as desalination, water recycling, and long-distance transfer, could similarly be made on the basis of their impact on energy consumption and in relation to water conservation.

Policy makers in the PRC should gain a better understanding of the water-energy nexus; develop or encourage research into decision-making tools for managing the water-energy nexus; strengthen integration and collaboration among water and energy authorities through dialogue and coordination, including the creation of a high-level political body for water management similar to the National Energy Commission; and, under high-level government leadership, draft a plan for coordinating activities related to water-energy nexus management undertaken by the different ministries.

\section{Strengthen the capacity of water sector regulatory bodies with respect to large} energy enterprices. Traditionally in the PRC, energy sector investments were given priority in water allocation as energy has been considered as a key input to sustained economic growth and industrial expansion. Water sector regulators (provincial units of the MWR) have traditionally granted favorable treatment to energy sector investments in water allocation because the investments, usually made by large state-owned enterprises, generate economic benefits and tax revenues for local governments. This explains the presence of a large number of coal mines, coal power plants, and coal chemical industries in water-stressed regions of the country despite their significant water requirement.

Water is allocated to energy sector projects at the time the project feasibility studies are approved by the provincial water regulators. By then the decision to 
develop a particular energy sector project has already been made as part of a national plan, and the provincial authorities have no choice but to allocate water to the projects. However, following recent calls to consider the impact of the projects on water resources, the approval of water allocation has become contingent on project compliance with water use efficiency standards set by provincial authorities, including the use of dry cooling for coal power plants, and with wastewater discharge requirements. Those requirements were made, for example, in the Regulation on Water Resources Assessment for Large-Scale Coal-Power Bases (issued in late 2013) and the policy paper on coal-to-gas and coal-to-liquid project planning (issued in 2014).

The government could further empower provincial water regulators, especially in water-stressed regions, to strictly enforce water use efficiency standards in existing as well as new energy sector activities, and to facilitate investment in water conservation in return for the transfer of water rights from existing water users. The regulators must be encouraged to give greater attention to optimizing water use in energy projects, and to concern themselves not only with how much water is needed for energy production but also with the likely sources of water and ways of easing competition with alternative uses. Such regulatory empowerment throughout the energy development process, from mining (e.g., coal, shale gas, petroleum) to final energy production (e.g., coal-to-chemical, power generation), will help mitigate the associated water stress.

Strengthen efforts to diversity the energy supply mix away from coal. The government is aware of the need to reduce dependence on coal to meet energy demand. Coal-based electricity generation and the use of coal in various industrial processes have been the biggest causes of air pollution and the PRC's contribution to climate change. Coal mining and the use of coal for electricity generation and chemical processes also have the largest share in industrial water withdrawal and water consumption and is a major cause for groundwater pollution. Water withdrawal and consumption by the coal industry in several provinces have become unsustainable, and are likely to damage ecological integrity in the long run.

Although the government intends to reduce the share of coal in primary energy supply to $62 \%$ by 2020 from $66 \%$ in 2014 , and is likely to set a cap on annual coal consumption at 4.2 billion tons by 2020 , much more is needed from the government, especially at the provincial level, to reduce the dependence on coal. Improving energy efficiency, reducing the energy intensity of the economy, and increasing the share of renewable energy and natural gas in the PRC's energy supply mix can reduce coal consumption, and the PRC has made commendable progress in this regard since 2006. But it must exert stronger efforts in the future.

Faced with overcapacity in coal mining, the government should give serious thought to decommissioning coal mines and banning coal-fired power generation altogether in regions suffering from extreme water stress. It has already made the adoption of dry-cooling technology a precondition for the establishment of new coal power plants in those regions. Even coal power plants with dry cooling, however, require water for scrubbing and air pollution control. In addition, over $45 \%$ of existing coal power plants are in water-stressed regions. These plants will have to be converted to dry cooling or decommissioned as the PRC diversifies its energy supply mix away from coal.

Several provinces, such IMAR, Shaanxi, and Shanxi, depend on coal mining, coal-based electricity generation, and coal chemical industries for much of their 
economic output and employment generation. Reducing coal production and coal consumption could significantly disrupt the economic structure of these provinces. The government may have to provide fiscal subsidies to coal-dependent provinces to manage the economic cost of industrial transformation.

Improve energy efficiency in water supply. The PRC's water sector requires innovative management to integrate and incorporate energy considerations. An energy (carbon) accounting system can be established in the urban water sector. Recent WRI analysis shows that existing wastewater treatment plants in the cities can reduce their energy consumption by $30 \%-50 \%$ if they adopt proper energy management measures. The PRC can also build a sludge-to-energy system to recover energy from wastewater and sludge. According to the WRI, biosolid digestion can reduce $\mathrm{GHG}$ emissions by $95 \%$ compared with the conventional landfill approach. Priority can also be given to water conservation, rainwater harvesting, and water recycling, which are less energy- and capital-intensive than water supply options like desalination, long-distance water transfer, and extraction of groundwater from deep aquifers

Continue efforts to apply economic instruments and market-based mechanisms in water resource allocation. Water resources and water services are still not being properly valued and priced in the PRC, which was regarded as part of reasons of low efficiency in water use. The PRC introduced pricing instruments into water management in the late 1980s, and has expanded their use from the pricing of hydrologic services to the pricing of water supply and wastewater treatment. But despite calls from the government for deeper water tariff reforms, local authorities, concerned about the likely reaction of the public, have been slow to implement tariff regulations. The underpricing of water resources or water services undervalues them and prevents water users from being truly concerned about water scarcity and increased water risks, and from improving water use efficiency. In view of the relatively low cost of water supply in the energy sector, water tariffs applicable to the energy sector can be substantially increased to encourage water conservation in energy sector activities.

In addition to setting appropriate water tariffs, the PRC reintroduced the water right (trading) approach into water resources management by selecting seven pilot provinces in 2014. Water use rights and wastewater discharge rights could be awarded to energy production and other water users in advance of future trading among these users. The trading system is expected to lead to more efficient and economical use of water. But, in the absence of regulations and management measures, such a trading system is still a remote possibility. The PRC should invest significantly in research and policy development to make up for this weak regulatory and policy environment.

Invest more in water and energy data collection infrastructure. Over the last decade, the PRC has made important efforts to develop the necessary infrastructure for energy data collection and disclosure. However, there is still a lack of reliable data on water withdrawal, consumption, and discharge in energy production and on energy consumption in water supply. This lack of reliable data has diminished opportunities to harness the synergies in the water-energy nexus and prevented decision makers and planners from making optimal choices in water and energy sector development (J. Daqian and R. Anuradha, 2015). 
A clear understanding of the water-energy nexus is crucial to an adequate response, and it depends on the availability of timely data related to the waterenergy nexus. During the 13th Five-Year Plan period (2016-2020) and beyond, the PRC should establish a reliable and transparent data acquisition and disclosure system for water and energy data, including real-time geographic information system-based monitoring. 


\section{REFERENCES}

Anthony, J. J. et al., 2016. , Integrated Groundwater Management: Concepts, Approaches and Challenge.

Asia Pacific Energy Research Center and ADB. 2014. Asia Pacific Energy Overview 2014.

ADB. 2011. Impact Stories from the People's Republic of China Partnership

Chen, Y. 2014. Practice and Exploration on Water Right Transfer in the Yellow River Basin and Its Development Direction in the Near Future. Journal of Economics of Water Resources 32 (1): 23-26. In Chinese.

CEC. 2011. Statistical Report of Electricity Generation in China (2010). http://www.cec. org.cn/xinxifabu/2011-02-09/39714.html

CEC. 2015 a. Trend of Electricity Generation Supply and Demand in 2015. http://www.cec. org.cn/guihuayutongji/gongxufenxi/dianligongxufenxi/2015-03-30/135847.html

China Electricity Council (CEC). 2015 b. China Electricity Generation: Current and Outlook. http://www.cec.org.cn/yaowenkuaidi/2015-03-10/134972.html

China Energy Net. 2014. China Shale Gas Regulation and Policy Framework.

China Energy Net. http://www.china5e.com/subject/show_873.html

China Energy Net. 2016. 2030 Hydropower Projection. http://www.china5e.com/news/ news-935853-1.html

China National Coal Association. 2014. http://news.1kuang.com/news-10928-1.html

Cornot-Grandolphe, S. 2014. China's Coal Market: Can Beijing Tame 'King Coal'? The Oxford Institute for Energy Studies.

Daqian, J. and R. Anuradha. 2015. The 'thirsty' water-electricity nexus: field data on the scale and seasonality of thermoelectric power generation's water intensity in China. Environmental Research Letters, Volume 10, Number 2.

Environmental Protection Agency. 2014. The Impact of Traditional and Alternative Energy Production on Water Resources; Assessment and Adaptation Studies.

Fu, X. and L. Zhong. 2014. Water-Energy Nexus of Urban Water Systems for Chengdu's Low-Carbon Blueprint. World Resources Institute. http://www.wri.org.cn/ Chengduwater

Gao, J. 2012. Water and Energy Nexus. Master's thesis, Tianjin University.

Global Water Partnership. 2015. China's Water Resources Management Challenge: The "Three Red Lines." Technical focus paper. Stockholm.

Greenpeace. 2014. A detailed analysis of water demand by 500 MW power plants. http://www. Greenpeace.org/thegreatwatergrab.

Gulbenkian Think Tank on Water and Future of Humanity. 2013. Water and Energy. (Chapter Water and Future of Humanity, pp. 159-184) 
Hu, C. 2014. Solving the Water Challenges for Coal Fired Power Generation Industry. Tsinghua-Harvard Forum.

International Energy Agency. 2014. World Energy Outlook 2014. Paris, IEA.

Jiang, Y. 2009. China's Water Scarcity. Journal of Environmental Management. Volume 90 Issue 11, pp. 318-319

Li G. 2007. Introduction of China's Hydropower Development. China Power Education [M]: Special Issues of Management Theory and Education Research.

Li, H. et al. 2014. Analysis of Rationality of Coal Based Synthetic Natural Gas Production in China Energy Policy, 71 (2014), pp. 180-188.

Li, Z., L. Pan, and L. Ma. 2014. Assessing Water Issues in China's Coal Industry. Cornerstone (Spring). http://www.cornerstonemag.net

Lingying, P. et al. 2011. "Water issues in the coal supply chain in China. 2011 International Conference on Materials for Renewable Energy \& Environment, Shanghai, pp. 1578-1581

Mayers, R. A. 2012. Encyclopedia of Sustainability Science and Technology 2012. Edited by R. A. Mayers ISBN 978-0-387-89469.

Meldrum, J. et al. 2013. Life Cycle Water Use for Electricity Generation: A Review and Harmonization of Literature Estimates. Environmental Research Letters 8, doi: 10.1088/1748-9326/8/1/015031.

Melilo, J. M., T. Richmond, and G. Yohe, eds. 2014: Climate Change Impacts in the United States; The National Climate Assessment. U.S. Global Change Research Program, 841 pp. doi, 10.7930/JOZ31WJ2.

Meng, J., and P. Wang. 2005. Analysis on the Cost of Water Supply from South-to-North Diversion Project. Water Resources Planning and Design 1.

Ming, Z. et al. 2012. Renewable Energy Development Thrives During China's 12th FiveYear Plan.: North China Electric Power University. http://www.powermag.com/ renewable-energy-development-thrives-during-chinas-12th-five-year-plan

Ministry of Water Resources (MWR). 2004. Approval of Ningxia Yellow River Water Right Transfer Planning. http://www.mwr.gov.cn/slzx/slyw/200411/ t20041117_146881.html

MWR. 2011. China Water Resource Bulletin 2010. Beijing.

MWR. 2012. China Water Resources Bulletin 2011. Beijing.

MWR. 2013. China Water Resources Bulletin 2012. Beijing.

MWR. 2013b. Bulletin of 1st National Census for Water. http://www.mwr.gov.cn/ 2013pcgb/merge1.pdf

MWR. 2014. China Water Resource Bulletin 2013. Beijing.

MWR. 2015. China Water Resource Bulletin 2014. Beijing. 
Murthy, G.S.R., K.G. Murty, and G. Raghupathy. 2014. Designing Earth Dams Optimally. Case Studies of Operation Research Volume 212.

National Energy Administration. 2016. Guidance on Energy Work Plan in 2016. http:// zfxxgk.nea.gov.cn/auto82/201604/t20160401_2219.htm

National Bureau of Statistics. 2014. National Economic and Social Development Statistics Bulletin. http://www.stats.gov.cn/tjsj/zxfb/201502/t20150226_685799.html

National Development and Reform Commission. 2013. 12th Five Year Plan for Energy Development. In Chinese. http://www.gov.cn/zwgk/2013-01/23/ content_2318554.htm

Oppenheimer, M. et al. 2014. Emergent risks and key vulnerabilities. In: Climate Change 2014: Impacts, Adaptation, and Vulnerability. Part A: Global and Sectoral Aspects. Contribution of Working Group II to the Fifth Assessment Report of the Intergovernmental Panel on Climate Change. Cambridge, United Kingdom, and New York, NY, USA: Cambridge University Press pp. 1039-1099.

Public Utilities Board. Singapore. NEWater Overview.

Qin, Y. et al. 2015. China's energy water nexus - assessment of the of the energy sector's compliance with the "3 Red Lines". Industrial water policy.

Reig, P., T. Luo, and J. N. Proctor. 2014. Global Shale Gas Development: Water Availability and Business Risks Report. World Resources Institute. http://www.wri. org/sites/default/files/wri14_report_shalegas.pdf

South-North Water Transfer Project Office. 2012. Introduction of the South-North Water Transfer Project. http://www.nsbd.gov.cn/zx/gcgh/

South-North Water Transfer Project Office. 2015. http://www.nsbd.gov.cn/zx/ zxdt/201512/t20151215_407073.html

State Council. 2012. Implementing the Most Strict Water Resources Management System. http://www.mwr.gov.cn/slzx/slyw/201202/t20120216_313991.html

State Oceanic Administration PRC. 2015. Report of National Seawater Usage 2014. Available: http://www.soa.gov.cn/zwgk/hygb/hykjnb_2186/201508/ t20150805_39389.html

Thopi, G. A. and A. Pouris. 2016. A 20 year forecast of water usage in electricity generation for South Africa amidst water scarce conditions. Renewable and Sustainable Energy Reviews Volume 62 September 2016 pp. 1106-1121.

Wang, J. et al. 2012. China's Water Energy Nexus: Greenhouse Gas Emissions from Groundwater Extraction. Environmental Research Letters. http://iopscience.iop. org/article/10.1088/1748-9326/7/1/014035/pdf

Wang, J., L. Zhong, and Y. Long. 2016. Baseline Water Stress: China. World Resources Institute. http://www.wri.org/publication/baseline-water-stress-china

Water in the West 2013: Water and Energy Nexus: A Litreature Review. A joint pogram of Standford Woods Institute for the Environtment and Bill Lane Center for the American West. August 2013. 
Wen, H. et. al. 2014. Water-Energy Nexus in the Urban Water Source Selection: A Case Study from Qingdao. World Resources Institute. http://www.wri.org.cn/ Qingdaowater

Wen, H., T. Luo, and T. Shiao. 2013. China's Response to Air Pollution Poses Threat to Water. World Resources Institute. http://www.wri.org/blog/2013/10/ china\%E2\%80\%99s-response-air-pollution-poses-threat-water

Du, W., Y. Fan, and X. Tang. 2016. Two-part pricing contracts under competition: the South-to-North Water Transfer Project supply chain system in China. International Journal on Water Resource Development. Volume 32 Issue 6.

Williams, E. D., and J. E. Simmons. 2013. Water in the Energy Sector: An Introduction. BP International. www.bp.com/energysustainabilitychallenge

World Economic Forum. 2013. Global Risks 2013. 8th ed. Cologny, Geneva. http:// www3.weforum.org/docs/WEF_GlobalRisks_Report_2013.pdf

World Resource Institute. 2014. Global Shale Gas Development: Water Stress at Shale Gas Plays. www.wri.org/resources/maps/global-shale-gas-development -water-stress-shale-play

United Nations World Water Assessment Programme. 2014. The United Nations World Water Development Report 2014; Water and Energy. Paris; United Nations Educational, Scientific and Cultural Organization.

Yanagi, T. 2008. Decrease in Yellow River discharge and its impact on the marine environment of the Bohai Sea. From Headwaters to the Ocean; Hydrological Change and Water Management - Hydrocharge. CRC Press.

Yellow River Conservancy Commission, Ministry of Water Resources.

http://www.yellowriver.gov.cn/hhyl/hhgk/qh/szyl/201108/t20110814_103518.html

Yue, C, and Z. Shang. 2015. Water Pricing in China; Impacts of Socioeconomic Development. Global Issues in Water Policy. Volume 9.

Xi, L., J. Liu, and C. Zheng. 2016. Energy for Water Utilization in China and Policy Implications for Integrated Planning. International Journal of Water Resources Development. Volume 32 Issue 3.

Zhang, C. et al. 2016. Managing Scarce Water Resources in China's Coal Power Industry. Environmental Management. Volume 57 Issue 6.

Zhang, W. and X. Guan. 2011. Practice and Exploration on Water Right Transfer in the Yellow River Basin and Its Development Direction in the Near Future. International Symposium on Water Resource and Environmental Protection. 2011 pp. 1043-1046. doi: 10.1109/ISWREP.2011.5893192.

Zhou, H. C. Discussion on Issues of Energy-Saving, Cost-Reducing and Means of Realization of Urban Wastewater Treatment Plant. 


Water and energy are both valuable resources and indispensable for human society and economic development. By nature, water and energy are interlinked. Water plays a critical role in the generation of electricity for cooling of thermal power plants and in hydropower, as well as in the production of fossil fuels such as coal; energy is required to treat, distribute, and for wastewater treatment. Choices made in either of the sectors may have unintended and often negative implications on the other sector. This report analyzes the trade-off between the two sectors in the context of the People's Republic of China and proposes recommendations to ensure that the choices made are sustainable in the long run.

\section{About the Asian Development Bank}

ADB's vision is an Asia and Pacific region free of poverty. Its mission is to help its developing member countries reduce poverty and improve the quality of life of their people. Despite the region's many successes, it remains home to a large share of the world's poor. ADB is committed to reducing poverty through inclusive economic growth, environmentally sustainable growth, and regional integration.

Based in Manila, ADB is owned by 67 members, including 48 from the region. Its main instruments for helping its developing member countries are policy dialogue, loans, equity investments, guarantees, grants, and technical assistance. 